\title{
Monitoring Colonias Development along the United States-Mexico Border: A Process Application using GIS and Remote Sensing in Douglas, Arizona, and Agua Prieta, Sonora
}

By Laura M. Norman ${ }^{1}$, Angela J. Donelson ${ }^{2}$, Edwin L. Pfeifer ${ }^{1}$, Alven H. Lam ${ }^{3}$, and Kenneth J. Osborn $^{4}$

Open-File Report 2004-1212

2004

U.S. DEPARTMENT OF THE INTERIOR U.S. GEOLOGICAL SURVEY

\footnotetext{
${ }^{1}$ U.S. Geological Survey, 520 N. Park Ave. \#355, Tucson, AZ 85719

${ }^{2}$ U.S. Department of Housing and Urban Development, 160 N. Stone Ave. Tucson, AZ 85701

${ }^{3}$ U.S. Department of Housing and Urban Development, 451 7th Street, SW, Rm. 8118, Washington, DC 20410

${ }^{4}$ U.S. Geological Survey, 3020 State University Drive East, Suite 4003, Sacramento, CA 95826, deceased
} 


\begin{abstract}
The U.S. Department of Housing and Urban Development (HUD) and the U.S. Geological Survey (USGS) have developed a joint project to create Internet-enabled geographic information systems (GIS) that will help cities along the United States-Mexico border deal with issues related to colonias. HUD defines colonias as rural neighborhoods in the United States-Mexico border region that lack adequate infrastructure or housing and other basic services. They typically have high poverty rates that make it difficult for residents to pay for roads, sanitary water and sewer systems, decent housing, street lighting, and other services through assessment. Many Federal agencies recognize colonias designations and provide funding assistance.

It is the intention of this project to empower Arizona-Sonora borderland neighborhoods and community members by recognizing them as colonias. This recognition will result in eligibility for available economic subsidies and accessibility to geospatial tools and information for urban planning. The steps to achieve this goal include delineation of colonia-like neighborhoods, identification of their urbanization over time, development of geospatial databases describing their infrastructure, and establishment of a framework for distributing Web-based GIS decision support systems. A combination of imagery and infrastructure information was used to help delineate colonia boundaries. A land-use change analysis, focused on urbanization in the cities over a 30year timeframe, was implemented. The results of this project are being served over the Internet, providing data to the public as well as to participating agencies.

One of the initial study areas for this project was the City of Douglas, Ariz., and its Mexican sister-city Agua Prieta, Sonora, which are described herein. Because of its location on the border, this twin-cities area is especially well suited to international manufacturing and commerce, which has, in turn, led to an uncontrolled spread of colonias. The USGS worked with local organizations in developing the Web-based GIS database. Community involvement ensured that the database and map server would meet the current and long-term needs of the communities and end users. Partners include Federal agencies, State agencies, county officials, town representatives, universities, and youth organizations, as well as interested local advocacy groups and individuals. A significant component of this project was development of relationships and partnerships in the border towns for facilitating binational approaches to land management.
\end{abstract}




\section{TABLE OF CONTENTS}

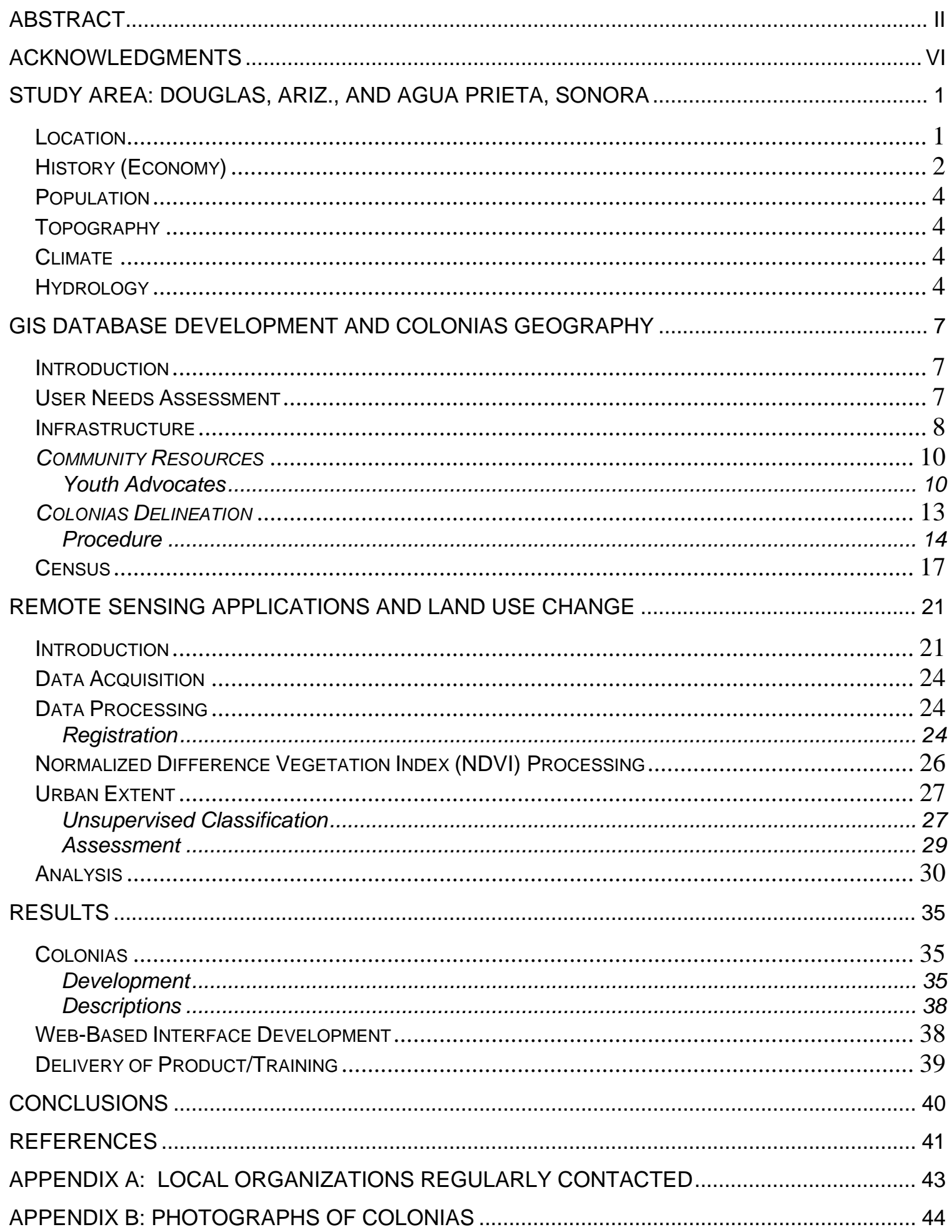


APPENDIX C: METADATA GENERATED ACCORDING TO THE FEDERAL GEOGRAPHIC DATA COMMITTEE (FGDC) STANDARDS FOR ALL NEW COVERAGES.............................. 50

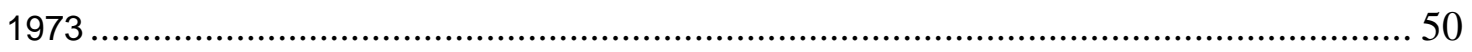

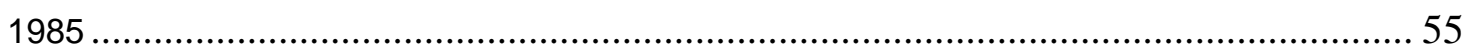

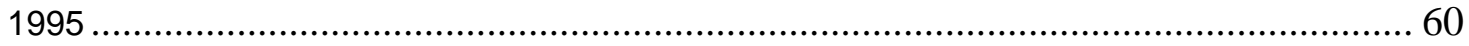

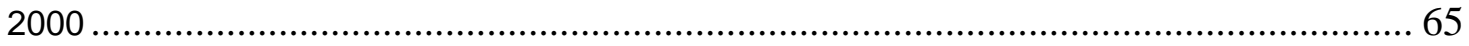

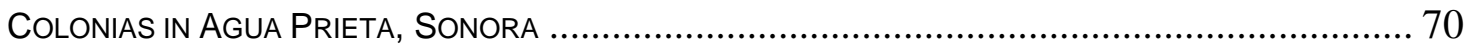

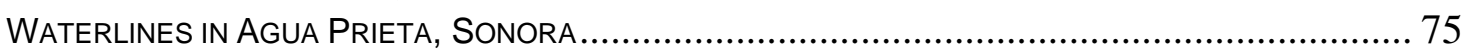

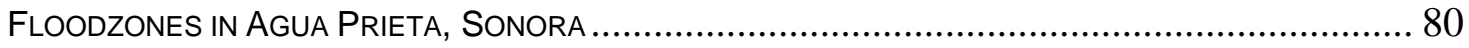

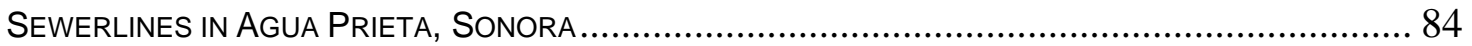

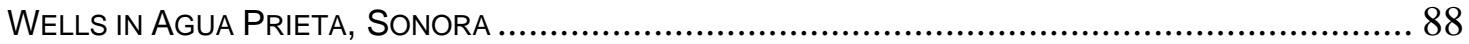

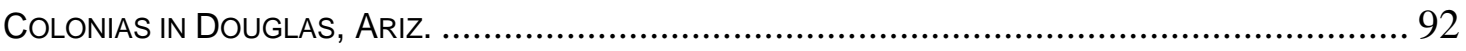

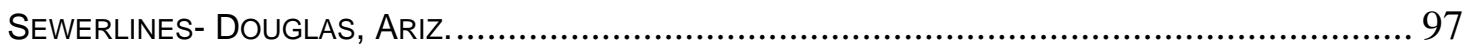

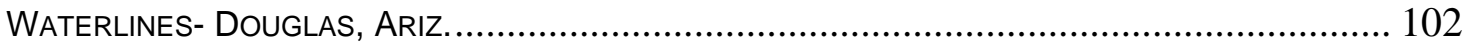

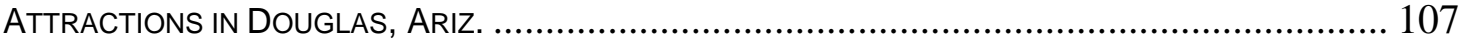

\section{LIST OF FIGURES}

Figure 1: MAP OF THE StATES OF ARIZONA AND SONORA SHOWING CITIES, MAJOR HIGHWAYS, AND RIVER SYSTEMS IN THE VICINITY OF THE CITIES OF DOUgLAS, ARIZ., AND AgUa PRIETA, SONORA. 1

FIgURE 2: USGS DigITAL RASTER GRAPHIC (DRG) OF DOWNTOWN DOUGLAS, ARIZ., AND AGUA

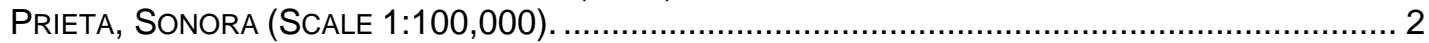

FIGURE 3: COCHISE COUNTY EMPLOYMENT BY SECTOR, 1960 AND 1990 (U.S. BUREAU OF THE CENSUS, 1960 AND 1990)................................................................................. 3

FIGURE 4: LANDSAT SATELLITE IMAGE OVERLAIN WITH TOPOGRAPHIC CONTOURS, STREAMS, AND THE

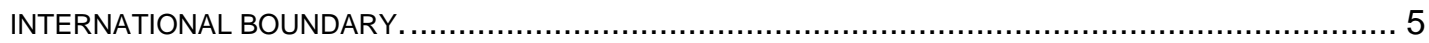

FigURE 5: VIEW OF THE STREET 5 LOOKING EAST FROM AV. 14 (COCEF/BECC, 1998).................... 6

FiguRE 6: FLOOD ZONES LOCATED WITHIN AGUA PRIETA (DERIVED FROM COCEF/BECC, 1998)......... 7

FIGURE 7: SEWER LINES FROM HOUSES EXTENDING INTO A NEARBY ARROYO (PHOTO BY SILVIA VILLALOBOS DE ZUÑIGA)....

FIGURE 8: WATER TANK IN AGUA PRIETA (PHOTO BY SILVIA VILLALOBOS DE ZUÑIGA) ........................

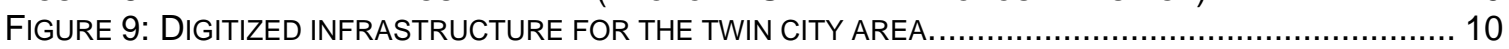

Figure 10: CARLOS DE LA TORRE, DiRECTOR OF Public Works, CITY OF DOUgLAS, PRESENTED DEMONSTRATION OF GLOBAL POSITIONING SYSTEM. .......................................................... 12

FIGURE 11: ARCIMS APPLICATION PORTRAYING ATTRACTION DATABASE CREATED BY YOUTH ADVOCATES! AND EXAMPLE OF ACCOMPANYING PHOTOGRAPH. .......................................... 13

FIGURE 12: DESIGNATED COLONIAS LOCATIONS WITHIN THE COCHISE COUNTY BOUNDARY, IDENTIFIED

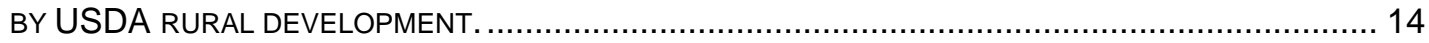

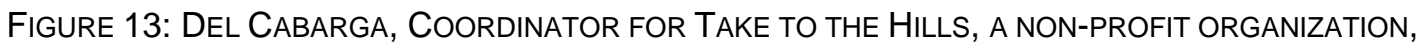

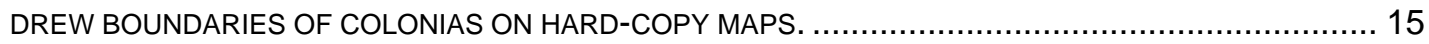

FIGURE 14: NEWLY DIGITIZED ROADS, SEWER LINES, AND WATER LINES USED TO IDENTIFY COLONIA

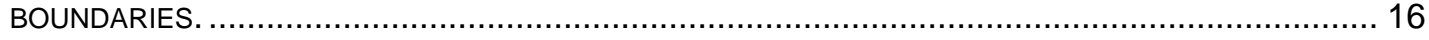

FIGURE 15: U.S. CENSUS BLOCKS WITHIN THE NEWLY DELINEATED CITY COLONIAS BOUNDARIES. ....... 17

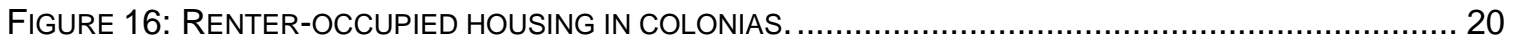

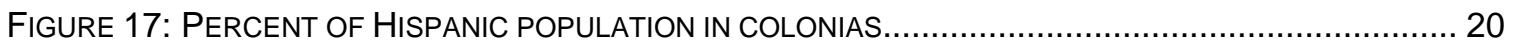

FIGURE 18: A FLOOR BED SHARED BY 13 BROTHERS AND SISTERS IN ONE FAMILY'S HOUSE IN AGUA PRIETA (PHOTO BY SILVIA VILLALOBOS DE ZUÑIGA) ......................................................... 21

FIGURE 19: AERIAL PHOTOGRAPH SHOWING DOUGLAS, ARIZ., IN NORTHERN (UPPER) HALF AND AGUA PRIETA, SONORA, IN THE SOUTHERN (LOWER) HALF, DIVIDED BY THE INTERNATIONAL BORDER. PHOTO (1970) DEPICTS SMOKESTACK AND SMOKE TRAILING TO THE NORTH FROM A NOWABANDONED SMELTER.

FiguRE 20: SATELLITE IMAGE TAKEN IN 2001, SHOWING DOUGLAS, ARIZ., IN THE NORTHERN (UPPER) HALF AND AGUA PRIETA, SONORA, IN THE SOUTHERN (LOWER) HALF, DIVIDED BY THE INTERNATIONAL BORDER. 
FIGURE 21: LANDSAT DATASETS, REGISTERED AND CLIPPED TO DESCRIBE THE DOUGLAS AND AGUA PrietA StUdY AREA $(1973,1985,1995$, AND 2000). THE IMAGES SHOW DOUgLAS, ARIZ., (NORTHERN HALF) AND AGUA PRIETA, SONORA, (SOUTHERN HALF); DIVIDED BY THE UNITED STATES-MEXICO BORDER.

FIGURE 22: THE ERDAS MODELMAKER WAS EMPLOYED TO ADD THE NUMBER 1 TO ALL VALUES AND THEN MULTIPLY BY 100 TO DISPLAY THE PRODUCT OF THE NDVI IN 200 GRAY LEVELS, VIEWABLE BY AN

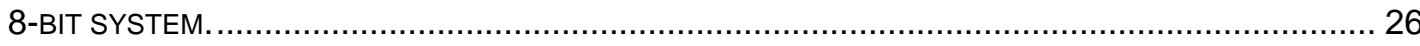

FIGURE 23: VEGETATION LAYER (GREEN) DERIVED FROM CALCULATIONS OF THE NDVI 2000 LANDSAT DATASET, OVERLAIN ON DOQQ WITH STREET LINES AND CITY PARKS.

FIGURE 24: 1973 ISODATA SET AND REGISTERED ORIGINAL TRUE COLOR WITH URBAN AREA DEFINED IN RED.

FIGURE 25: 1985 ISODATA SET AND REGISTERED ORIGINAL TRUE COLOR WITH URBAN AREA DEFINED IN ORANGE.

FIGURE 26: 1995 ISODATA SET AND REGISTERED ORIGINAL TRUE COLOR WITH URBAN AREA DEFINED IN

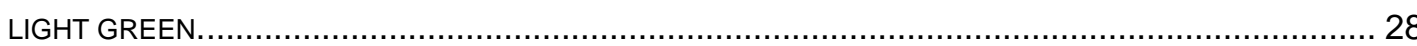

FIGURE 27: 2000 ISODATA SET AND REGISTERED ORIGINAL TRUE COLOR WITH URBAN AREA DEFINED IN BLUE.

FIGURE 28: THE 1995-DERIVED URBAN DATA WERE SUPERIMPOSED ON THE 1996 DOQQ TO ENSURE AN ACCURATE PORTRAYAL OF THE BOUNDARY ................................................................. 30

FIGURE 29: THE NLCD PORTRAYING CONDITIONS CIRCA 1992 WAS COMPARED TO THE NEWLY DERIVED

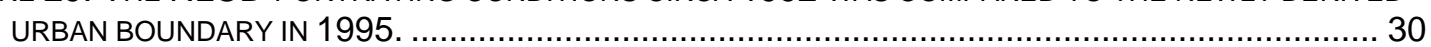

FIGURE 30: URBAN GROWTH DEPICTED FROM LANDSAT IMAGERY FROM THE YEARS 1973, 1985, 1995, AND 2000.

FIGURE 31: URBAN GROWTH OF THE DOUGLAS/AGUA PRIETA AREA THROUGH THE YEARS PLOTTED ONTO HILL-SHADED DIGITAL ELEVATION MODELS (DEMS), EXAGGERATED 7 TIMES .............................. 32

Figure 32: THE ENTIRE STUdY AREA OF DOUgLAS AND AGUA PRIETA IS INCREASING IN SIZE THROUGH TIME.

FIgURE 33: URBAN GROWTH BAR CHART DEPICTING ACREAGE IN DOUGLAS, ARIZ., AND AgUA PRIETA, SONORA.

FIGURE 34: X-Y SCATTER PLOT AND LINEAR REGRESSIONS DISPLAYING URBAN GROWTH IN THE AREA OF DOUGLAS, ARIZ., AND AGUA PRIETA, SONORA, INCLUDING A 10-YEAR FORECAST..................... 35

FIGURE 35: PIE CHART ILLUSTRATING GROWTH IN THE STUDY AREA. ........................................... 36

FIGURE 36: URBAN EXTENT INFORMATION WITH COLONIAS, SEWER, AND WATER LINE INFORMATION

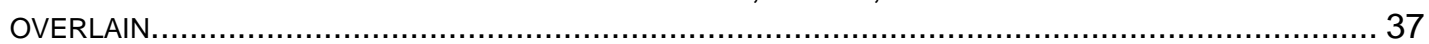

FIGURE 37: ARCIMS COLONIAS MAPPING WEBSITE PORTRAYING DATASETS IN DOUGLAS AND AGUA PRIETA (HTTP://CODD.ART.SRNR.ARIZONA.EDU/COLONIAS)............................................... 39

Figure 38: Cochise COMMUNITY COllege, Douglas CAMPUS, "USGS-HUD \& GIS TRAINING" SIGN. .

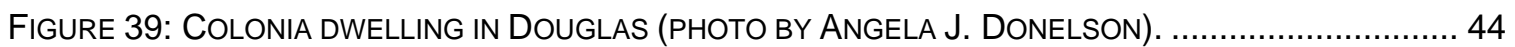

FiguRE 40: THE PIRTLEVILLE COLONIA, OUTSIDE OF DOUgLAS (PHOTO BY ANGELA J. DONELSON). .... 44

FigURE 41: TRAILERS COMPRISE SOME COLONIAS IN DOUGLAS (PHOTO BY ANGELA J. DONELSON)..... 45

FIGURE 42: HOUSES ARE MADE OF VARIOUS MATERIALS IN COLONIA EMPACADORA, AGUA PRIETA (PHOTO BY SILVIA VILLALOBOS DE ZUÑIGA).

FiguRE 43: ONE WOMAN LIVING IN COLONIA EMPACAdORA, AGUA PRIETA (PHOTOS By SiLVIA

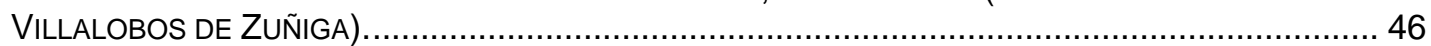

Figure 44: House In COlonia Southern, AgUa PRIETA (PHOTO by SiLVIA VILLALOBOS DE ZUÑIGA).46

FIGURE 45: THIS FAMILY IN COLONIA BACHICUY, AGUA PRIETA IS NOT ENTITLED TO GOVERNMENT SUBSIDIES DUE TO OWNERSHIP OF AUTOMOBILE (A LUXURY) (PHOTO BY SILVIA VILLALOBOS DE ZUÑIGA).

FiguRE 46: HOUSE WITH WATER TANK IN COLONIA BACHICUY, AGUA PRIETA (PHOTO BY SILVIA

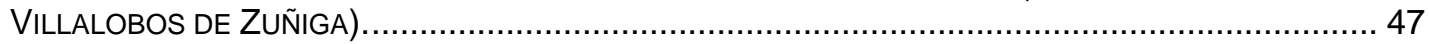

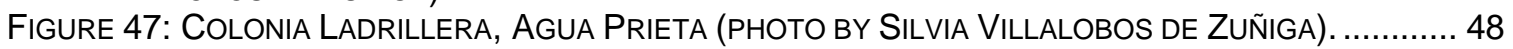

Figure 48: MATERIALS For houses IN COLONIA Pueblo NueVo, Agua PRIETA ARE MAKESHIFT (PHOto

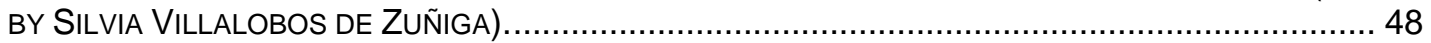

FiguRE 49: CARDBOARD ROOFING TYPICAL IN COLONIA OF AGUA PRIETA (PHOTO BY SILVIA VILLALOBOS DE ZUÑIGA). 


\section{LIST OF TABLES}

TABLE 1: IMPORTANT ATTRACTIONS IDENTIFIED BY YOUTH ADVOCATES! .......................................... 11

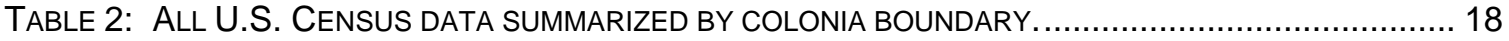

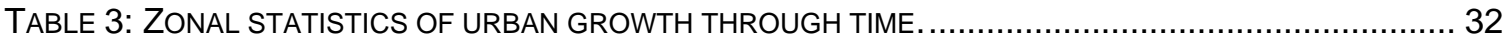

TABLE 4: ZONAL STATISTICS OF THE URBAN EXTENT CALCULATED BY INDIVIDUAL LOCATION................. 34

\section{Acknowledgments}

The authors wish to thank William Acevedo, Karen Bolm, Jean Parcher, and Sean Stone of the U.S. Geological Survey, for their extremely helpful reviews of this material. 


\section{Study Area: Douglas, Ariz., and Agua Prieta, Sonora}

\section{Location}

The City of Douglas is located in Cochise County, Ariz., on the United States-Mexico border (fig.1).

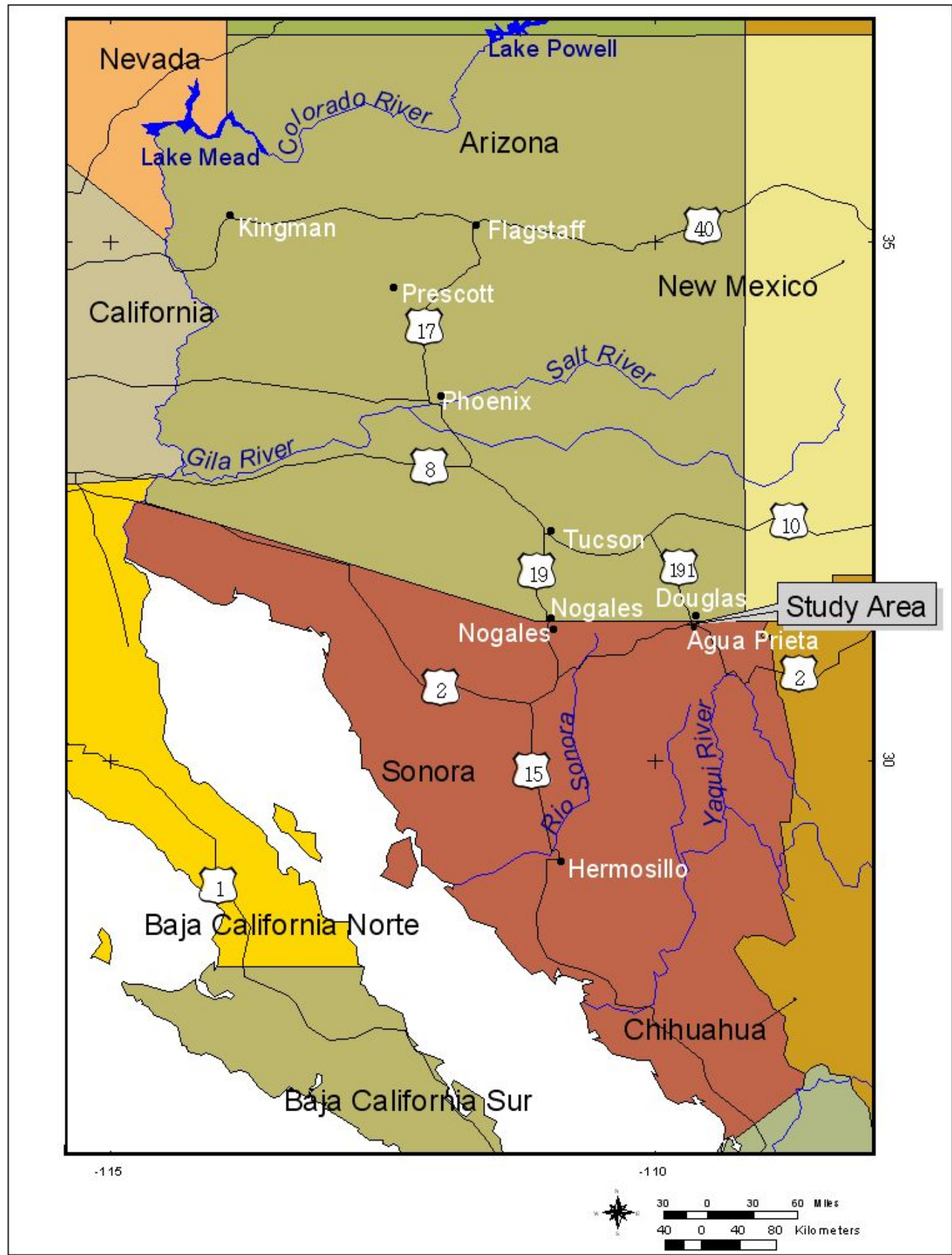

Figure 1: Map of the States of Arizona and Sonora showing cities, major highways, and river systems in the vicinity of the Cities of Douglas, Ariz., and Agua Prieta, Sonora. 
The City of Douglas is located 118 miles southeast of Tucson, 74 miles from Interstate 10 via Highway 191 (or 80). The unincorporated community of Pirtleville is located just northwest of Douglas. Because of its location on the Mexican border, Douglas is especially well suited to international manufacture and commerce; businesses based in Douglas benefit from the maquiladora (twin-plant) concept by utilizing the labor force of its Mexican companion city, Agua Prieta (fig. 2).

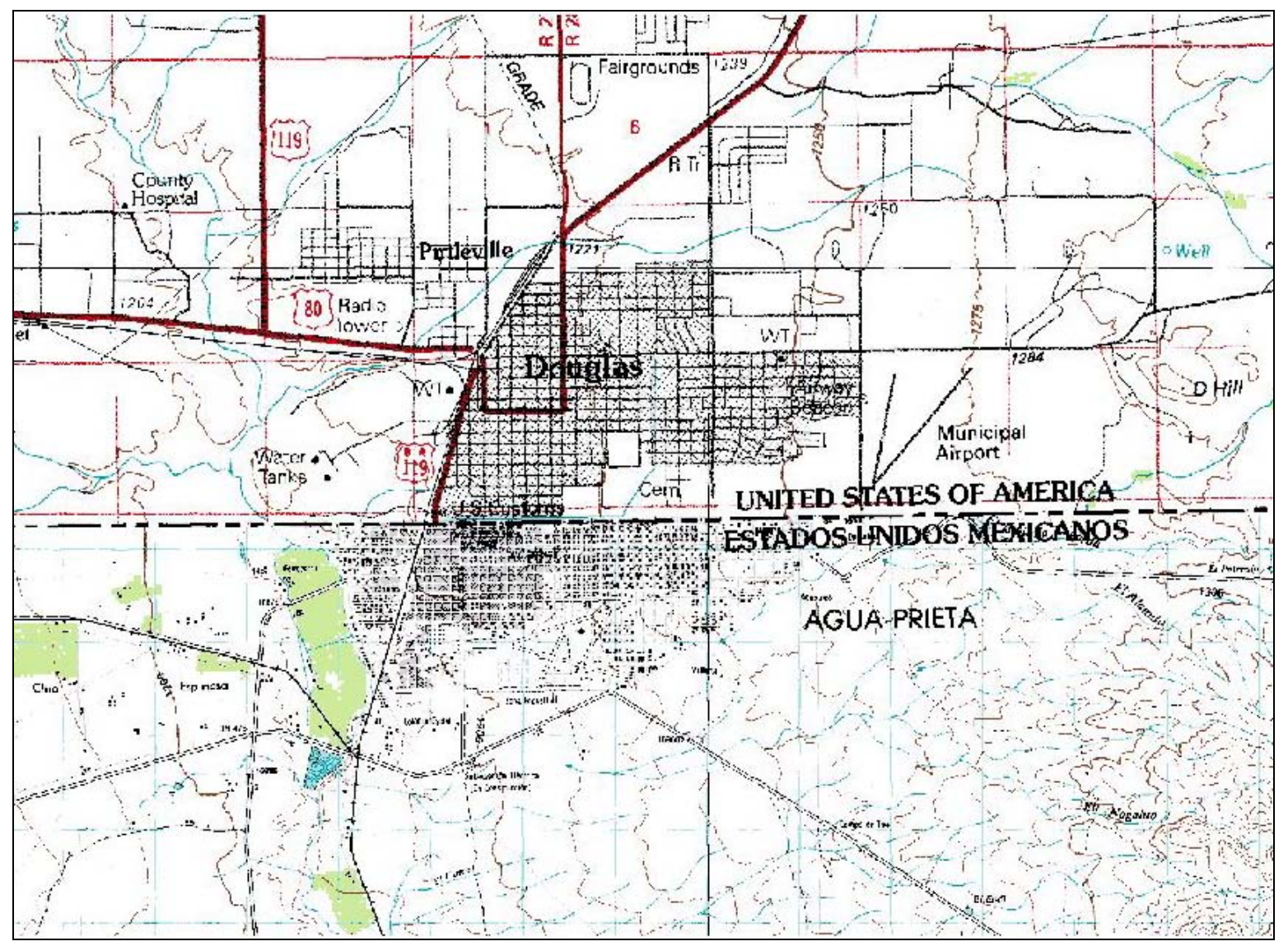

Figure 2: USGS Digital Raster Graphic (DRG) of downtown Douglas, Ariz., and Agua Prieta, Sonora (Scale 1:100,000).

\section{History (Economy)}

To understand the Douglas-Agua Prieta border history, long-established patterns of rural economic underdevelopment must be examined. With the arrival of the Southern Pacific Railroad in the 1880s, Arizona, in the minds of many east-coast financiers, acquired a "civilized" mode of transportation (Trennert, 1988). The construction and financing of the railroad was a bi-national United States and Mexican effort, which largely sought to extract and transport copper and mineral deposits in the Arizona-Sonora region (Myrick, 1967). Transportation of copper became financially feasible with the completion of the railroad.

The founding of the City of Agua Prieta dates to 1899, two years before the construction of the highway "Douglas Arizona - Mineral of Nacozari of Garcia," which was built to connect the mines in Mexico with the United States markets. Douglas was founded in 1900 as a coppersmelting center. Shortly thereafter, in 1901, two large mining interests-Phelps Dodge and the Calumet and Arizona_built smelters in Douglas. By 1903, Douglas was served daily by 19 freight and 12 passenger trains (Martynec and others, 1994). Agua Prieta served as a point of crossing at the border and as a transit stop for transporting mining products. The area where the Agua Prieta is currently located used to be an Indian ranch known as Bachicul. Over time, the 
Mexican population moved to the border area, and concentrated in several blocks around the railroad. In the following decades, Agua Prieta grew in a reticular fashion, its boundaries reaching the United States border in the north and the Agua Prieta River in the west. On August 28,1916 , the area was designated a village and on November 11, 1942, it was made a city (INEGI, 1995).

Between 1880-1890, ranchers increased cattle operations from 400,000 head to nearly one million head (Seltzer, 1959). By the 1920s, farming was well established in the border region, assisted by federally subsidized irrigation technology (Kearney, 1995). The Arizona cattle industry similarly enjoyed a period of expansion. In Arizona, range cattle became especially important to the Cochise County economy and by the 1950s, beef cattle were the second most important agricultural industry in the state, after cotton (Kent, 1983). Arizona agriculture both served and expanded the economic base developed by the mining industry and the railroads. Agriculture in the Arizona border region depended largely on Mexican low-cost labor (Weaver, 2001).

The late 1950s and early 1960s marked a profound change in the economic base of the entire Arizona economy. In southern Arizona, employment in mining and agriculture declined significantly and was succeeded by a service economy. The Bracero program that had previously brought millions of Mexican farm laborers to work the agricultural fields of America was terminated. Mechanization of agriculture eliminated the need for many of the workers required in the past and the end of the Bracero program stopped importation of low-cost Mexican labor. In an effort to offset some of the massive unemployment, the Mexican government launched the Programa Nacional Fronterizo (or PRONAF, the National Border Program) in 1961 to promote tourism and, soon after, the Border Industrialization Program (BIP) in 1965. The BIP especially helped spur much larger-scale development on the Mexican side of the border through incentives for establishing twin plant manufacturing operations, or maquiladoras. The ability to send parts and raw materials to Mexico, and obtain finished goods duty-free, prompted maquiladora operators to set up small-scale United States operations on the Arizona side of the border, with larger Mexican assembly operations on the Sonoran side.

Because of the copper industry and agriculture, the economy of this nonmetropolitan area continued to grow in the early 1900s. Yet, a decline in the southern Arizona mining industry manifested itself fully in the 1970s. Today the entire region is transitioning from the copper and cattle industries of the past to modern manufacturing in bonded assembly plants, as well as to tourism. The increase in manufacturing and tourism has generated increased migration of Mexican citizens from other regions of Sonora. Population growth of the twin city area has created a new workforce in public administration and service industries (fig. 3) to accommodate these people.

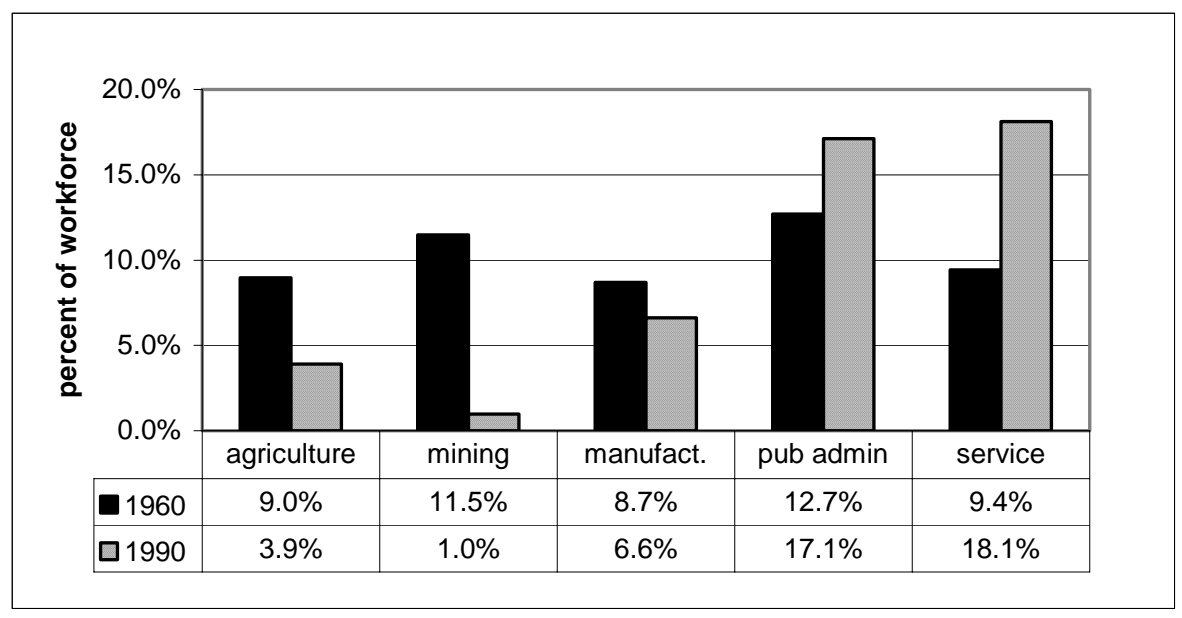

Figure 3: Cochise County employment by sector, 1960 and 1990 (U.S. Bureau of the Census, 1960 and 1990).

Beginning in the 1960s, with the implementation of the North American Free Trade Agreement (NAFTA), the maquiladora industry has focused much attention on the border and is 
most renown for the big boom in the 1980s. In 2001, however, this industry suffered a serious decline in employment. While there is continued investment in manufacturing, particularly in the border areas (Cañas and Coronado, 2002), the decline in employment can be attributed to the recent interest in other foreign markets, such as China. This suggests that the border economy will once again need to re-invent itself to accommodate future economic directions.

\section{Population}

The City of Douglas is predominantly comprised of Hispanic families who have resided in the United States for generations. The average family size is 20 percent higher than the United States average and the median age is 28 years. The population of Douglas in 2001 was 21,336 people, comprising 6,117 households (http://www.infods.com/freedata). Median household income in Douglas is $\$ 26,490$, versus the nationwide average of $\$ 41,369$ (http://www.infods.com/freedata/), and the poverty rate, according to census information, is 55 percent (http://www.ezec.gov/ezec/Ariz./border.html).

The population for the City of Agua Prieta and its suburbs has been calculated in many different ways by INEGI, the National Counsel of Population (CONAPO), and the General Censuses of Population and Dwelling carried out by the federal government in Mexico. Depending on the urban growth rate used, current population estimates range from 112,000 to 132,000 within the city limits to 173,000 to 185,000 including the suburbs (COCEF/BECC, 1998).

\section{Topography}

Douglas and Agua Prieta are located within the Whitewater International Watershed. The elevation of the cities is about 3,990 feet or approximately 1,200 meters (fig. 4). The Mule Mountains are located to the west, the Swisshelm and Perilla Ranges are to the east, and the Chiricahuas are north.

\section{Climate}

The high desert climate of the twin city area provides 320 sunny days a year and an annual total rainfall of 13.05 inches, with the majority of the rain falling during the "monsoon" season in July and August. The average daily high temperature is $79.2^{\circ} \mathrm{F}$ and the average low is $44.4^{\circ} \mathrm{F}$.

\section{Hydrology}

The name "Douglas" is from the Gaelic meaning "Dark River" or "Blood River". Prior to the first settlement, the name "Agua Prieta" was used by cattlemen and Indians to describe the cloudy water of the river. The Agua Prieta headwaters lie in the United States, at an altitude of 2,450 m., in the Chiricahua Mountains, $50 \mathrm{~km}$ north of Douglas and Agua Prieta. At its upper end, it is named Ash Creek and drains generally west, changing course to the south and southeast, where the name changes to Whitewater Draw. At the border, the name changes again to Agua Prieta (fig. 4). Alluvial deposits form the aquifer, which supplies water to the City of Agua Prieta. The water is primarily used for domestic, farm, commercial, and industrial purposes (COCEF/BECC, 1998). 


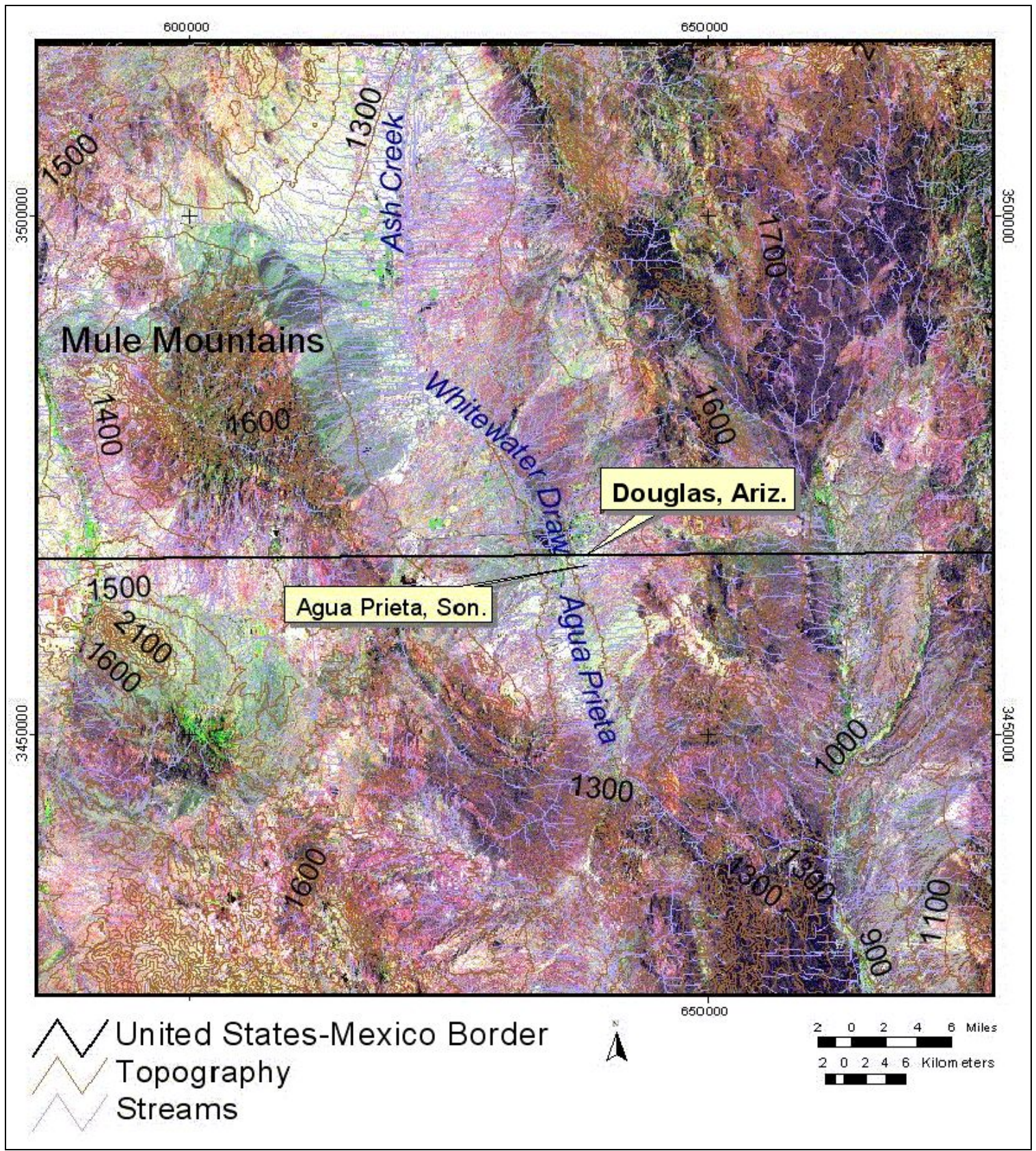

Figure 4: Landsat satellite image overlain with topographic contours, streams, and the international boundary.

Given the relatively flat terrain, Agua Prieta is prone to flooding in the summer rains (fig. 5). The flood zones are located in the southwest, in proximity to the River Agua Prieta, and in the southeast (fig. 6), where a residential area is located. 


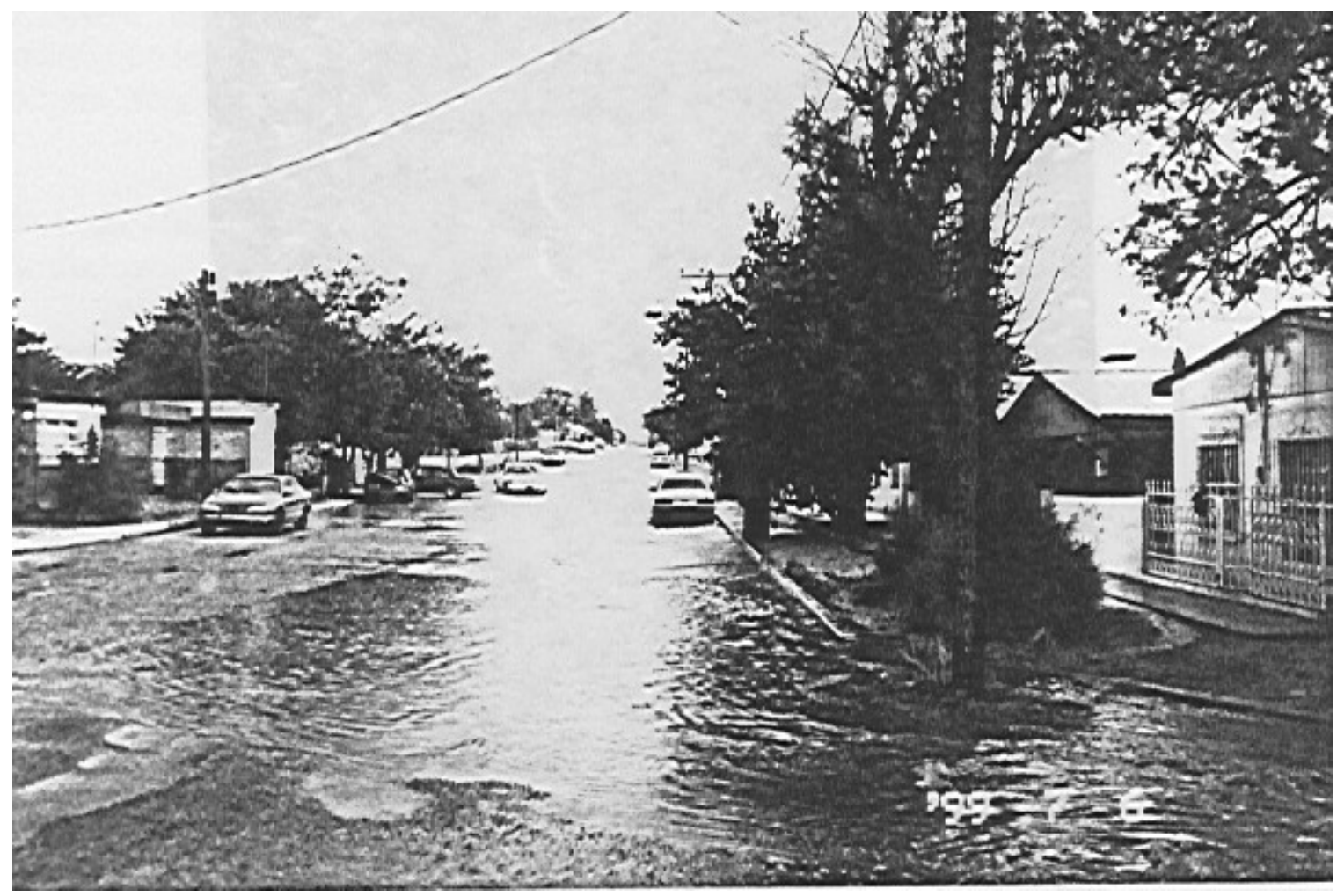

Figure 5: View of the Street 5 looking east from Av. 14 (COCEF/BECC, 1998). 


\section{- Flood Zones in Agua Prieta}

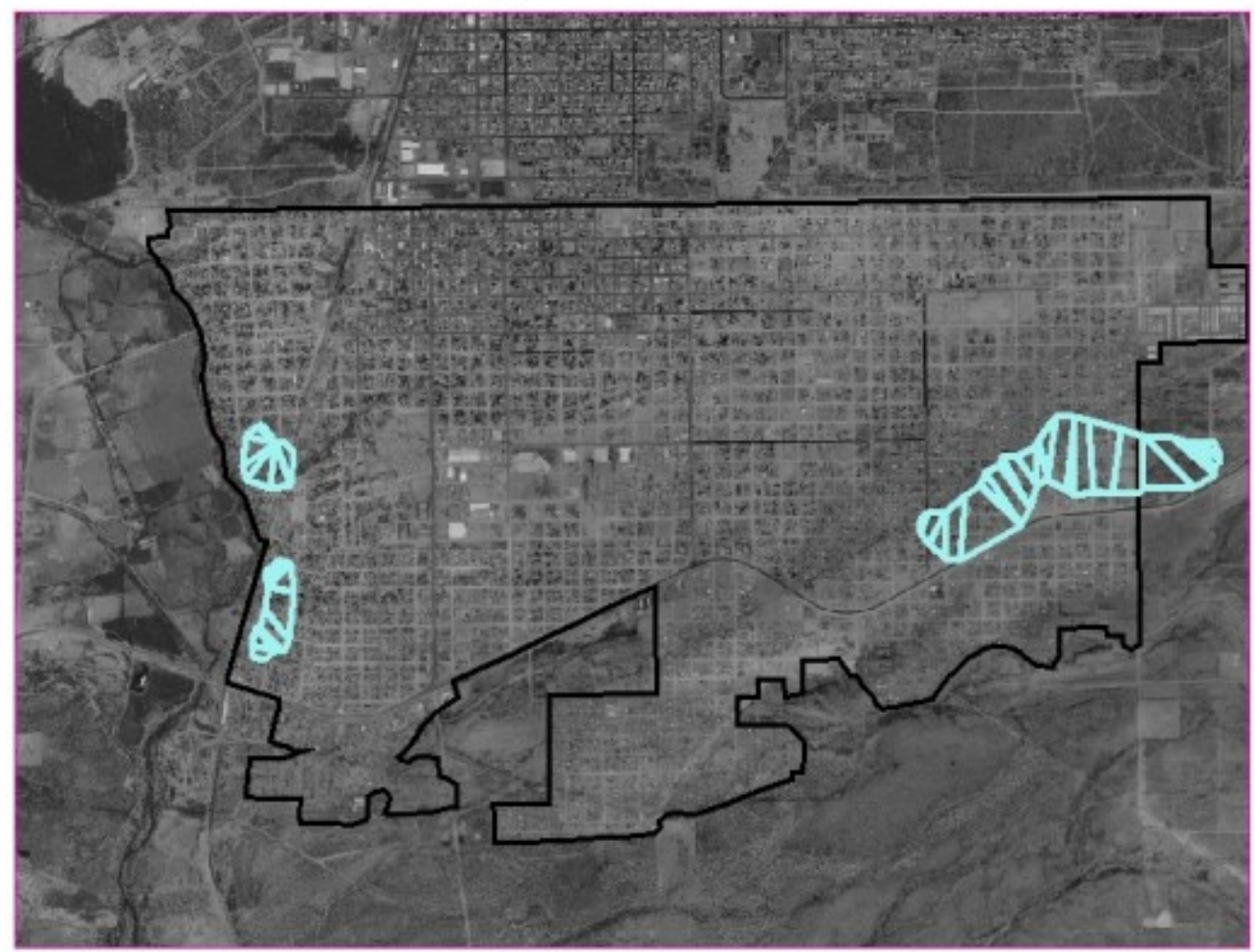

$1: 35,301$

$\begin{array}{lll}0 & 0.2 & 0.4\end{array}$ 0.8 Miles Projection UTM, Zone 12, Datum NAD83, Units meters, created by Laura M. Norman, July 30, 2003

Figure 6: Flood zones located within Agua Prieta (derived from COCEF/BECC, 1998).

\section{GIS Database Development and Colonias Geography}

\section{Introduction}

The purpose of this project was to make available relevant geospatial datasets, with a focus on infrastructure, such as sewer lines, water lines, and housing elements, for ease in delineation and further servicing of those colonias in need of funding or support. A robust GIS database requires the compilation of many datasets, including transportation, hydrography, topography, census data, and urban extents (Crawford and others, 1996).

\section{User Needs Assessment}

The first task was to meet with HUD representatives to discuss user needs. The second task was to establish contacts with local representatives and interested parties to exchange information and to collaborate on the desired end product. In-depth field analysis, onsite meetings, and discussions with local collaborators were conducted in the design and development phase of this bi-national digital dataset. 
A list of local organizations was complied for the area (Appendix A) and representatives from these organizations were invited to a meeting on December 12, 2002, in Douglas, Ariz. A user needs assessment, defining the suggested planning tools that were identified, was developed.

\section{Infrastructure}

Infrastructure data acquired from the City of Douglas Public Works Department were in AutoCAD format, and contained the locations of sewer and water lines in relation to streets in Douglas, Ariz. These data were digitized through the means of dead reckoning in Arc View 3.3, onto Digital Orthophoto Quarter Quadrangles (DOQQs).

Silvia Villalobos de Zuñiga captured some photographic examples of Agua Prieta's current makeshift infrastructure systems (figs. 7- 8). Infrastructure data gathered by COCEF/BECC (1998) for the master plan of Agua Prieta was systematically translated and synthesized. AutoCAD drawings describing the area were rectified and digitized within a GIS. According to the report submitted by the U.S. Army Corps of Engineers, the potable water infrastructure of the City of Douglas consists of tubing ranging from 3 to 18 inches in diameter, 10 active wells, 4 abandoned wells, 4 storage tanks, and a pressure station (COCEF/BECC, 1998).

Geographic features describing the sewer and water lines in the twin cities were automated into the geospatial database (fig. 9).

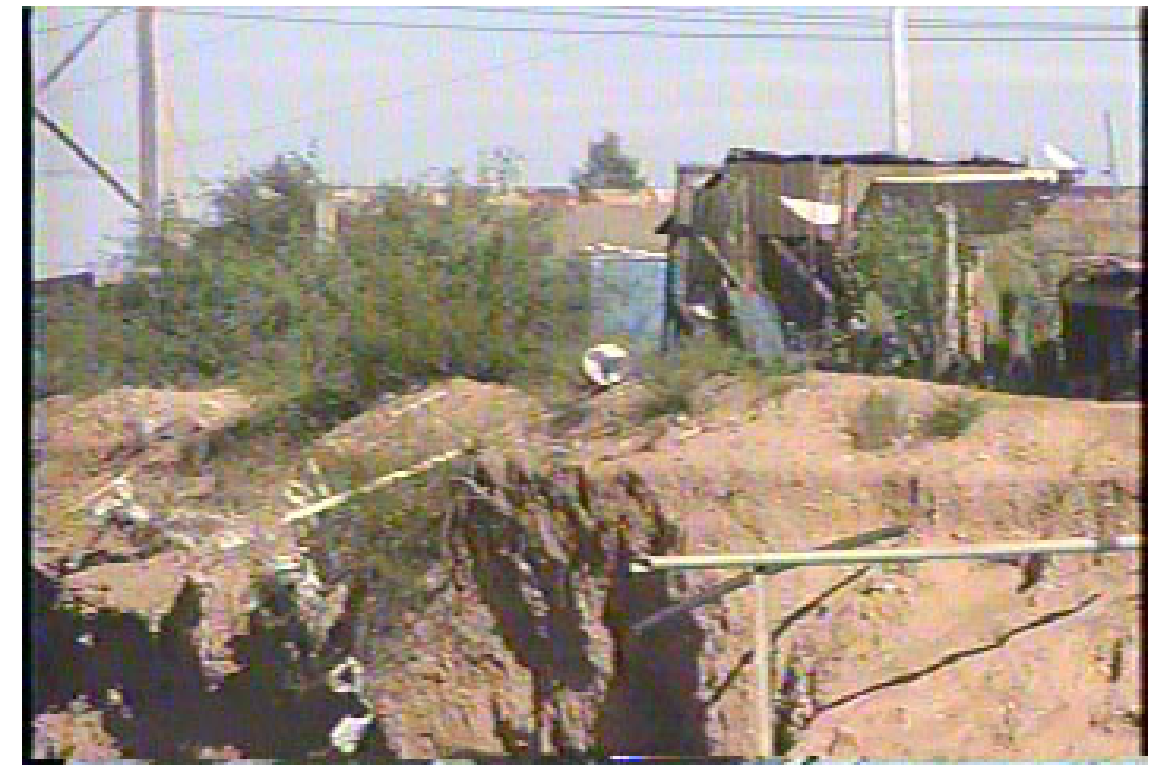

Figure 7: Sewer lines from houses extending into a nearby arroyo (photo by Silvia Villalobos de Zuñiga). 


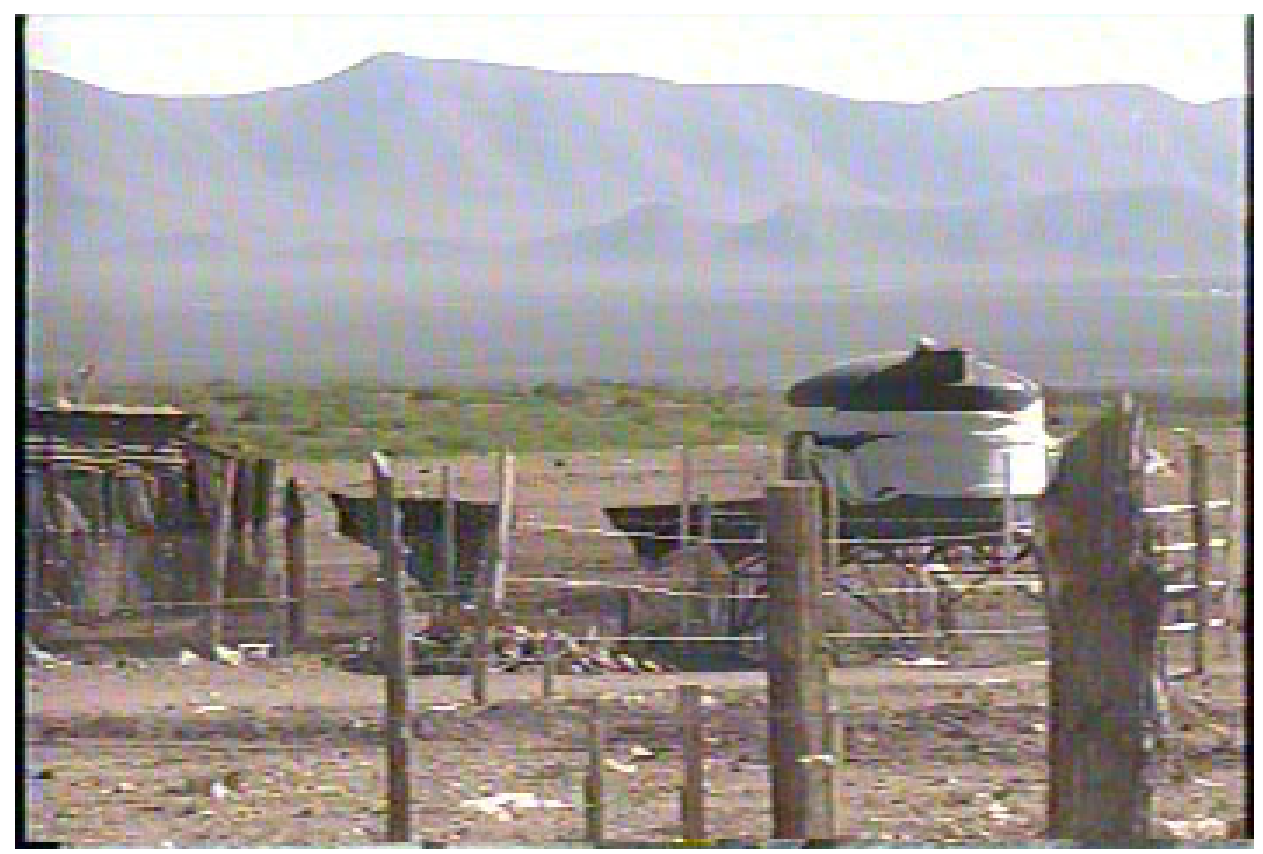

Figure 8: Water tank in Agua Prieta (photo by Silvia Villalobos de Zuñiga). 


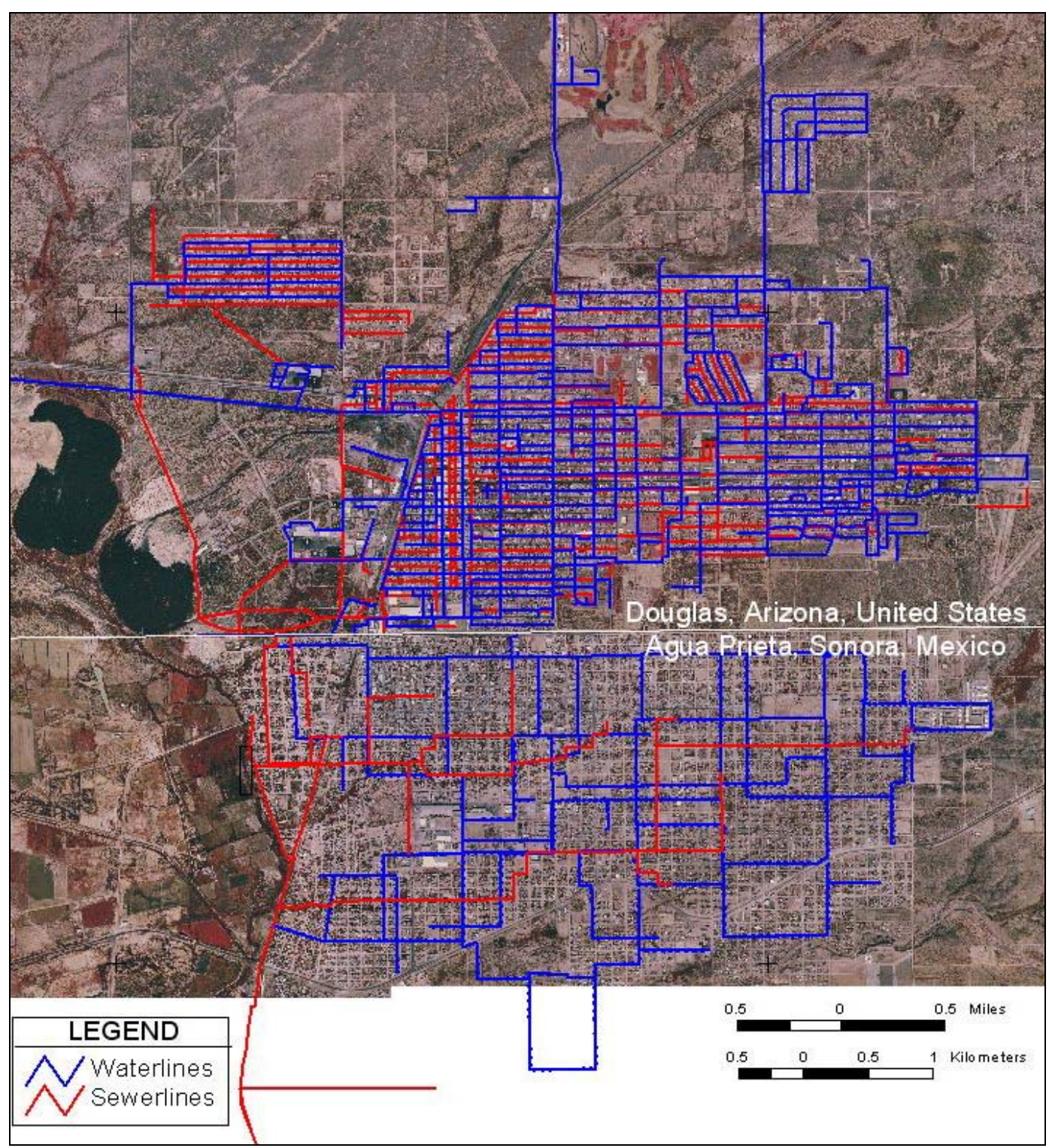

Figure 9: Digitized infrastructure for the twin city area.

\section{Community Resources}

For reference and potential planning, the location of community attractions was considered to be an important dataset for this project. Many citizens and especially local businesses expressed a desire to have their city's featured resources searchable via the Internet.

\section{Youth Advocates}

The Southeast Arizona Health Behavioral Services (SEAHBS) sponsors a group called the New Turf/ Youth Advocates, which is comprised of about 20 high-school-aged young adults and mentored by Ana Maria Flannigan. A "photo-points" project for the twin cities was designed and implemented by the youth group in four phases:

1. Identification of important attractions in their community. These included a new skate park, community pools, and soccer fields (see table 1). 
2. Documentation of these sites throughout the city using a digital camera.

3. Association of the locations of the resources with the photographs using Global Positioning System (GPS) readings and map coordinates. Carlos de la Torre, Director of Public Works, City of Douglas, instructed the youth group on using a Trimble 4700-4800 GPS system (fig. 10).

4. Incorporation of this information into the GIS database. The data can be viewed at the Web site by clicking on a point on a map and opening the corresponding photograph taken by the youths (fig. 11).

Table 1: Important attractions identified by Youth Advocates!

\begin{tabular}{|c|l|l|l|}
\hline ID & \multicolumn{1}{|c|}{ NAME } & \multicolumn{1}{|c|}{ ADDRESS } & \multicolumn{1}{c|}{ PHONE } \\
\hline 1 & Grand Theatre & 1139 N G Ave & $520-364-6144$ \\
\hline 2 & Douglas Aquatic Center & 1551 East 15th St. & $520-364-8846$ \\
\hline 3 & Coronado Courts & 1830 Bonita Ave. & $520-364-4637$ \\
\hline 4 & 15 th Street Park & 1200 15th St. & \\
\hline 5 & Veteran's Memorial Park & 1500 8th Street & \\
\hline 6 & Douglas Unified School District & 1600 North Louis & $520-805-0712$ \\
\hline 7 & Gadsden Hotel & 1046 North G Ave. & $520-364-4481$ \\
\hline 8 & Giggles & 1801 East 9th St. & $520-364-8397$ \\
\hline 9 & Huber Middle School & 15 th and Washing & $520-364-2840$ \\
\hline & Immaculate Conception & & \\
10 & Catholic Church & 928 C Ave. & $520-364-8494$ \\
\hline 11 & Douglas Library & 560 East 10th St. & $520-364-3851$ \\
\hline 12 & LM's Body Builders & 1012 North G Ave. & $520-364-3996$ \\
\hline 13 & McDonald's of Douglas & 104 East 5th St. & $520-364-8388$ \\
\hline 14 & Douglas Cinema & & $520-364-5000$ \\
\hline 15 & Douglas Police Department & 300 East 14th St. & $520-364-8422$ \\
\hline 16 & Post Office & 601 East 10th St. & $520-364-3621$ \\
\hline 17 & The Williams House & 1001 D Ave. & $520-364-7370$ \\
\hline 18 & Port of Entry & 1 N. Pan America & \\
\hline 19 & Pachanga's & Agua Prieta & \\
\hline 20 & Raul Castro Park & 10 th St. & \\
\hline 21 & Skate Park & & \\
\hline 22 & Health Department & 315 E. 7th St. & \\
\hline 23 & Walmart & 204 W. 5th St. & \\
\hline 24 & Safeway & & \\
\hline 25 & Four Churches Square & & \\
\hline & & & \\
\hline
\end{tabular}




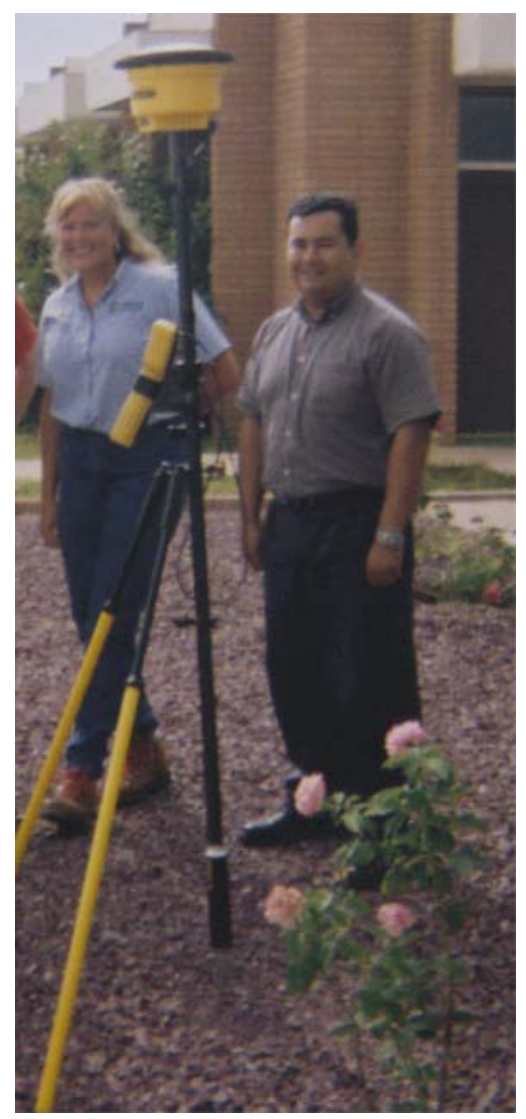

Figure 10: Carlos de la Torre, Director of Public Works, City of Douglas, presented demonstration of Global Positioning System. 


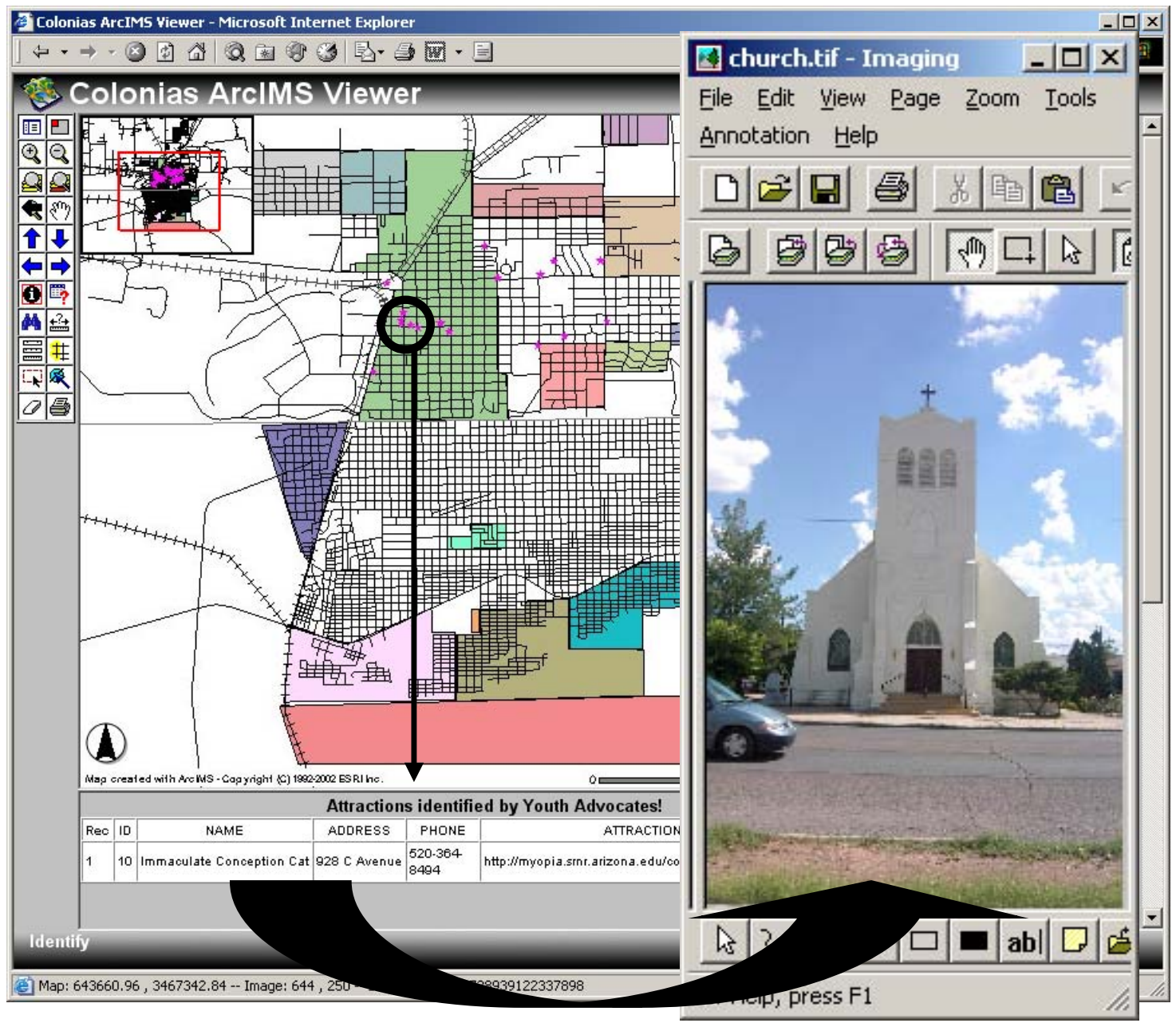

Figure 11: ArcIMS application portraying attraction database created by Youth Advocates! and example of accompanying photograph.

\section{Colonias Delineation}

Colonias were defined by the Cranston-Gonzales Act of 1990 as rural communities and neighborhoods located within 150 miles of the United States-Mexican border and that lack adequate infrastructure (sewer or water lines) and/or housing. Some colonias may be entire border communities, while others are comprised of neighborhoods within incorporated communities (http://www.hud.gov/groups/frmwrkcoln/whatcol.cfm).

There was only one known 'colonias' geospatial dataset describing the study area, which is based on specific U.S. Department of Agriculture (USDA) rural development colonias definitions generated for Cochise County, and does not incorporate Douglas proper (fig. 12). The City of Douglas declared itself a colonia in 1996 as Resolution No. 96-132, under the State Community Development Block Grant Program, pursuant to the Housing and Community Development Act of 1974, as amended, Section 916. However, the USDA rural development does not recognize this area for colonia funding (USDA: 306C) because its population exceeds the stated limit of 10,000 people. So, while it qualifies as an area lacking sewer lines, water lines, or adequate housing structures, it does not meet the requirements to receive available colonia funding. 


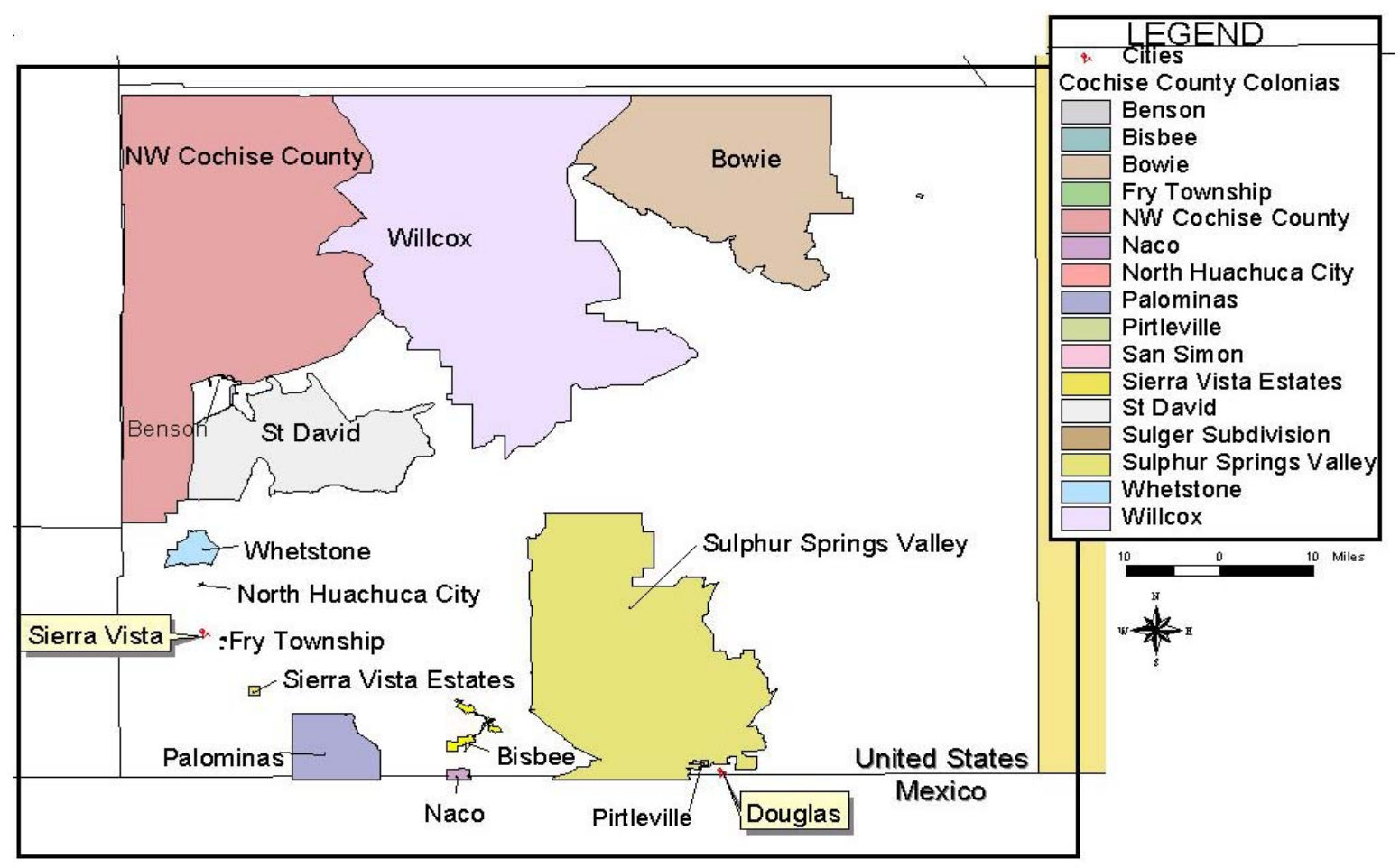

Figure 12: Designated colonias locations within the Cochise County boundary, identified by USDA rural development.

Many states take advantage of the available colonia funding sources by designating all areas fitting the legal description of a colonia. According to studies implemented by the U.S. Census Bureau, the State of Texas recognizes 1,821 colonias whose average population is 1,336 and the State of Arizona recognizes 182, whose average population is 2,871 . It is suggested that this discrepancy may be explained by the greater resolutions with which the Census Designated Places (CDPs) were designated by the officials in Texas (that is, Texas Attorney General's Office), working with Census Bureau staff, prior to Census 2000 (Ratcliffe, 2003). This results in many areas of Texas, which lack adequate housing or infrastructure, qualifying for funding opportunities made available to recognized colonias. Therefore, for this project, the USGS identified smaller, colonia-like neighborhoods within incorporated communities of selected Arizona borderlands to be recognized as colonias in the future, thereby competing for some of those funds.

With the help of local officials, citizens, and hard-copy city land-use maps, the delineations were approximated, automated, and incorporated into the database. The integration of spatial and demographic data from a variety of sources allowed for accurate depictions of colonias populations. Geospatial and digital data describing infrastructure (City of Douglas Department of Public Works) and census information (U.S. Census Bureau and others) helped to delineate neighborhood-style colonias that exist within the city itself. Some of these data were available as hard-copy maps or in AutoCAD format and needed to be digitized. All data created by the USGS have metadata generated to describe their source, scale, and other pertinent information required by the Federal Geographic Data Committee (FGDC) standards (Appendix B).

\section{Procedure}


Using a suitability-capability analysis (SCA) originally described by McHarg (1969), neighborhoods were systematically designated as colonias in this study. The SCA was based on community member assessments of the housing suitability and/or infrastructure capability of a neighborhood, using the newly digitized sewer and water lines in concert with street maps and prior knowledge, to pinpoint known colonia boundaries. For example, an area was deemed a colonia if the area's housing conditions were identified as inadequate (suitability ranking) and/or whether or not the area had access to infrastructure (that is, capability to access sewer or water lines). Those areas previously recognized by agencies, including the USDA, FONAVIT, and FOVISTE, were also delineated and identified as colonias in this study.

Chuck Ebner (Assistant Director, Department of Public Works, City of Douglas), Rosael Torres (Housing Authority, City of Douglas), Carlos de la Torre (Director, Department of Public Works, City of Douglas), and Carol Huddleston (head of Turning Point, a non-profit local organization) helped to identify the poorest neighborhoods in the City of Douglas to designate as colonias for this project.

In the City of Agua Prieta, Silvia Villalobos de Zuñiga (Director of Agua Prieta's National System for the Integral Development of the Family (DIF) and sister to the Mayor of Agua Prieta, Irma Villalobos de Terán); Del Cabarga (dual citizen and coordinator for Take to the Hills, a nonprofit organization), and Reverend Jesus Gallegos (minister at Lily of the Valley Presbyterian Church in Agua Prieta, Mexican affiliate of the Frontera de Cristo border ministry), identified the poorest neighborhoods (barrios pobres) to designate colonias for this project.

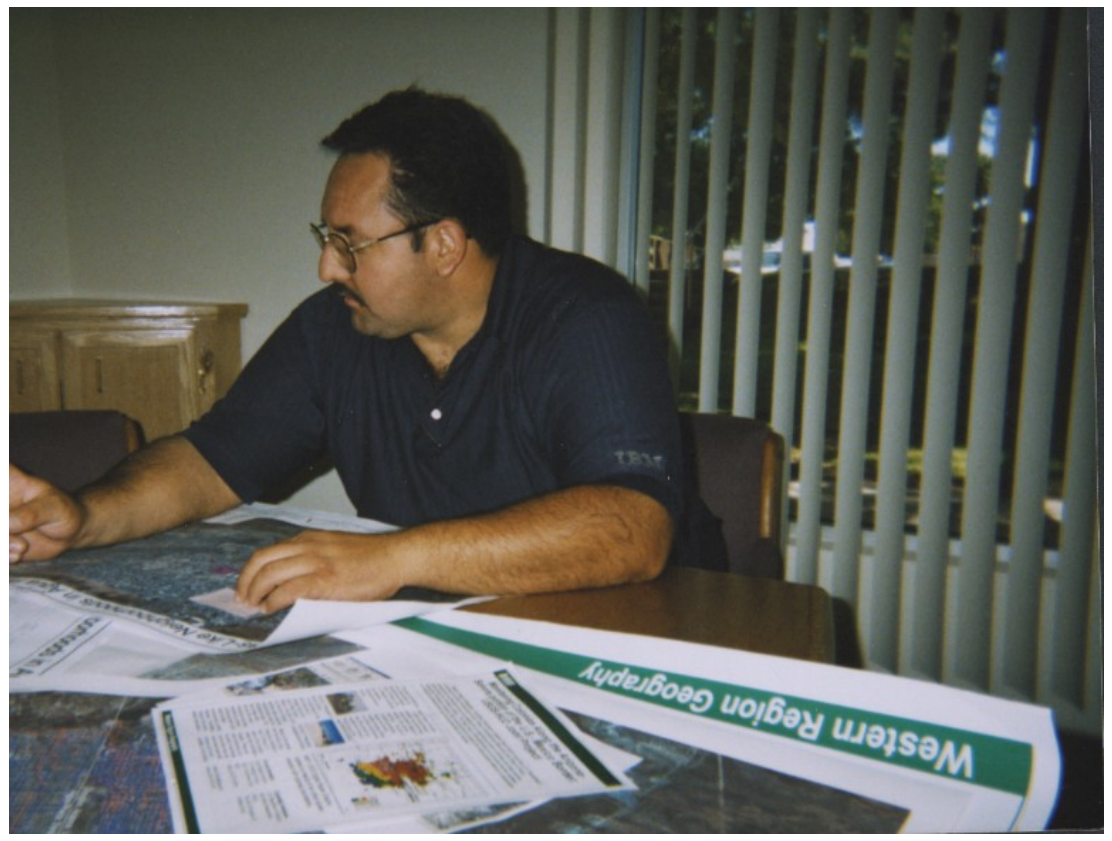

Figure 13: Del Cabarga, Coordinator for Take to the Hills, a non-profit organization, drew boundaries of colonias on hard-copy maps.

Approximations were based upon previous knowledge and familiarity with the most impoverished and underprivileged areas known to the city at that time. The polygon boundaries were then digitized and attributed (fig. 14). 


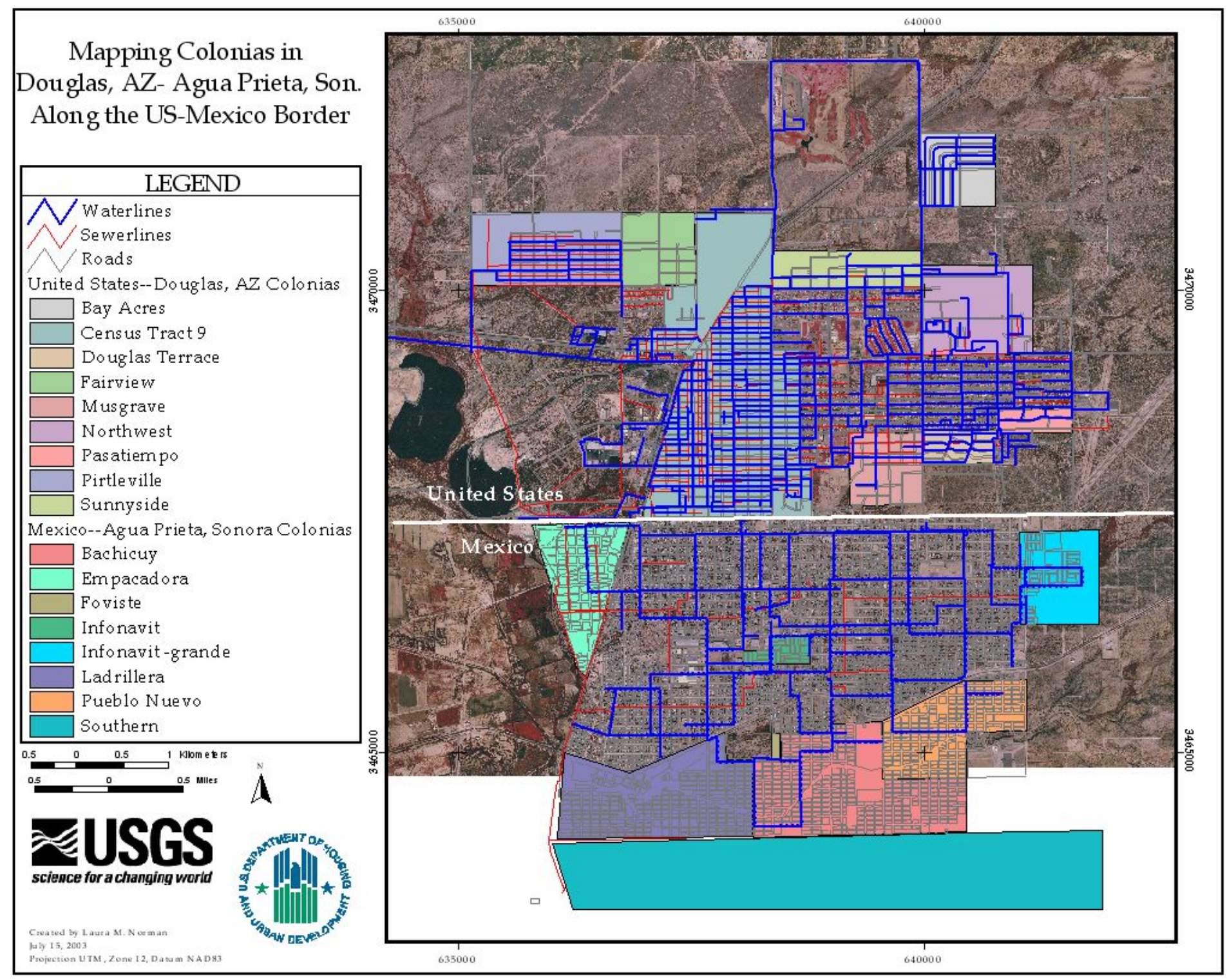

Figure 14: Newly digitized roads, sewer lines, and water lines used to identify colonia boundaries. 
The U.S. Census GIS data were imported (fig. 15) and clipped to the colonia boundaries of Douglas, Ariz., to accurately describe the population (see figure 16 and table 2) and housing elements (fig. 17) within these polygonal features.

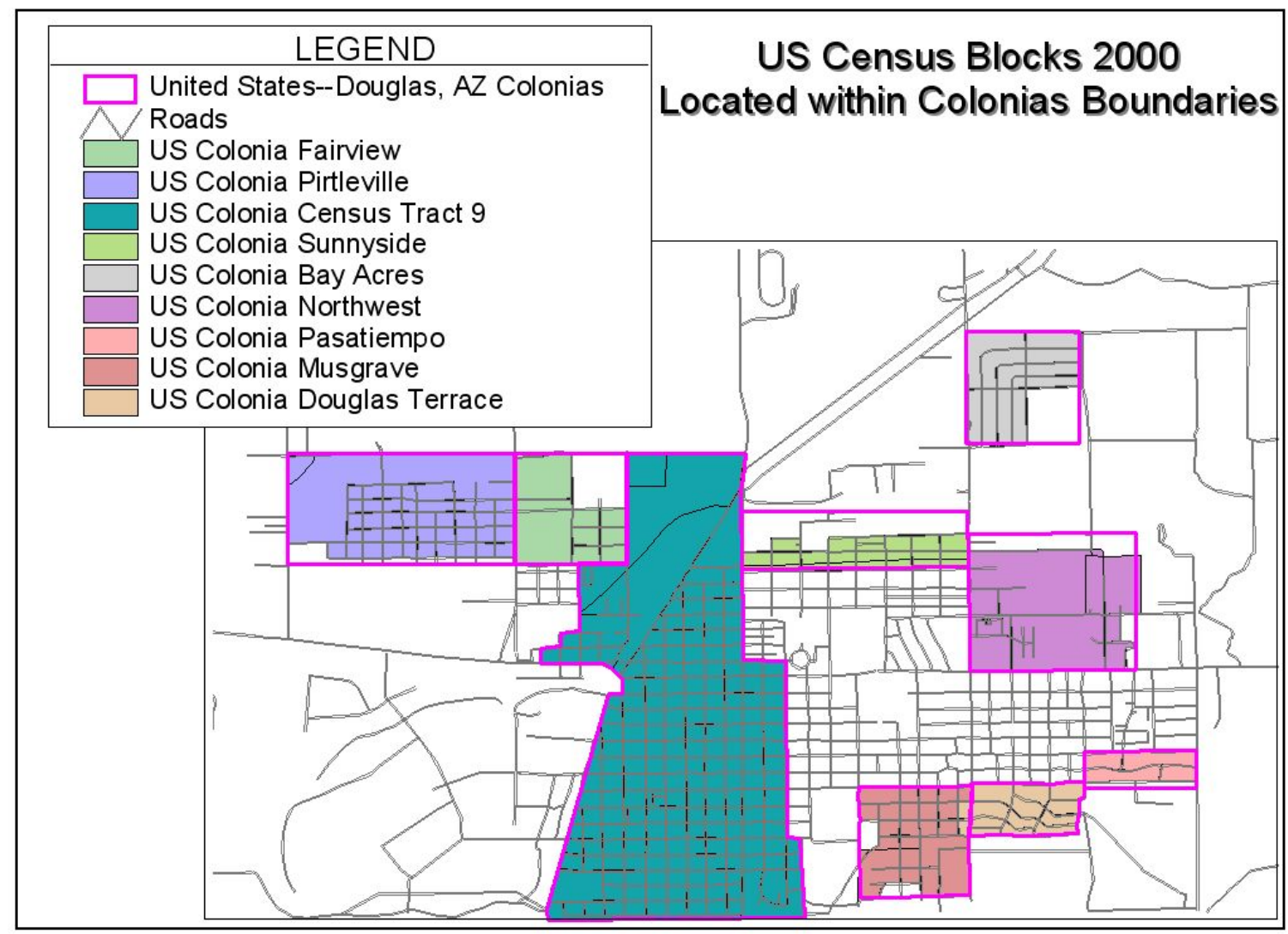

Figure 15: U.S. Census blocks within the newly delineated city colonias boundaries. 
Table 2: All U.S. Census data summarized by colonia boundary.

\begin{tabular}{|c|c|c|c|c|c|c|c|c|c|}
\hline Census data & Pirtleville & Pasatiempo & Northwes & Musgrave & Fairview & \begin{tabular}{|l} 
Census \\
Tract 9
\end{tabular} & $\begin{array}{c}\text { Bay } \\
\text { Acres }\end{array}$ & Sunnyside & \begin{tabular}{|l|} 
Douglas \\
Terrace
\end{tabular} \\
\hline Count & 44 & 4 & 12 & 23 & 9 & 205 & 13 & \begin{tabular}{|l|}
23 \\
\end{tabular} & 11 \\
\hline $\begin{array}{c}\text { Population } \\
2000\end{array}$ & 969 & 45 & 927 & 474 & 99 & 6759 & 878 & 510 & 411 \\
\hline White & 534 & 37 & 464 & 343 & 48 & 4282 & 464 & 350 & 234 \\
\hline $\begin{array}{l}\text { Black or } \\
\text { african } \\
\text { american }\end{array}$ & 9 & 0 & 5 & 2 & 0 & 45 & 0 & 0 & 1 \\
\hline $\begin{array}{c}\text { American } \\
\text { indian and } \\
\text { alaska native }\end{array}$ & 10 & 0 & 4 & 0 & 0 & 40 & 3 & 6 & 0 \\
\hline Asian & 7 & 0 & 0 & 0 & 0 & 23 & 0 & 2 & 4 \\
\hline $\begin{array}{c}\text { Native } \\
\text { hawaiian and } \\
\text { other pacific } \\
\text { islander } \\
\end{array}$ & 0 & 0 & 0 & 5 & 4 & 5 & 0 & 2 & 0 \\
\hline Other & 385 & 8 & 410 & 111 & 43 & 2156 & 376 & 145 & 165 \\
\hline $\begin{array}{c}2 \text { or more } \\
\text { races }\end{array}$ & 24 & 0 & 44 & 13 & 4 & 208 & 35 & 5 & 7 \\
\hline Hispanic & 920 & 20 & 837 & 415 & 93 & 6170 & 811 & 401 & 368 \\
\hline Males & 478 & 24 & 432 & 231 & 53 & 3133 & 442 & 258 & 194 \\
\hline Females & 491 & 21 & 495 & 243 & 46 & 3626 & 436 & 252 & 217 \\
\hline Age under 5 & 72 & 4 & 135 & 26 & 20 & 608 & 86 & 43 & 37 \\
\hline Age 5-17 & 250 & 13 & 272 & 134 & 22 & 1631 & 274 & 136 & 109 \\
\hline Age 18-21 & 69 & 1 & 73 & 26 & 11 & 451 & 62 & 37 & 21 \\
\hline Age 22-29 & 85 & 0 & 126 & 36 & 11 & 617 & 95 & 50 & 42 \\
\hline Age 30-39 & 113 & 6 & 116 & 67 & 20 & 724 & 135 & 77 & 47 \\
\hline Age 40-49 & 116 & 5 & 100 & 69 & 8 & 792 & 98 & 57 & 63 \\
\hline Age 50-64 & 156 & 10 & 67 & 73 & 4 & 862 & 74 & 64 & 60 \\
\hline Age 65 \& up & 108 & 6 & 38 & 43 & 3 & 1074 & 54 & 46 & 32 \\
\hline Median age & 32 & 43 & 20 & 30 & 15 & 30 & 23 & 29 & 27 \\
\hline $\begin{array}{c}\text { Median age, } \\
\text { males }\end{array}$ & 29 & 35 & 17 & 33 & 16 & 28 & 20 & 28 & 27 \\
\hline $\begin{array}{c}\text { Median age, } \\
\text { females }\end{array}$ & 35 & 44 & 23 & 29 & 12 & 32 & 25 & 30 & 29 \\
\hline Households & 296 & 16 & 287 & 149 & 23 & 2206 & 241 & 162 & 124 \\
\hline $\begin{array}{c}\text { Average } \\
\text { household } \\
\text { size }\end{array}$ & 3 & 3 & 3 & 3 & 3 & 3 & 3 & 3 & 2 \\
\hline $\begin{array}{c}\text { 1-person } \\
\text { household, } \\
\text { male }\end{array}$ & 18 & 1 & 22 & 15 & 2 & 230 & 22 & 9 & 7 \\
\hline $\begin{array}{c}\text { 1-person } \\
\text { household, } \\
\text { female }\end{array}$ & 41 & 3 & 27 & 14 & 0 & 292 & 13 & 12 & 8 \\
\hline $\begin{array}{c}\text { Married- } \\
\text { couple wl } \\
\text { own children }\end{array}$ & 88 & 6 & 93 & 41 & 12 & 508 & 100 & 52 & 46 \\
\hline
\end{tabular}




\begin{tabular}{|c|c|c|c|c|c|c|c|c|c|}
\hline under 18 yrs & & & & & & & & & \\
\hline \begin{tabular}{|c|} 
Married- \\
couple, no \\
own children \\
under 18 yrs
\end{tabular} & 74 & 4 & 30 & 36 & 4 & 480 & 43 & 37 & 35 \\
\hline \begin{tabular}{|c|} 
Male \\
householder, \\
no wife \\
present, wl \\
own children \\
under 18 yrs \\
\end{tabular} & 7 & 1 & 10 & 8 & 2 & 58 & 14 & 7 & 3 \\
\hline \begin{tabular}{|c|} 
Female \\
householder, \\
no husband \\
present, wl \\
own children \\
under 18 yrs \\
\end{tabular} & 19 & 0 & 78 & 17 & 2 & 280 & 26 & 22 & 11 \\
\hline \begin{tabular}{|l|} 
Families \\
\end{tabular} & 232 & 12 & 231 & 118 & 21 & 1629 & 202 & 137 & 107 \\
\hline $\begin{array}{c}\text { Average } \\
\text { family size }\end{array}$ & 4 & 3 & 3 & 3 & 3 & 3 & 3 & 3 & 3 \\
\hline $\begin{array}{c}\text { Housing } \\
\text { units }\end{array}$ & 349 & 18 & 317 & 171 & 30 & 2629 & 276 & 208 & 132 \\
\hline \begin{tabular}{|c|} 
Housing \\
units, urban
\end{tabular} & 0 & 0 & 0 & 0 & 0 & 0 & 0 & 0 & 0 \\
\hline $\begin{array}{c}\text { Housing } \\
\text { units, rural }\end{array}$ & 0 & 0 & 0 & 0 & 0 & 0 & 0 & 0 & 0 \\
\hline \begin{tabular}{|c|} 
Housing \\
units, vacant
\end{tabular} & 53 & 2 & 30 & 22 & 7 & 423 & 35 & 46 & 8 \\
\hline \begin{tabular}{|c|} 
Housing \\
units, owner \\
occupied
\end{tabular} & 262 & 15 & 123 & 107 & 19 & 1242 & 170 & 108 & 105 \\
\hline $\begin{array}{c}\text { Housing } \\
\text { units, renter } \\
\text { occupied }\end{array}$ & 34 & 1 & 164 & 42 & 4 & 964 & 71 & 54 & 19 \\
\hline
\end{tabular}

Using the derived dataset, it is possible to estimate housing elements. For example, the renter-occupied attribute was averaged and plotted to examine the relationship of rented vs. owner-occupied units in the colonias (fig. 16). 


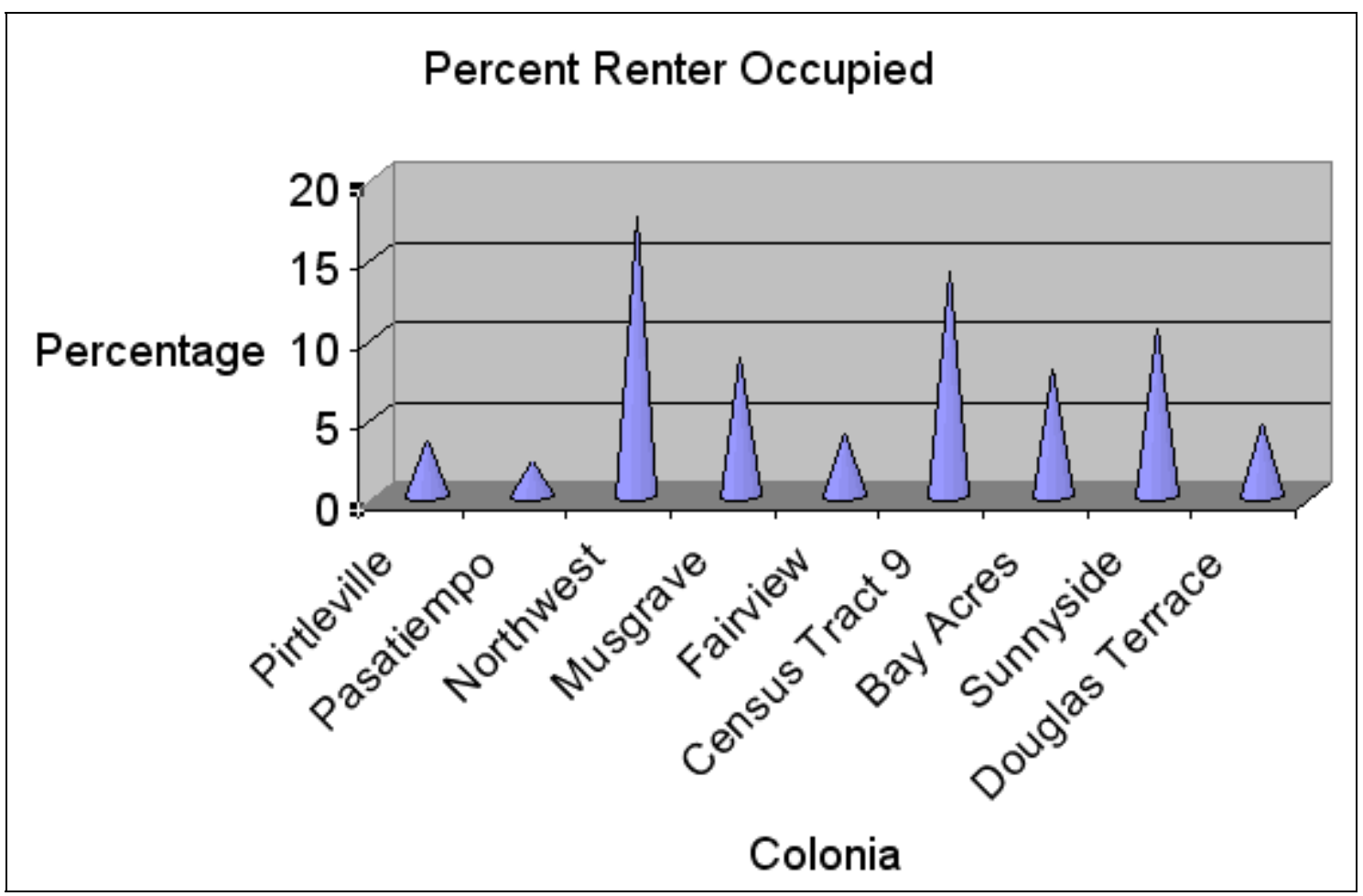

Figure 16: Renter-occupied housing in colonias.

It is generally assumed that most colonias are predominantly Hispanic (Ratcliffe, 2003), yet one of the seven defined in this study (Pasatiempo) is less than 50 percent Hispanic, see Figure 17.

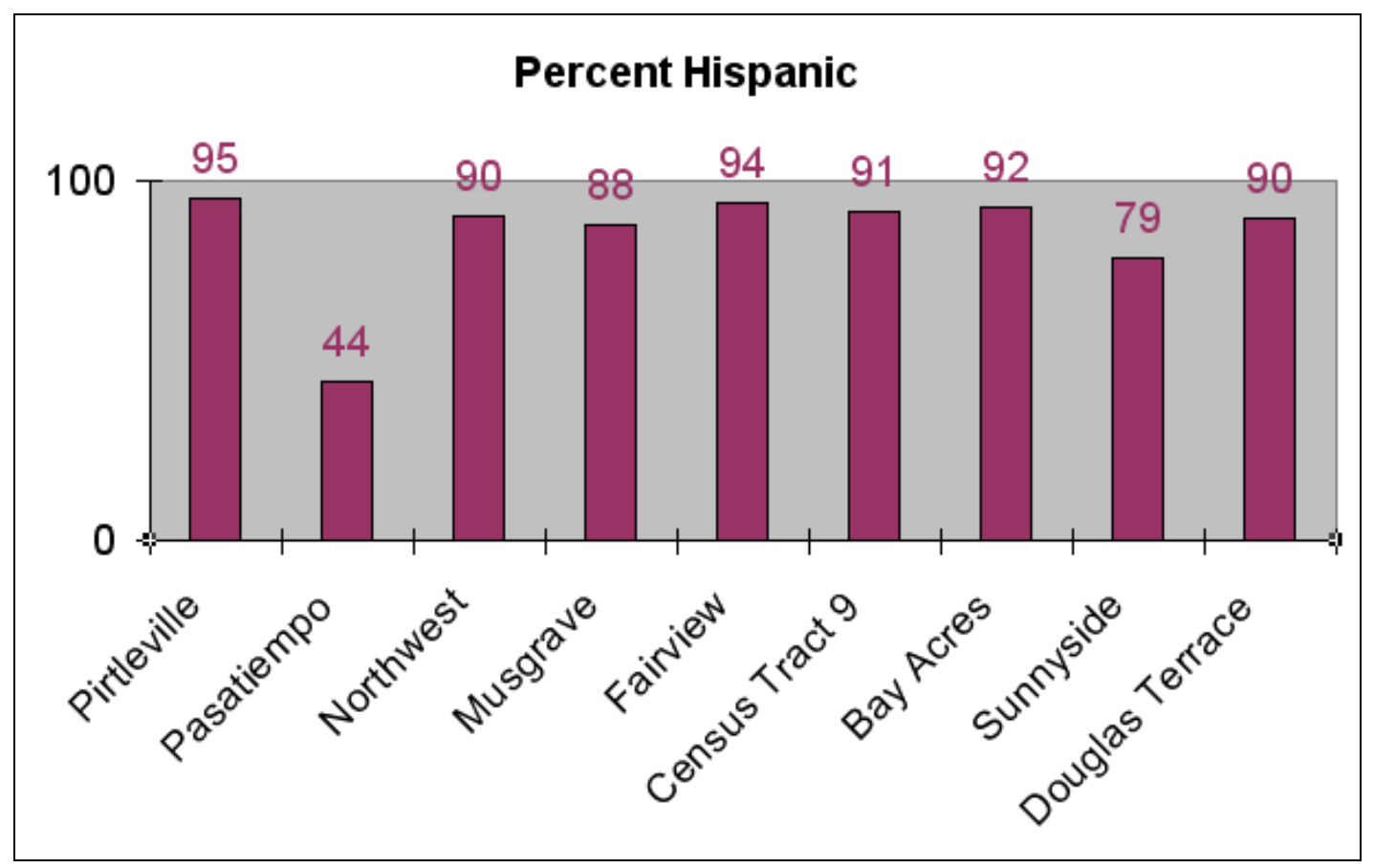

Figure 17: Percent of Hispanic population in colonias. 
These types of comparisons help to illustrate the changing environment along the United States-Mexico border by applying hard analysis to quantify population and characterize the colonias.

Census information in Agua Prieta was not available. The housing conditions were defined solely through visual analysis. Photographs by Sylvia Villabolos de Zuniga visually describe the conditions of some poor neighborhoods in Agua Prieta (fig. 18).

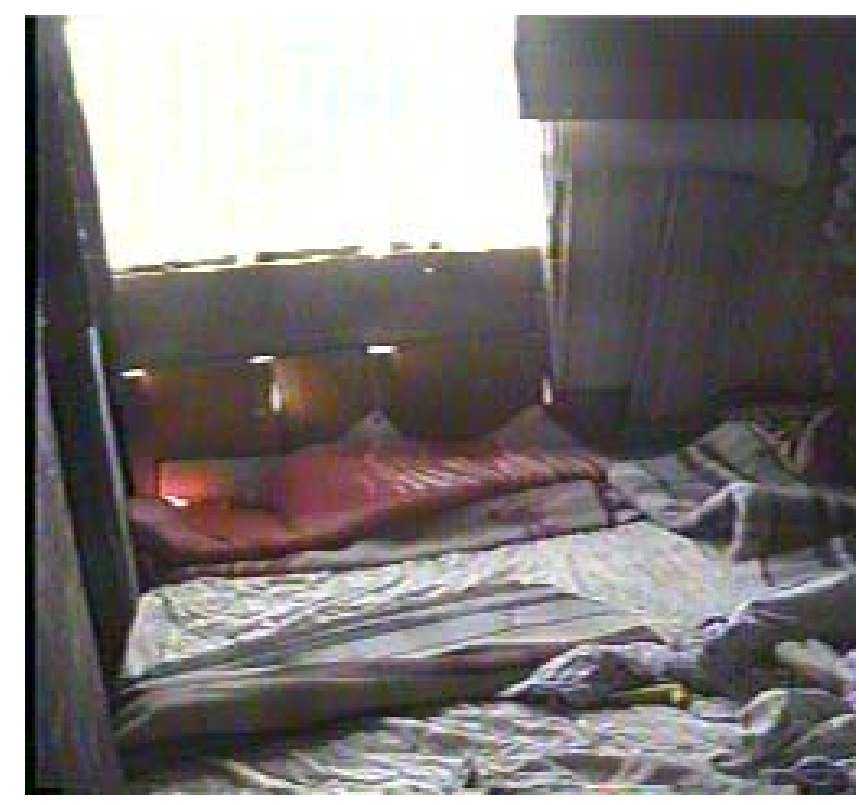

Figure 18: A floor bed shared by 13 brothers and sisters in one family's house in Agua Prieta (photo by Silvia Villalobos de Zuñiga).

\section{Remote Sensing Applications and Land Use Change}

\section{Introduction}

Urbanization is monitored to estimate populations, predict and plan direction of urban growth for development purposes, and to help monitor adjacent environmentally sensitive or riparian areas (Forney and others, 2001; Lee and Marsh, 1995). Many studies aim to depict land use change using remote sensing technologies (Shan, 1999; Jensen and others, 1995; Acevedo and others, 1999; Eastman and Fulk, 1993; Howarth, 1986; Jensen and Toll, 1982; Haack and others, 1987; Kirkland and others, 1994; Mack and others, 1995). Remote sensing and photogrammetric technology aid in describing international borders by helping analysts create seamless maps of features apparent on the Earth's surface while disregarding anthropogenic boundaries (Brady and others, 2002; Osborn, 1998).

The City of Douglas provided imagery (figs. 19-20), which shows that the urban extent of the twin city area had changed over the years. Temporal image processing and analysis was performed to quantify urban growth stemming from human settlement. A time-series change analysis from 1973 to 2000 was performed to identify recently developed areas. 


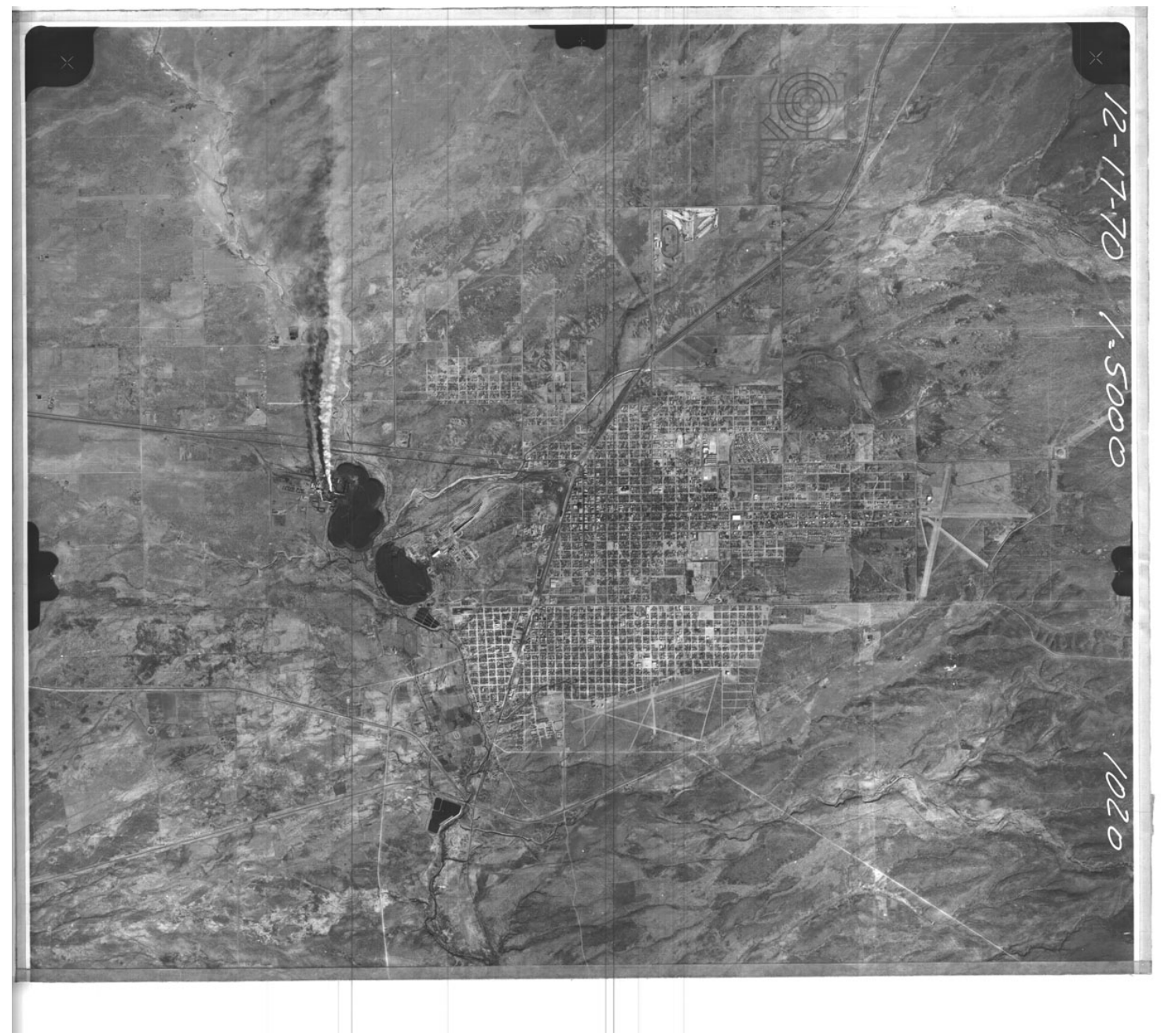

Figure 19: Aerial photograph showing Douglas, Ariz., in northern (upper) half and Agua Prieta, Sonora, in the southern (lower) half, divided by the international border. Photo (1970) depicts smokestack and smoke trailing to the north from a now-abandoned smelter. 


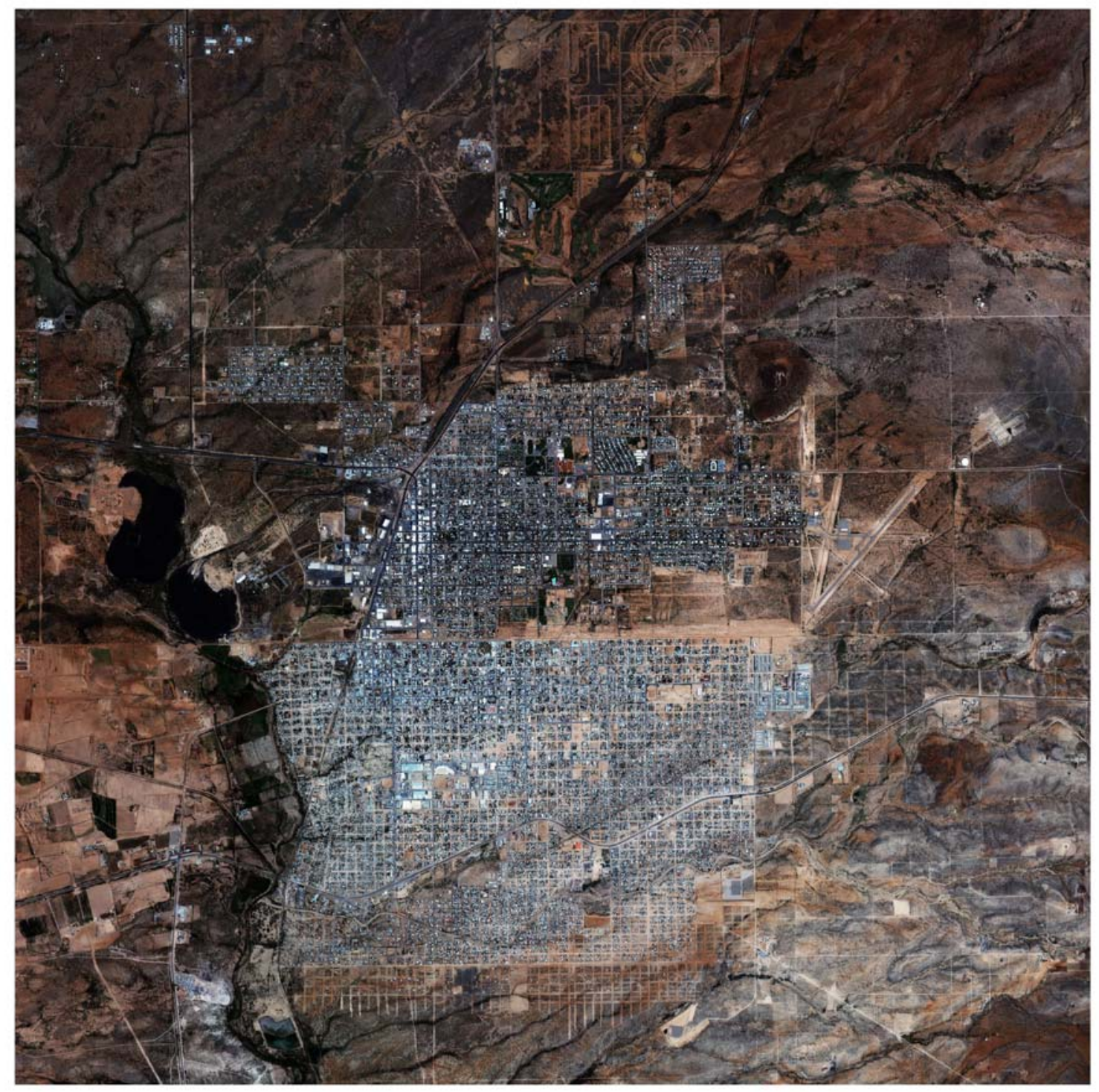

Figure 20: Satellite image taken in 2001, showing Douglas, Ariz., in the northern (upper) half and Agua Prieta, Sonora, in the southern (lower) half, divided by the international border.

Image interpretation and analysis required acquisition and processing of Landsat imagery, their georectification, and classification of urban and residential land use. These data were then used to produce maps of the past and current urban extent in the region. Because the classification value of urban extent is subject to the analyst's decision rules during the urban mapping process, the numbers listed in this study are approximations.

Software products used for this study include Erdas Imagine 8.5; ESRI ArcMap, Arclnfo 8.2 and it's GRID module, Arc View 3.3 and the extensions Spatial Analyst, 3D Analyst, Grids and Graticules, Geoprocessing, Microsoft Word, and Photo Editor. Hardware required a minimum of 2GB for data storage. Information on the World Wide Web was also accessed.

Identification of features using remotely sensed data involves use of computer software with the ability to identify pixels based upon their spectral reflection properties and to analyze pixels for statistical estimates. The Normalized Difference Vegetation Index (NDVI) was calculated from each of the data sets to derive estimates of vegetation. Clustering methods, 
called unsupervised classification procedures, were applied to determine the location of the spectral classes into which the pixels of urban definition are assigned.

\section{Data Acquisition}

The Arizona Regional Image Archive http://aria.arizona.edu is an online interdisciplinary resource system for digital image and map data for the Sonoran desert region, including the southwest region of the United States and northern Mexico. This source provides geospatial data via an interactive map that can be downloaded over the Internet.

Datasets were acquired from this website and included USGS products (DOQQs, DRGs, and Digital Elevation Models (DEMs), as well as Landsat satellite imagery. Landsat imagery of the Douglas, Ariz., and Agua Prieta, Sonora, area (Path 35 Row 38) was acquired for 06/04/1973, 06/06/1985, 06/18/1995, and 04/05/2000. The acquisition dates of the Landsat data were deemed appropriate because the angle of the sun was approximately the same on the four dates.

Although the satellite data were all acquired from Landsat systems, different sensors were utilized through the years, which may result in some discrepancy during analysis. The Landsat-1 satellite acquired the MSS imagery for 1973 at a 79-m resolution. Landsat- 5 TM sensor acquired TM data in 1985 and 1995 at a 30-m resolution. And the Landsat-7 Enhanced Thematic Mapper Plus (ETM+) data was acquired at 30-m resolution in 2000.

\section{Data Processing}

\section{Registration}

Geometric distortions were corrected by establishing a relationship between the satellite image and 1996 USGS DOQQ of the corresponding regions. Once the ground control points (GCPS) were established, the image was converted, or rubber sheeted, to the new coordinate system through a nearest neighbor resampling regime using a $3^{\text {rd }}$-order polynomial through a process called rectification. The newly registered data were then checked for accuracy through the process of overlay analysis. Each image was subset, registered, and clipped to the same bounding coordinates (fig. 21). 

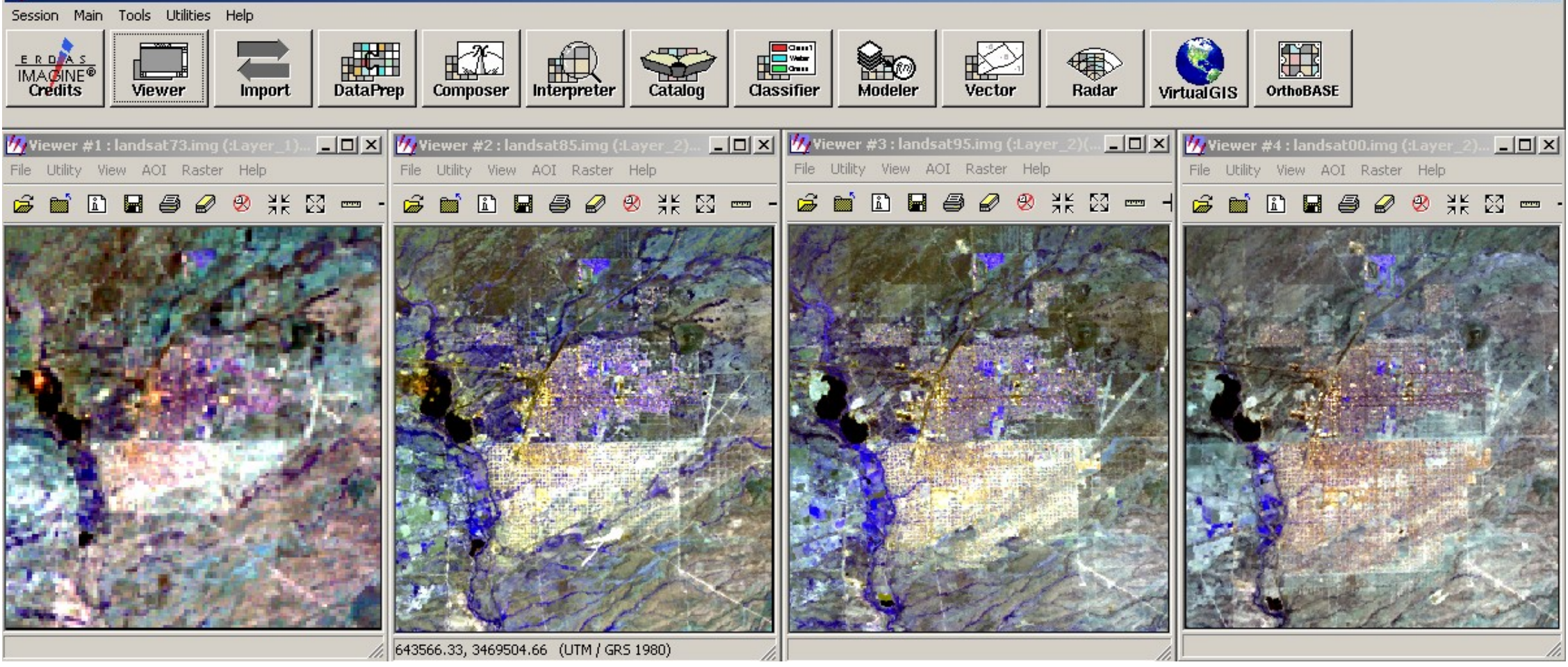

Figure 21: Landsat datasets, registered and clipped to describe the Douglas and Agua Prieta study area (1973, 1985, 1995, and 2000). The images show Douglas, Ariz., (northern half) and Agua Prieta, Sonora, (southern half); divided by the United States-Mexico border. 


\section{Normalized Difference Vegetation Index (NDVI) Processing}

NDVI was calculated for each of the Landsat data sets. To quantify the density of plant growth, NDVI uses the near-infrared radiation (NIR) minus the visible radiation of the red band (RED) divided by NIR plus RED. Written mathematically, the formula is:

$$
N D V I=(N I R-R E D) /(N I R+R E D)
$$

As indicated, due to changes in the sensors through the years, band number and width vary and, hence, comparison of the resulting datasets can be problematic and requires normalization. Calculations of NDVI for a given pixel always result in a number that ranges from minus one (-1) to plus one (+1). To display the result of this formula, the Erdas Modelmaker (fig. 22) was employed to complete the following stretch: the addition of the number 1 to all pixel values, to readjust the scale from ( -1 to +1$)$ to $(0$ to 2$)$ and subsequent multiplication of all pixel values by 100 to create an 8-bit gray-level image.

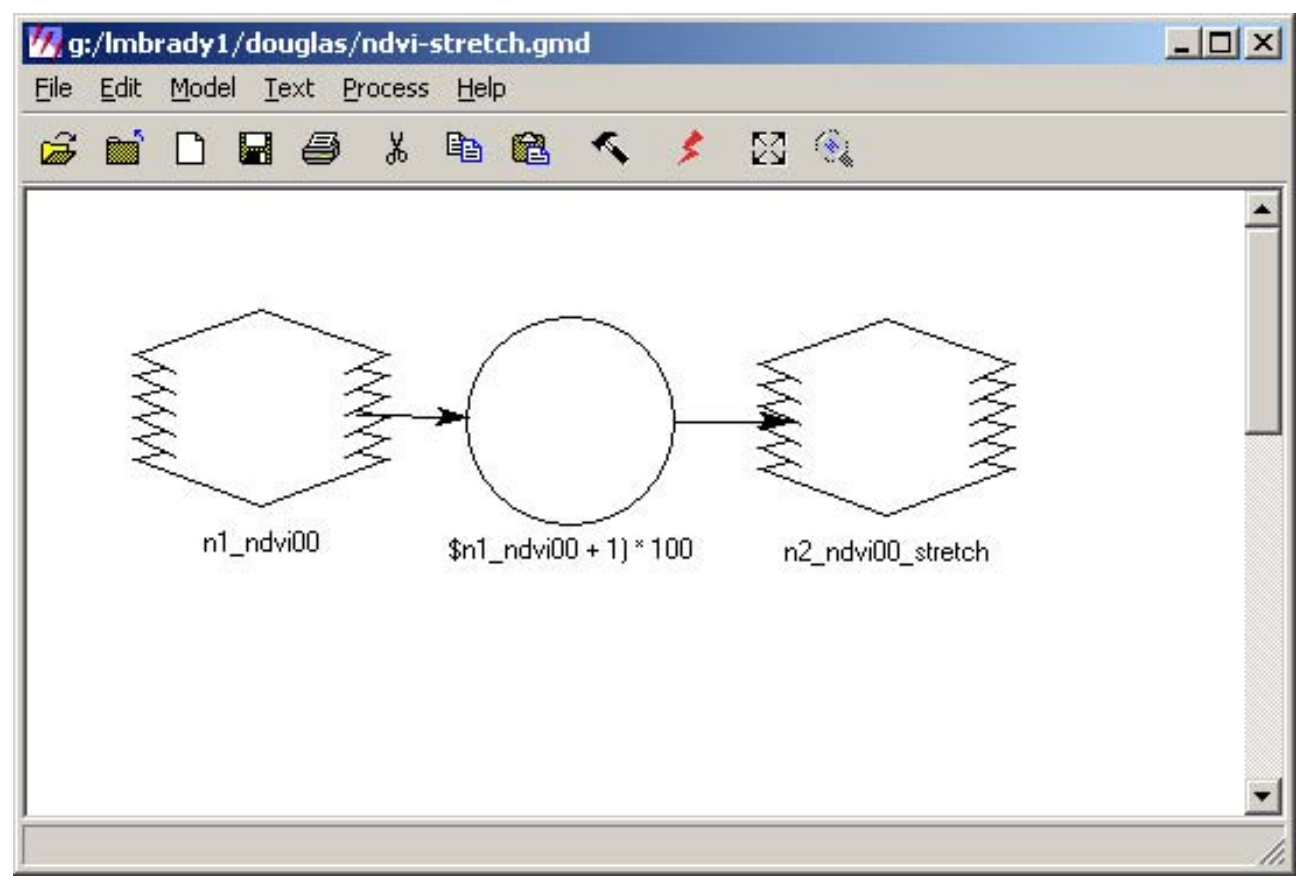

Figure 22: The Erdas Modelmaker was employed to add the number 1 to all values and then multiply by 100 to display the product of the NDVI in 200 gray levels, viewable by an 8-bit system.

The NDVI values were divided into three classes using quantile sampling. The lower two classes were masked out to create a coverage of high vegetation, compared with the location of known city parks and streets in Douglas, and draped over a DOQQ (fig. 23).

Examination of the NDVI dataset shows evidence that the City of Douglas is much more vegetated than the City of Agua Prieta. The vegetation in Douglas is apparent in golf courses, city parks, and residential yards. Agua Prieta, on the other hand, is very scarce in vegetation throughout the urban area, except for the area just west of the city, where dense vegetation due to agriculture is clustered around the river that drains the sewage treatment plant. 


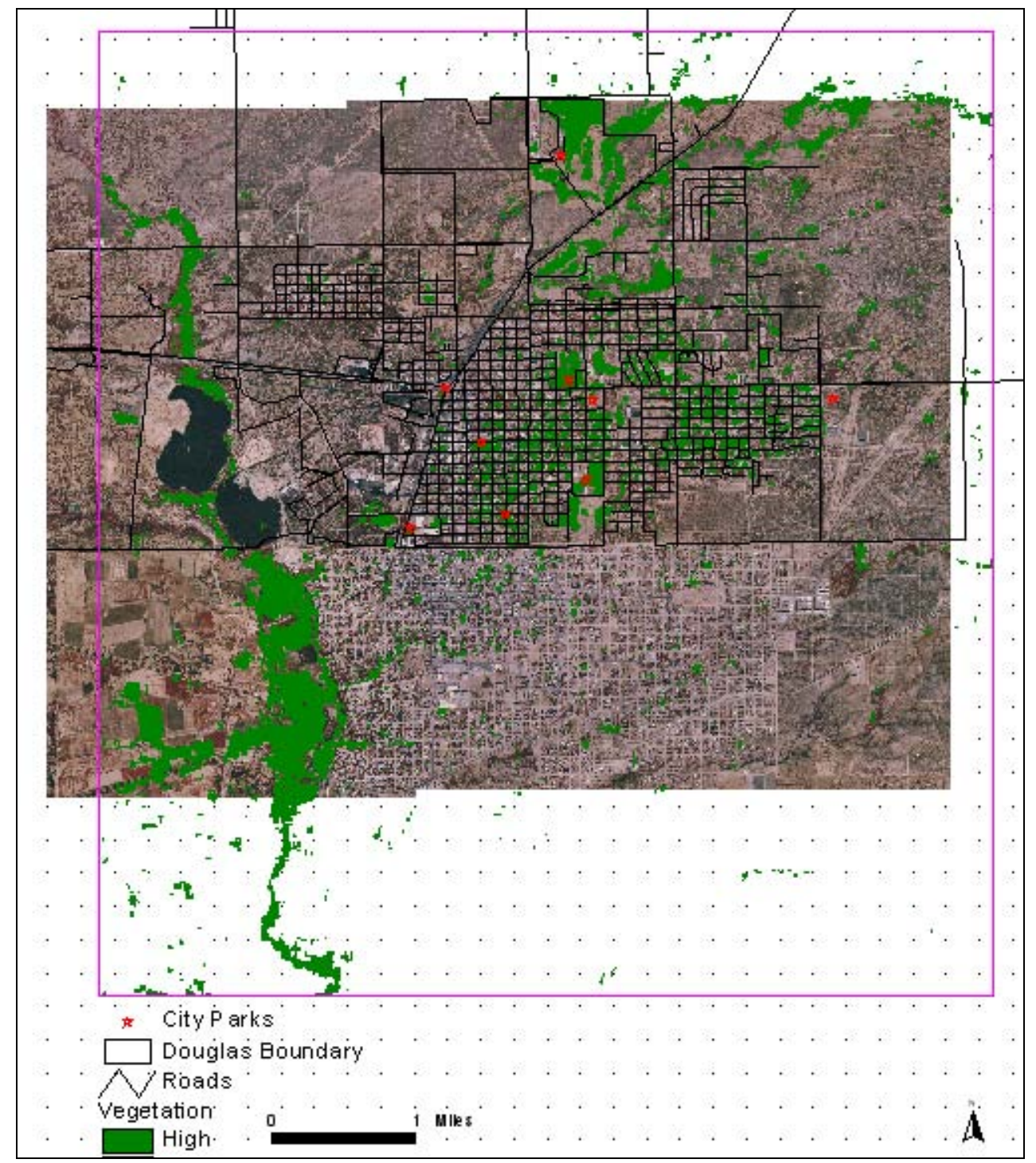

Figure 23: Vegetation layer (green) derived from calculations of the NDVI 2000 Landsat dataset, overlain on DOQQ with street lines and city parks.

\section{Urban Extent}

\section{Unsupervised Classification}

Datasets were systematically run through the Erdas Imagine isodata algorithm, using 6 iterations each, creating signature sets and imagery categorized into 20 classes. The isodata-clustering algorithm uses the minimum spectral distance formula to form clusters, beginning with arbitrary cluster means. Classes correspond to spectral signatures of dominant land use and land cover types. Signatures that appeared to be urban areas were isolated for future analysis.

Using the vegetation layer, isodata classifications, and registered original true-color Landsat imagery, the urban areas were identified and manually digitized at a 1:25,000 scale for each year of interest (figs. 24-27). 

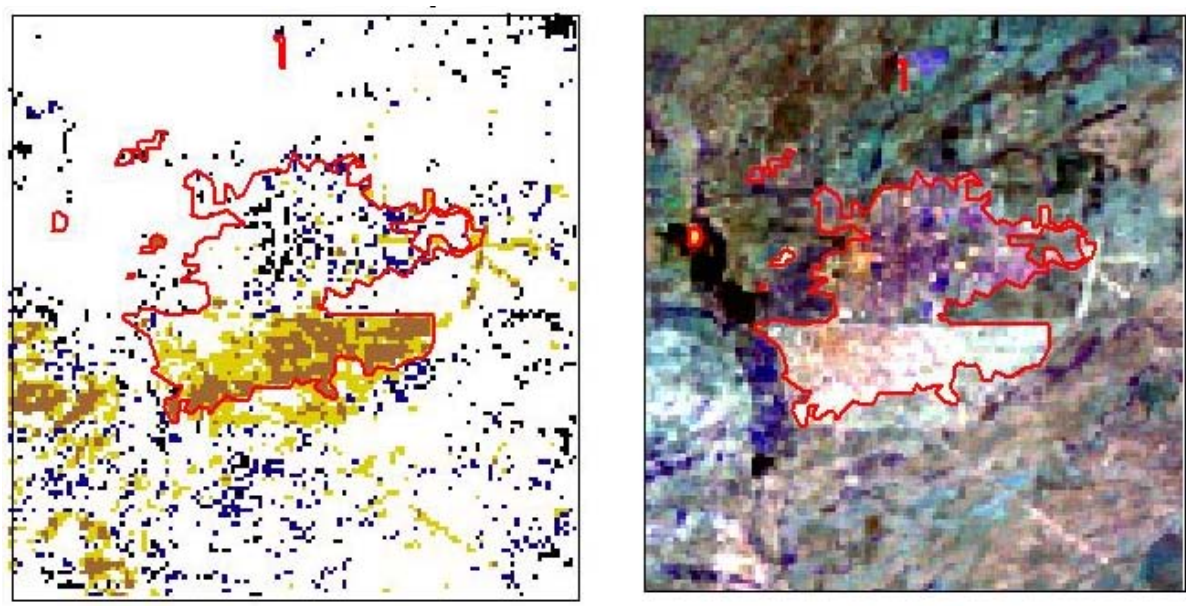

Figure 24: 1973 isodata set and registered original true color with urban area defined in red.
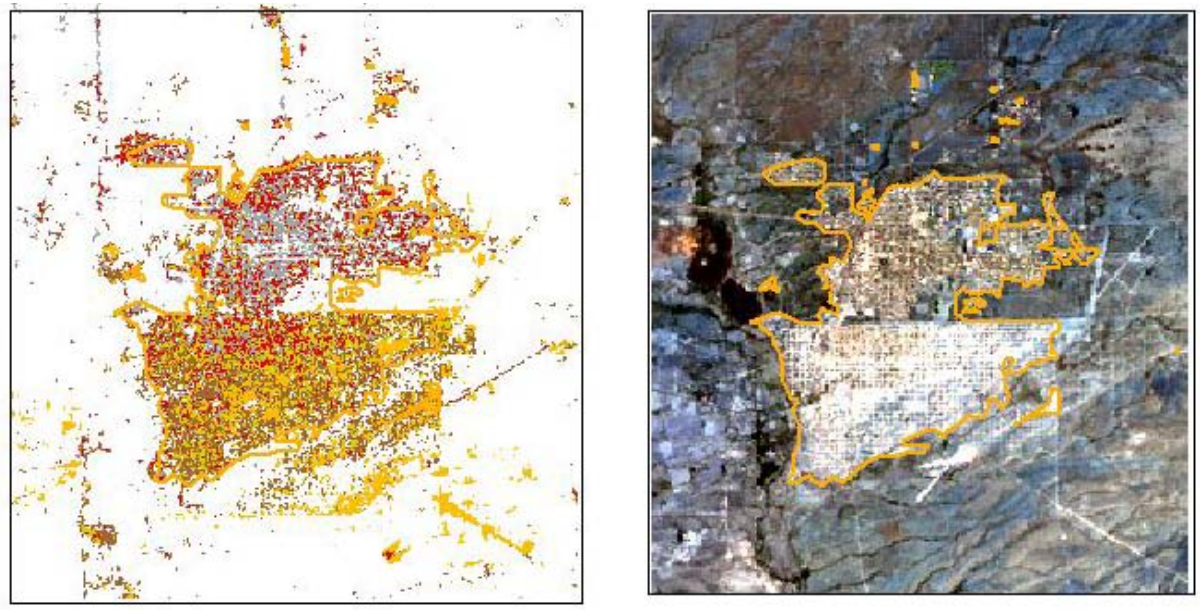

Figure 25: 1985 isodata set and registered original true color with urban area defined in orange.
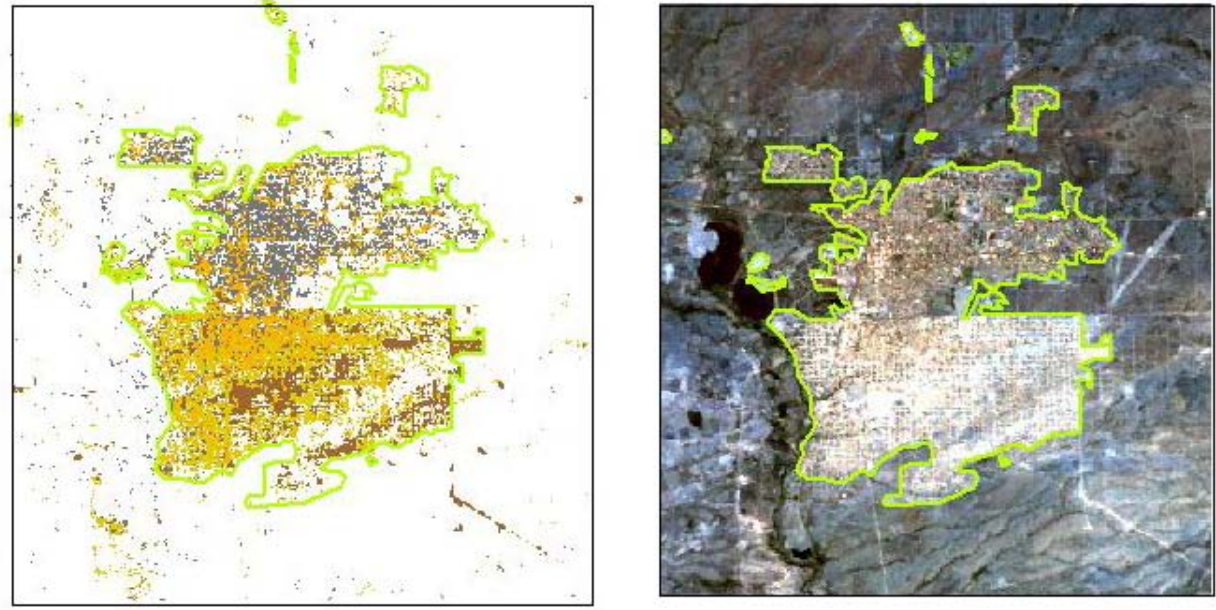

Figure 26: 1995 isodata set and registered original true color with urban area defined in light green. 

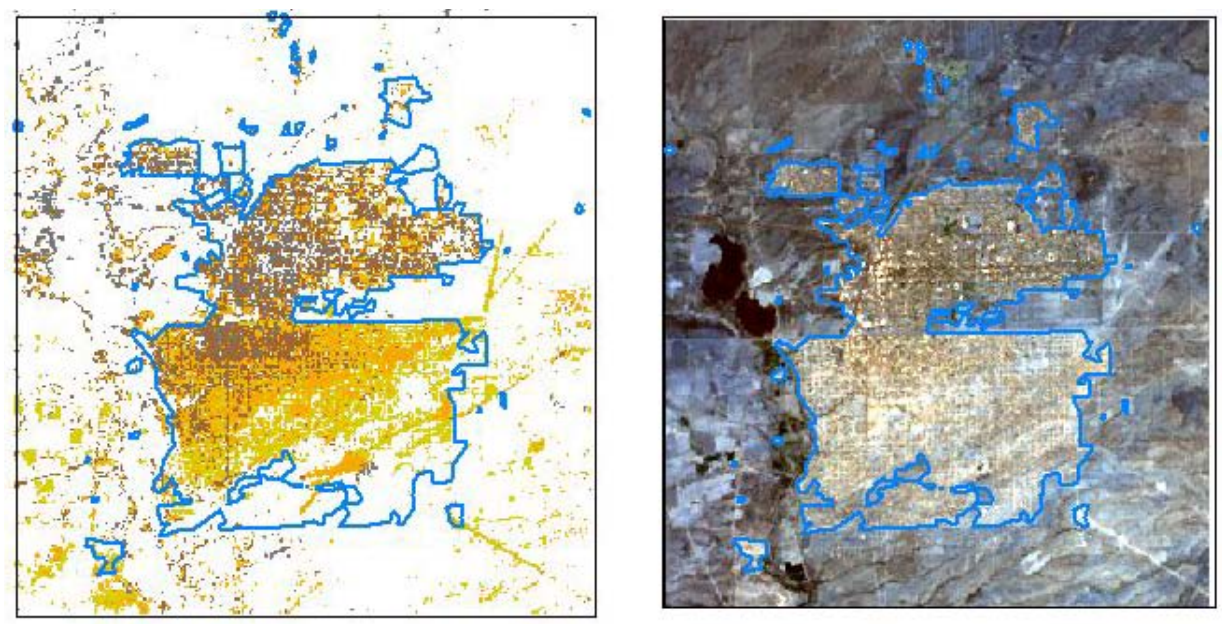

Figure 27: 2000 isodata set and registered original true color with urban area defined in blue.

\section{Assessment}

A visual verification was performed on the urban area delineated in 1995 by overlaying the polygon on the 1-m-resolution DOQQ captured in 1996 (fig. 28). This determined that an accurate depiction of urban extent had been calculated.

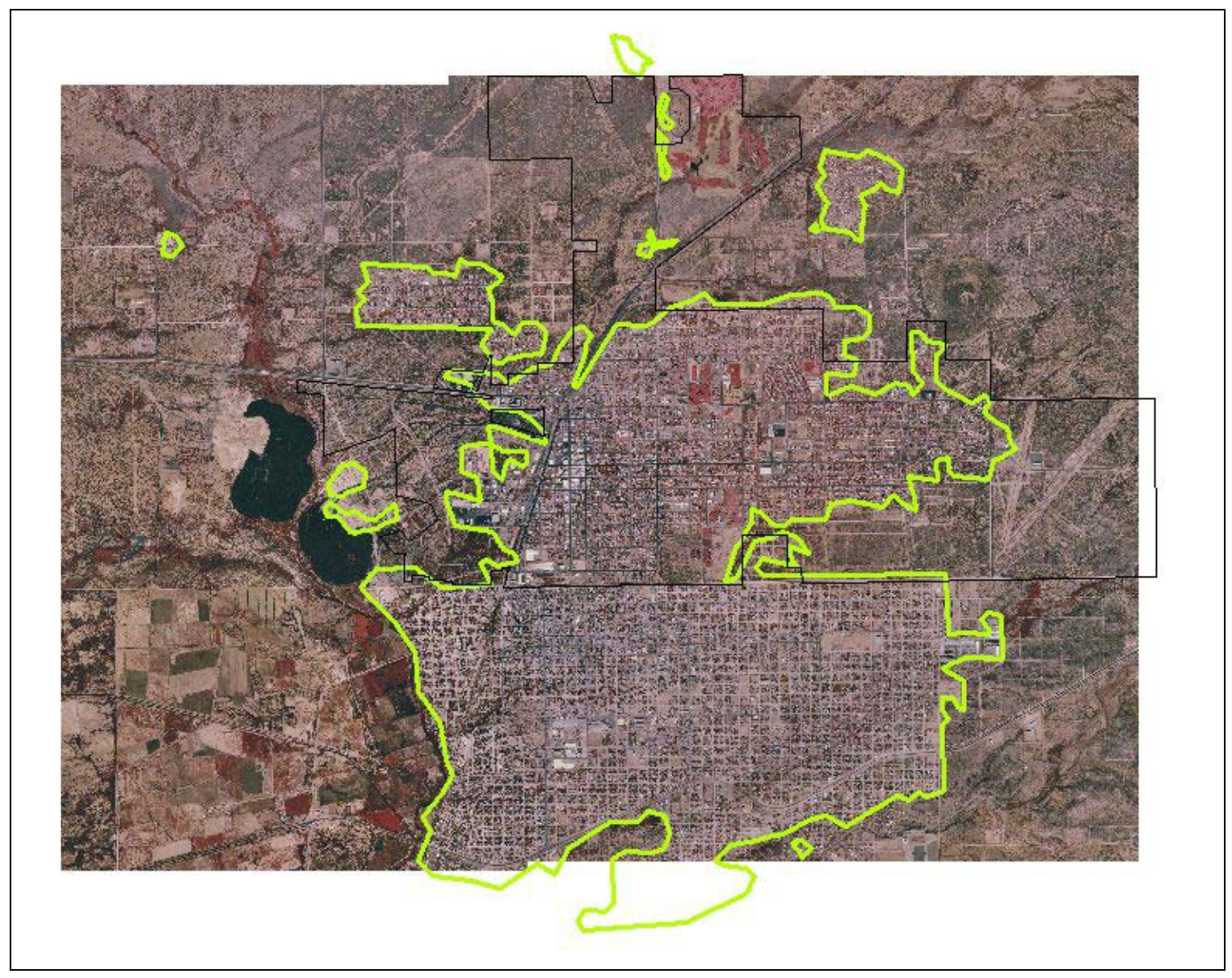


Figure 28: The 1995-derived urban data were superimposed on the 1996 DOQQ to ensure an accurate portrayal of the boundary.

The National Land Classification Dataset (NLCD) from 1992 was also compared to the 1995-derived data (fig. 29) as another qualitative comparison. This confirmed that the urban area estimated by derivation in this study was accurate.

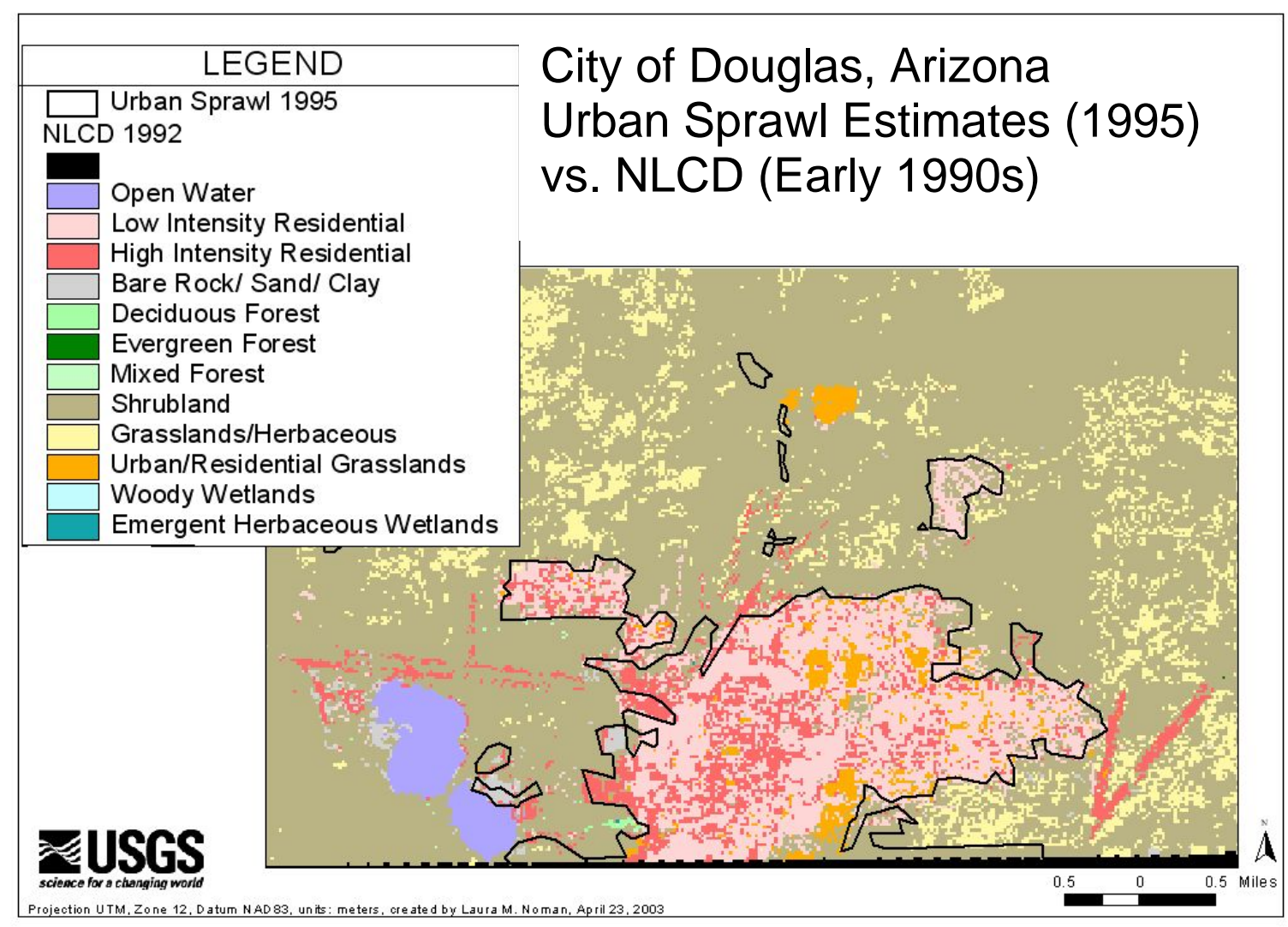

Figure 29: The NLCD portraying conditions circa 1992 was compared to the newly derived urban boundary in 1995.

Analysis

The results of quantification of the urban extent are presented in geospatial datasets that can be compared with other GIS information describing the city. This will provide graphical analysis of urban growth over time, in relation to development of infrastructure and colonias. The urban boundary vector files were converted to raster grids for statistical operations available in GIS software. These GRIDS are displayed under a USGS DRG and indicate rapid urban growth in Agua Prieta, Sonora, as well as some growth in Douglas, Ariz. (fig. 30). The DRG helps to identify cultural features on the ground. 


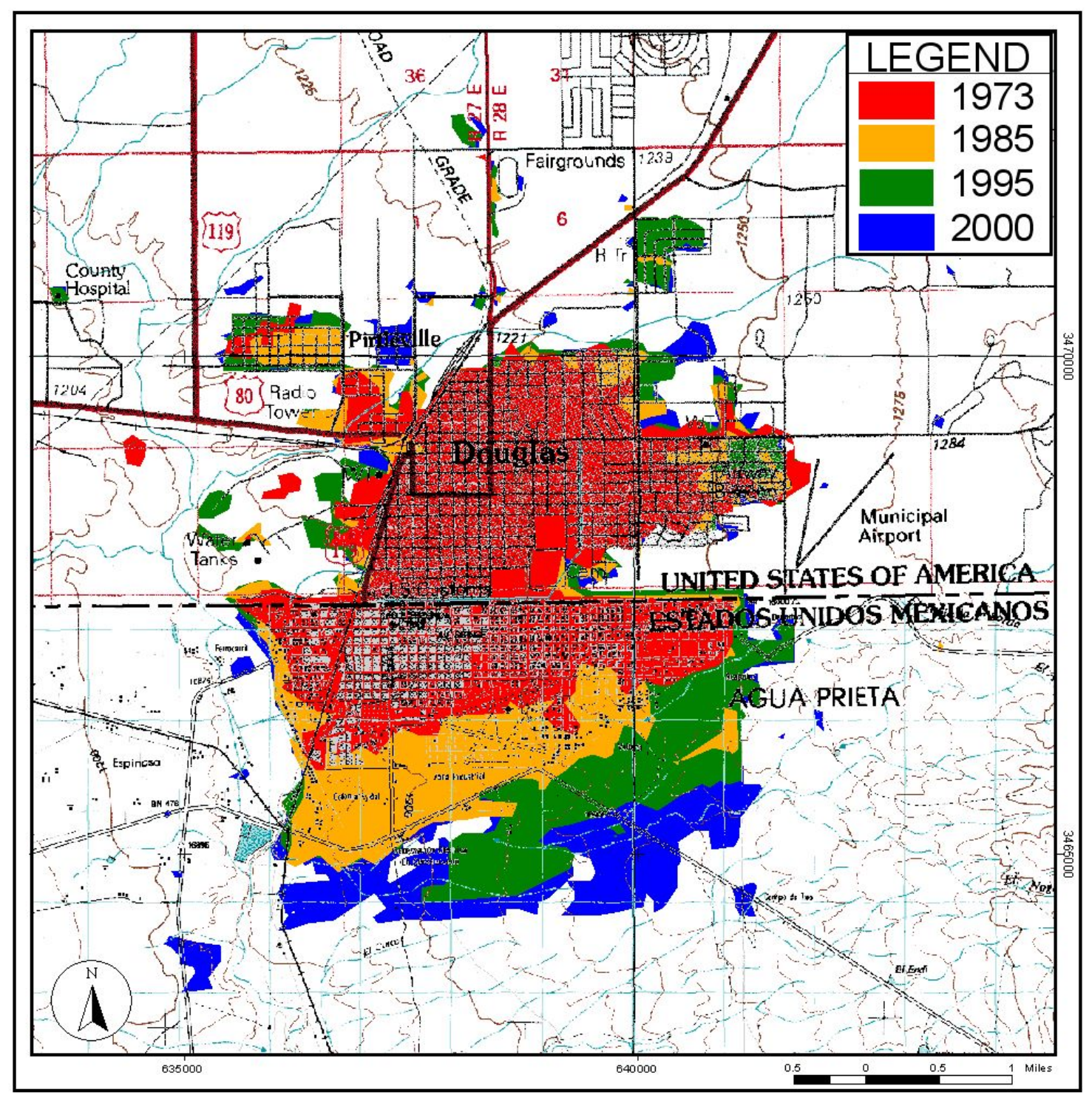

Figure 30: Urban growth depicted from Landsat imagery from the years 1973, 1985, 1995, and 2000.

Land-use change studies historically demonstrate urban growth in a time-series portrayal overlain on DEMs (Acevedo and others, 1999). Due to the extremely flat terrain in the study area (fig. 4), it was necessary to calculate a vertical exaggeration in the portrayal of the DEM to create a 3-D perspective and to examine growth in relationship to topographic features (fig. 31). This demonstrates that the topography in the area is not a factor that may hinder further development. 


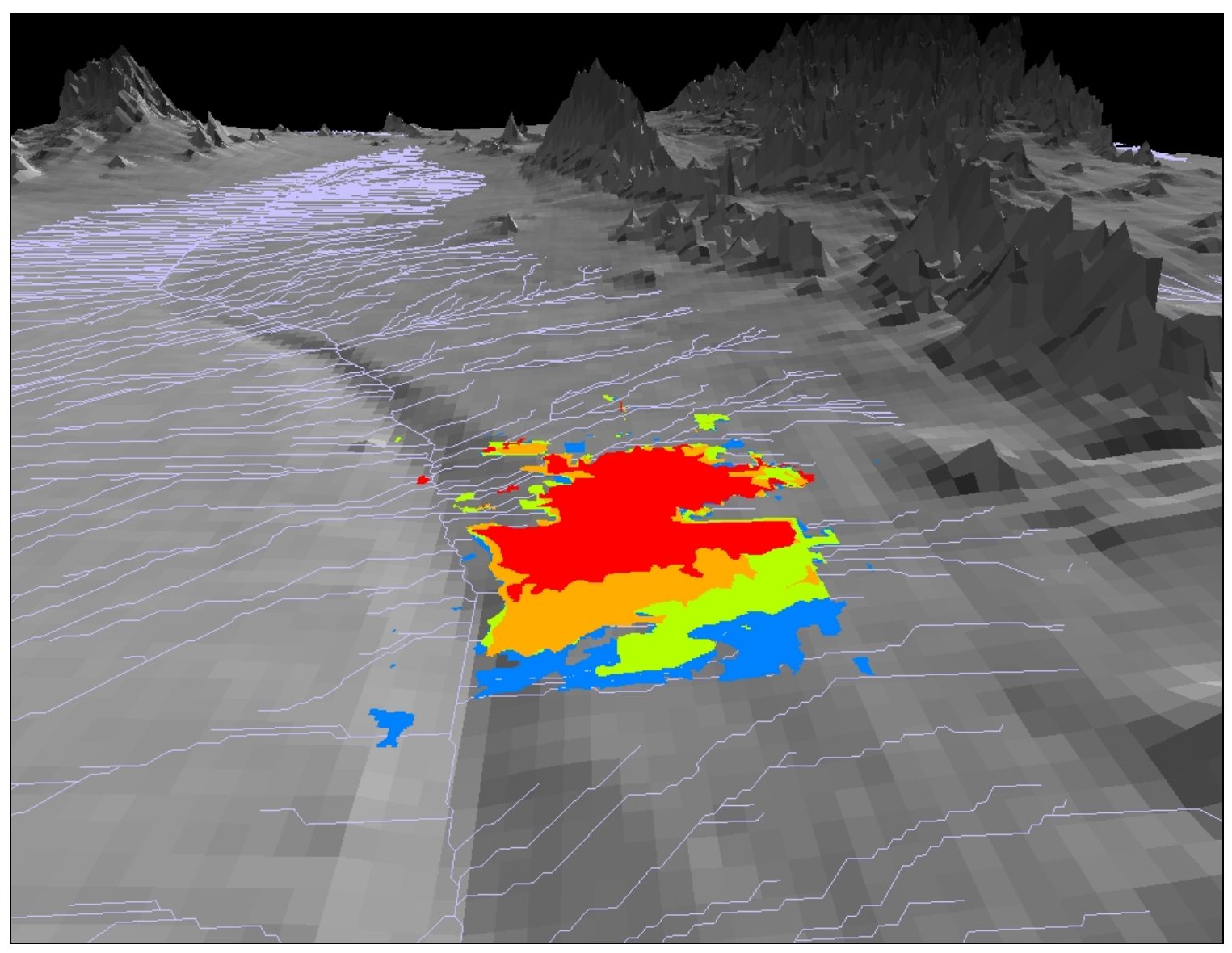

Figure 31: Urban growth of the Douglas/Agua Prieta area through the years plotted onto hill-shaded digital elevation models (DEMs), exaggerated 7 times.

After the conversion of these urban growth boundaries from vector to raster, zonal functions can be performed, including calculations of area (table 3), which can be plotted to examine relationships (fig. 32).

Table 3: Zonal statistics of urban growth through time.

\begin{tabular}{|r|r|r|r|r|r|}
\hline Dataset & \# Pixels & Square Meters & Acres & Hectares & Square Miles \\
\hline $\mathbf{1 9 7 3}$ & 16,381 & $14,742,900$ & 3,643 & 1,474 & 5.69 \\
\hline $\mathbf{1 9 8 5}$ & 22,153 & $19,937,700$ & 4,927 & 1,994 & 7.70 \\
\hline $\mathbf{1 9 9 5}$ & 28,369 & $25,532,100$ & 6,309 & 2,553 & 9.86 \\
\hline $\mathbf{2 0 0 0}$ & 31,952 & $28,756,800$ & 7,106 & 2,876 & 11.10 \\
\hline
\end{tabular}




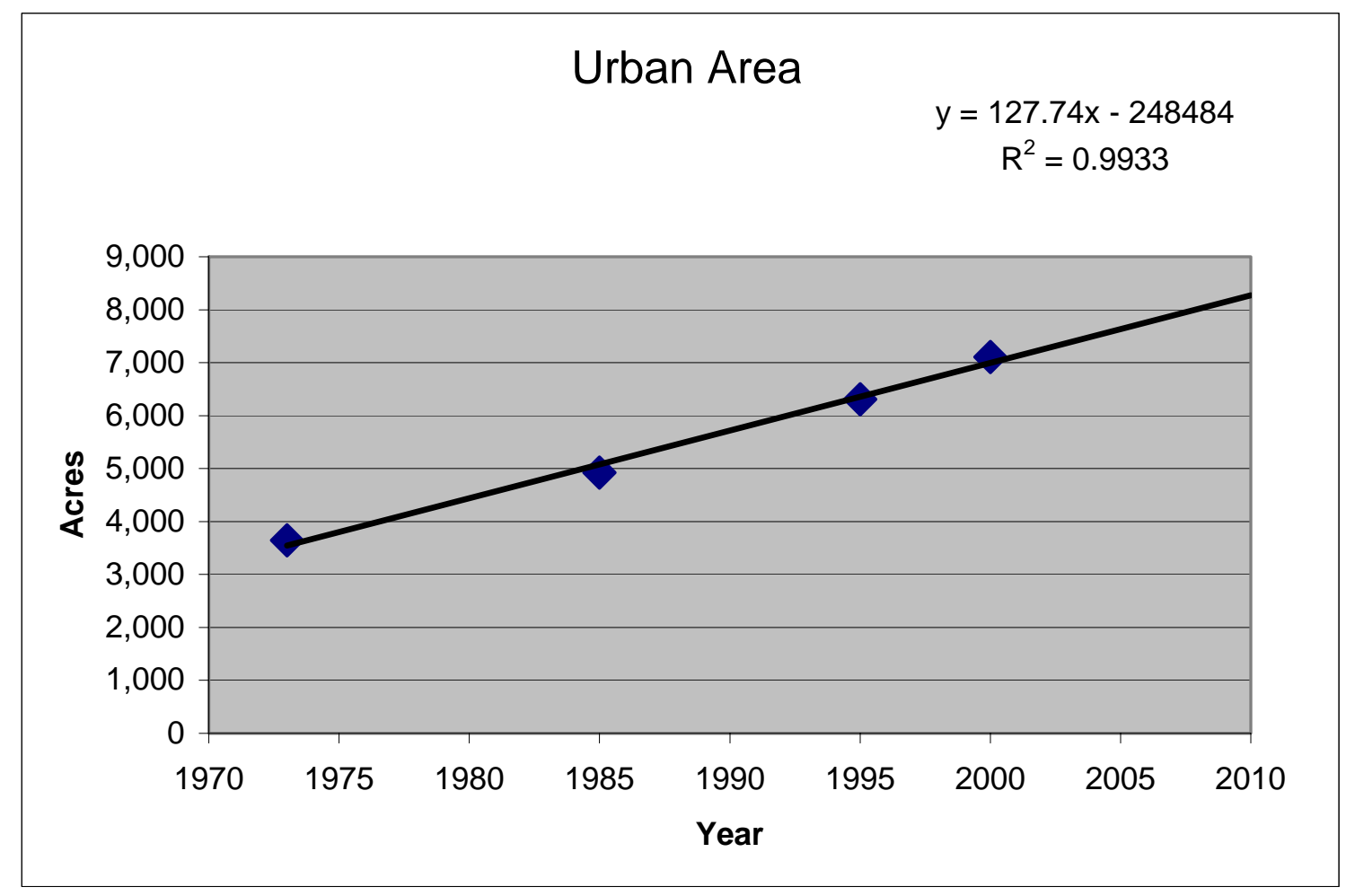

Figure 32: The entire study area of Douglas and Agua Prieta is increasing in size through time.

If growth continues in this steady climb (fig. 32), the estimated urban area in 2010 would be about 8,200 acres, which represents a 14 percent increase from 2000.

Datasets were divided at the international border to compare growth on either side (see fig. 33 -34 and table 4). It is apparent that the City of Douglas is growing more slowly than the City of Agua Prieta. Figures 33 and 34 suggest that the urban extent of the City of Douglas actually declined in size between 1995 and 2000, an unlikely scenario. This apparent decline may be explained by changes in interpretation of the area west of the city. Originally this area was classified as urban, but as growth continued, the area was subsequently interpreted as a factory and not residential. 
Table 4: Zonal statistics of the urban extent calculated by individual location.

\begin{tabular}{|r|r|c|c|c|}
\hline \multicolumn{1}{|c|}{ Douglas } & Pixels & $\mathbf{M}^{\wedge 2}$ & Acres & Hectares \\
\hline $\mathbf{1 9 7 3}$ & 9564 & $8,607,600$ & $2,126.98$ & 860.76 \\
\hline $\mathbf{1 9 8 5}$ & 10629 & $9,566,100$ & $2,363.83$ & 956.61 \\
\hline $\mathbf{1 9 9 5}$ & 12753 & $11,477,700$ & $2,836.20$ & $1,147.77$ \\
\hline $\mathbf{2 0 0 0}$ & 12592 & $11,332,800$ & $2,800.40$ & $1,133.28$ \\
\hline Agua Prieta & & & & \\
\hline $\mathbf{1 9 7 3}$ & 6844 & $6,159,600$ & $1,522.07$ & 615.96 \\
\hline $\mathbf{1 9 8 5}$ & 11561 & $10,404,900$ & $2,571.11$ & $1,040.49$ \\
\hline $\mathbf{1 9 9 5}$ & 15062 & $13,555,800$ & $3,349.71$ & $1,355.58$ \\
\hline $\mathbf{2 0 0 0}$ & 16930 & $15,237,000$ & $3,765.14$ & $1,523.70$ \\
\hline
\end{tabular}

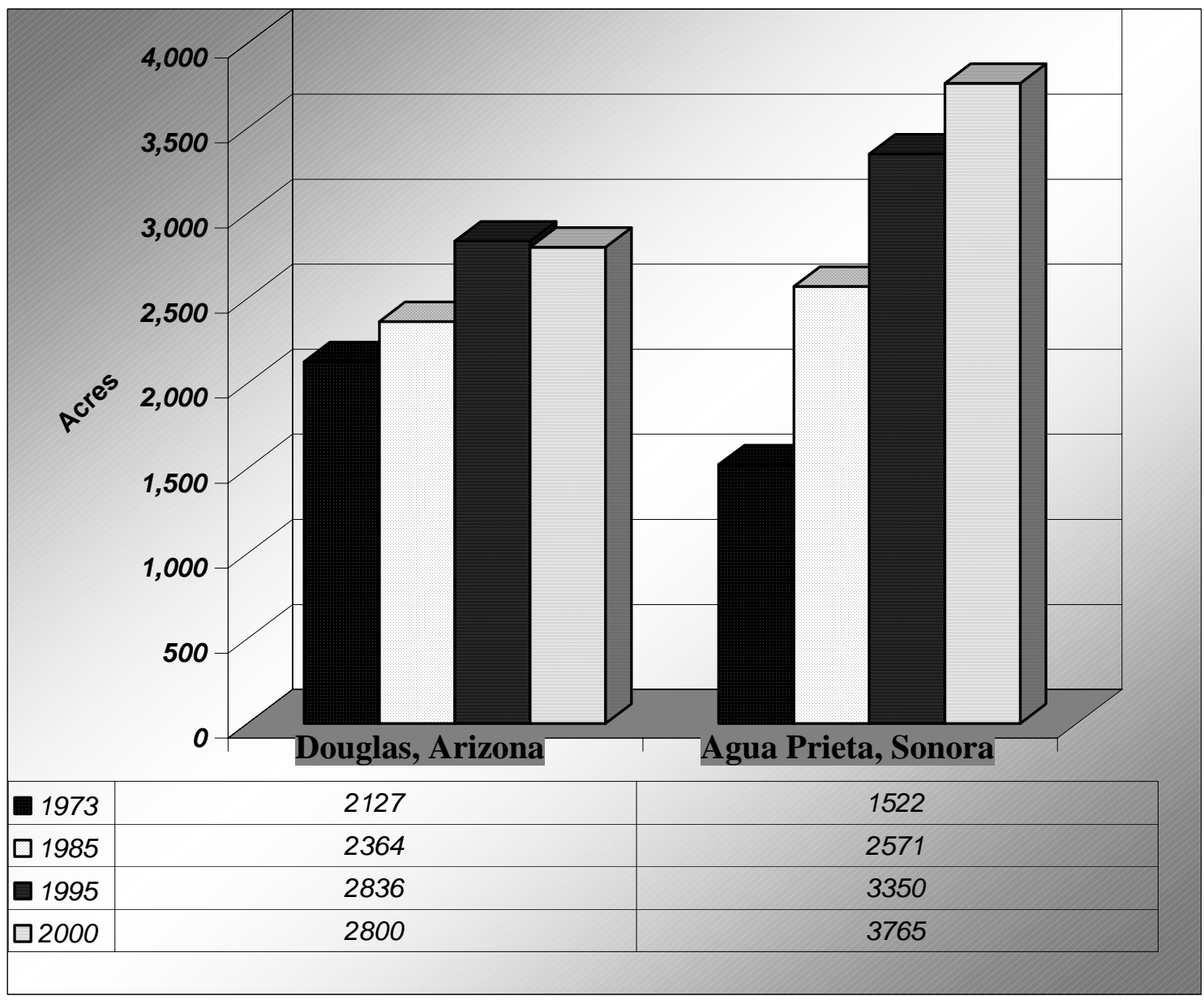

Figure 33: Urban growth bar chart depicting acreage in Douglas, Ariz., and Agua Prieta, Sonora. 


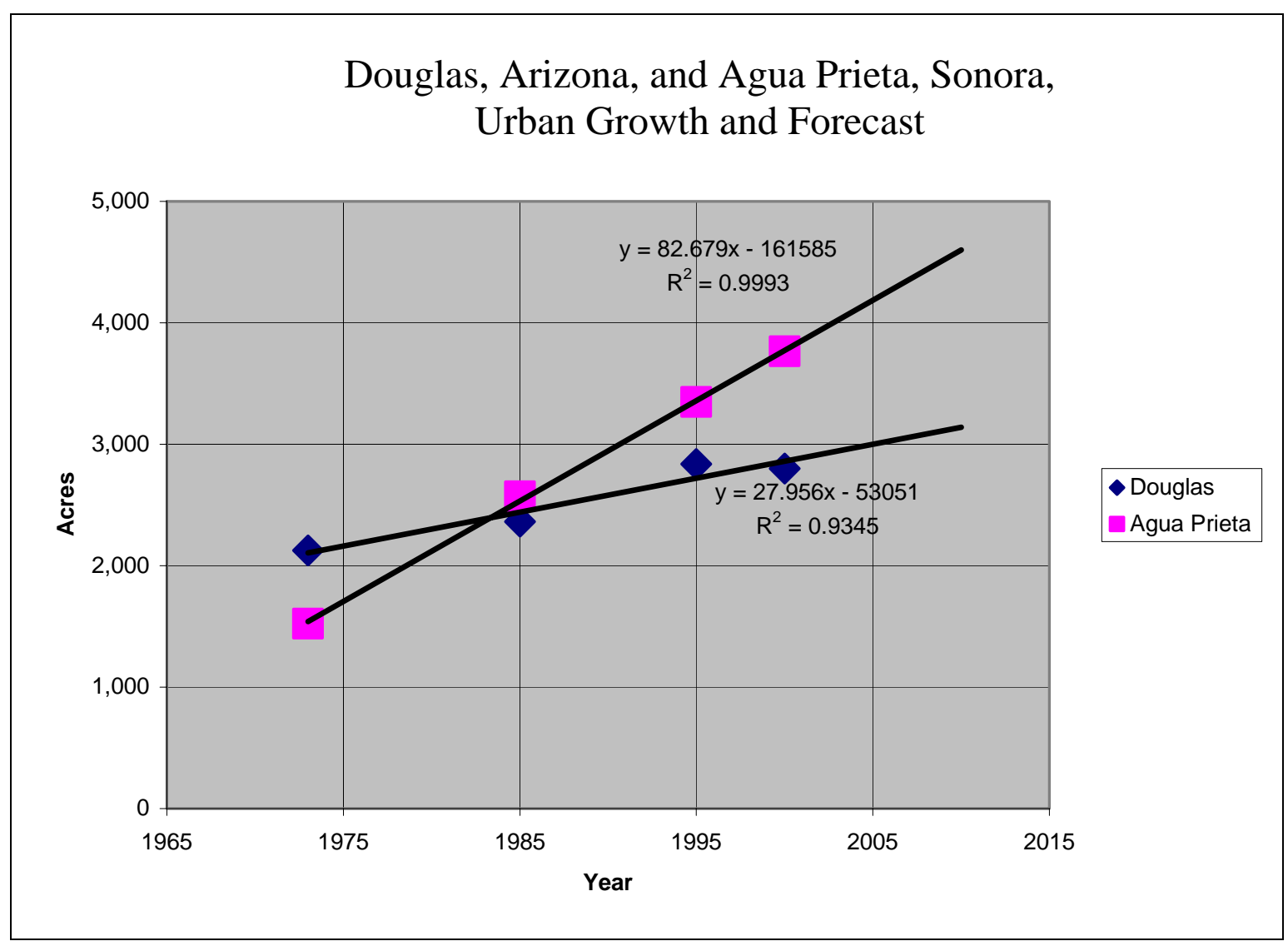

Figure 34: $X-Y$ scatter plot and linear regressions displaying urban growth in the area of Douglas, Ariz., and Agua Prieta, Sonora, including a 10-year forecast.

According to the linear regressions (fig. 36), by the year 2010, the Douglas area would increase by about 400 acres to a total of 3,150 acres, and Agua Prieta would increase about 1,000 acres to a total of 4,600 acres.

\section{Results}

\section{Colonias}

\section{Development}

Estimates of urban extent have been quantified and substantiate the hypothesis of an exponential increase in Mexican colonias in sister-city urban areas, in congruity with recent economic incentives generated by recent international policy. Based on the results from the urban growth study, the entire area has nearly doubled in size over 27 years (fig. 35). 


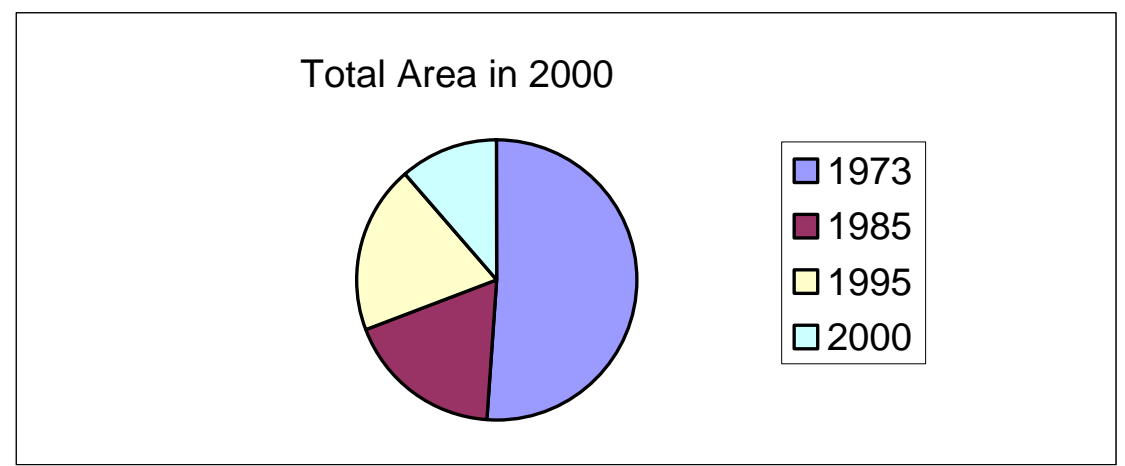

Figure 35: Pie chart illustrating growth in the study area.

The majority of growth has occurred in Agua Prieta, where the city's urban extent was 60 percent larger in 2000 than in 1973 . The Douglas extent has grown by 25 percent. These numbers indicate that Agua Prieta has grown 2.5 times its original size in 27 years. It is not clear from this study what has driven this land-use conversion, although it is possible that the implementation of international economic policies have dramatically affected urban growth in the Mexican portion of the study area. If current trends continue, by 2010 , it is expected that Douglas will grow by 11 percent and Agua Prieta will grow by 21 percent.

The SCA overlay analysis of vector datasets on the derived urban extent boundaries helped to identify new colonia developments and their spatial relationships, as well as access to infrastructure and housing conditions as described by community members (fig. 36). This type of combined geospatial, tabular, and remote-sensing analyses allows assumptions to be made concerning growth and development along a timeline for each of the newly defined colonias.

The lack of basic water and sewer infrastructure has been identified as a primary factor contributing to the health problems experienced by colonias residents (Ratcliffe, 2003). By identifying the areas in need of servicing, they may become designated as colonias to secure access to programs and funds that help support them. 


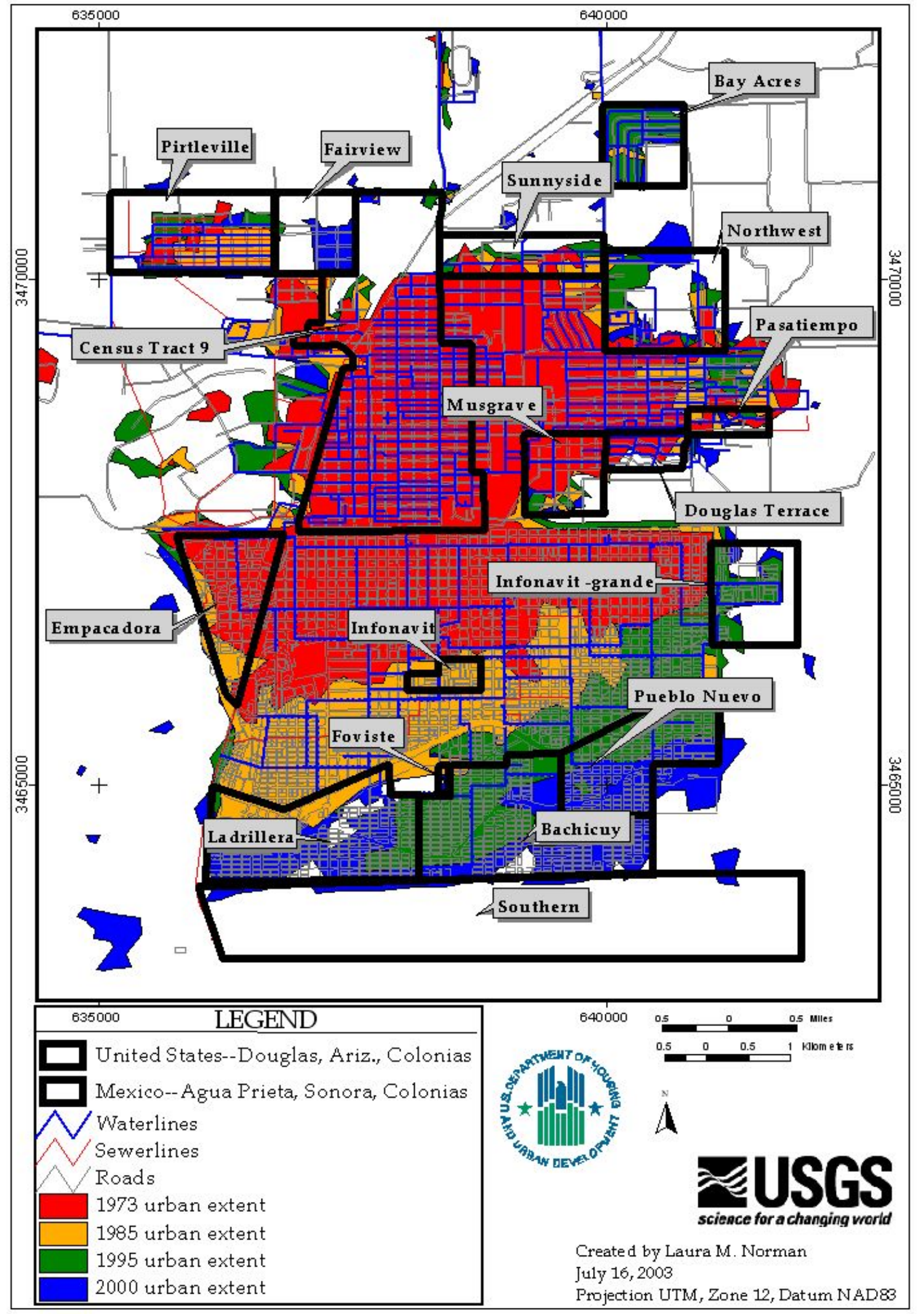

Figure 36: Urban extent information with colonias, sewer, and water line information overlain. 


\section{Descriptions}

United States colonias are predominantly older settlements that have been steadily increasing in size. The pre-existing colonias dataset for Cochise County was compared to the new city colonias derived dataset. The area described as Pirtleville colonia is consistent with the city defined boundary for Pirtleville and the Sulphur Springs Valley colonia, recognized by the USDA (fig. 12), holds portions of some newly named and recognized colonias boundaries (Fairview, Bay Acres, and Sunnyside) on the outskirts of the City of Douglas. Some new colonias do not fall in any previously defined colonia boundary.

The Pirtleville colonia was established prior to 1973, grew extensively in 1985, and has since been growing slowly. It is equipped with both sewer and water lines within its urban extent. Fairview colonia seems to be the most recently developed area. While houses existed in the Fairview area prior to 2000 , it was not previously recognized as urban. This may explain why Fairview lacks infrastructure. Development in Bay Acres and Northwest colonias probably occurred around 1995, but as of 2000, they have not grown much, although a small urban area was identified in 1985 imagery. Bay Acres is equipped with water lines, but not sewers. Sunnyside, Musgrave, Douglas Terrace, and Pasatiempo were urban in 1973, and have been growing slowly and steadily. Sunnyside has both water and sewer lines, but Pasatiempo and Douglas Terrace only have water. The Pasatiempo colonia is different than the other colonias because it has the smallest population consisting of predominantly non-Hispanic people living in predominantly owner-occupied housing units. It is apparent that the newer colonias-Fairview, Bay Acres, Northwest, and Musgrave-have not been equipped with water and sewer lines. Delineation of these areas will help to secure funding to implement these systems.

Mexican colonias appear predominantly in those areas of Agua Prieta where settlement is new. In the delineation of these colonias, some sociological details were described by community members and documented herein. The oldest is Colonia Empacadora which, according to personal interviews with Reverend Jesus Gallegos, is known to be a very dangerous area. This area west of the railroads tracks is very poor and completely lacks sewer lines. The Colonias Infonavit, Infonavit-grande, and Fovista were established as Federally subsidized housing areas for many migrant workers from Oaxaca and southern Mexico, who moved into the area to work at the maquillas. According to Sylvia Villabolos de Zuniga, these colonias provide well-built track homes, which are extremely small apartment-like dwellings with only one restroom facility for all tenants. Many migrant workers, who travel with large families, occupy these units. The apartments are described as 20 - by 20 -foot rooms, holding 6 or more people. The Infonavit colonia was built directly around the industrial portion of the city around 1985, and the Infonavitgrande colonia was established at the city limits around 1995.

Colonia Pueblo Nuevo and colonia Bachicuy, both of which are situated in a flood zone, were established around 1995. The lack of sewers in these areas necessitated use of outhouses and privy houses, which run out in floods, potentially infecting the drinking water with fecal coliform bacteria. According to Reverend Jesus Gallegos, who runs a community center in this neighborhood offering medical care, coliform contamination causes stomach infections in many of the children. Colonia Ladrillera was primarily inhabited in 2000 and colonia Southern appeared sometime after 2000. According to Del Cabarga, these areas were originally part of ajidos and sell for about U.S. $\$ 600$ for an 18 - by 20 -foot lot. While streets exist throughout Agua Prieta, most are unpaved, and those that are paved tend to become covered in dirt because there are no street sweepers. This area is growing at a rapid rate and new colonias are being developed as growth occurs.

\section{Web-Based Interface Development}

The resulting geospatial database has been uploaded to a map service for the purpose of Web-based distribution. Through a collaborative effort with the University of Arizona's School of Renewable Natural Resources, utilizing relationships already established with the USGS, and expanding on ideas in congruence with the newly established Center on Impacts of Urban 
Development in Southern Arizona's Desert Environment (CIUDAD), a Web portal was opened to support the USGS/HUD efforts at http://codd.art.srnr.arizona.edu/colonias (fig. 37).

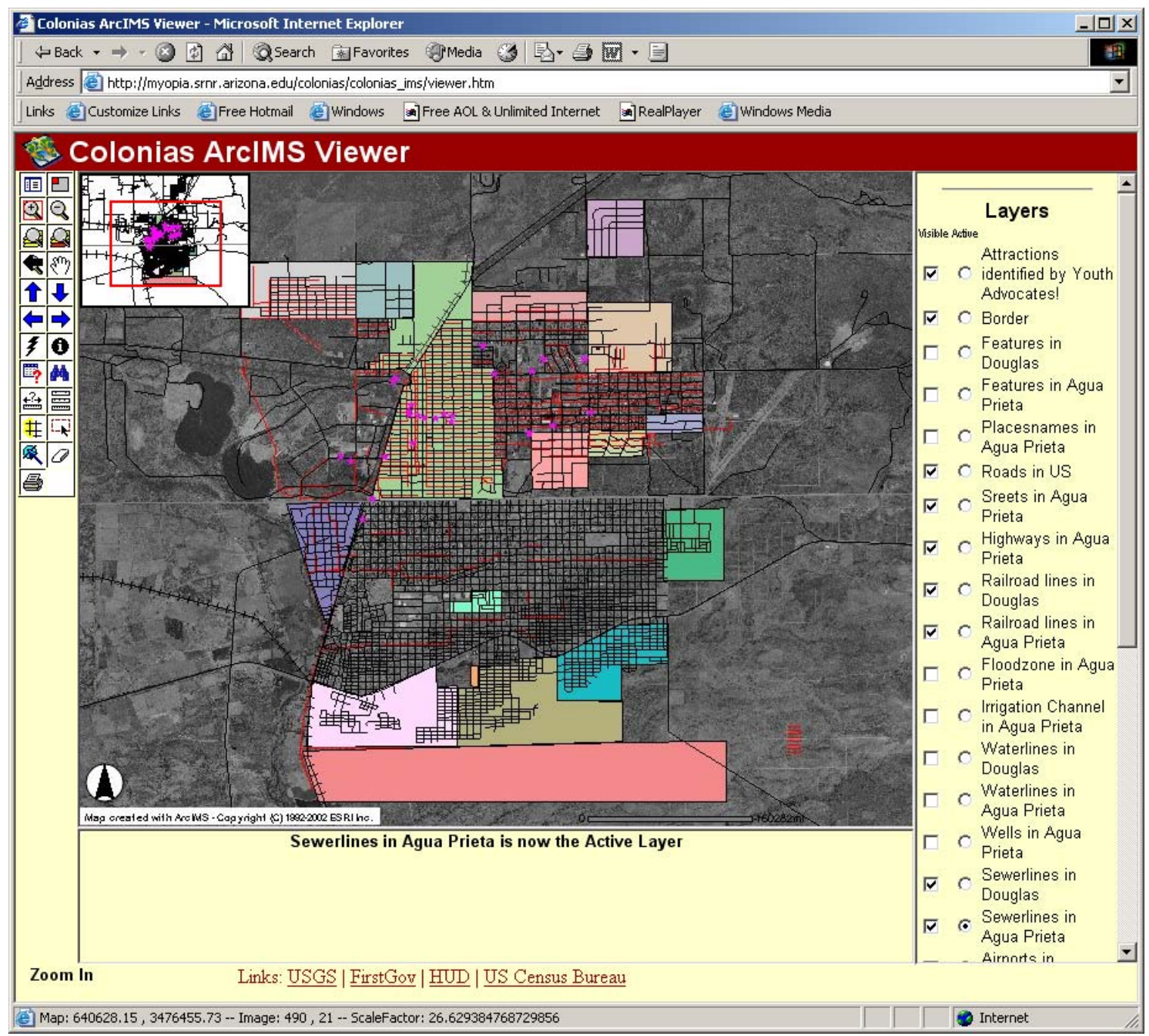

Figure 37: ArcIMS colonias mapping website portraying datasets in Douglas and Agua Prieta (http://codd.art.srnr.arizona.edu/colonias).

\section{Delivery of Product/Training}

Development of this database was accomplished in cooperation with many different people within the communities of Douglas and Agua Prieta. Hard-copy maps, describing the sewer, water, aerial photos, and colonia boundaries, were supplied on request to those interested parties. Brochures, describing the project in English and Spanish, were developed and distributed to multiple community groups and non-profit organizations, including Focus Future, Turning Point, and Take it to the Hills. Associates of the Arizona Department of Environmental Quality were contacted via e-mail and telephone. Regular e-mail and newsletters, describing the status of the project, were sent to the people on the contact list. The U.S. Census and U.S. Border Patrol were contacted in regards to potential partnerships and interest in the current project. The project was also presented at the ESRI International User Conference in July 2003. On September 17th and 24th, 2003, workshops were held in Douglas, Ariz., to demonstrate utility and access to the newly digitized geospatial dataset. The focus of these meetings was to review 
the project. The meetings demonstrated the development and application of a bi-national web mapping service for Douglas and Agua Prieta. The purpose of this map service was described as support for border communities' urban planning and community development activities. Time was allocated during the meetings to provide user feedback and to discuss future maintenance of the web mapping service. The first meeting was held on September 17, 2003, at the City of Douglas Council Chambers and included a presentation of the database, a demonstration of data, description of products, a talk about possible applications, and an explanation of Internet system requirements. The Youth Advocates also made a presentation describing their work.

The second meeting was held at Cochise College, Douglas Campus on September 24, 2003 (fig. 39). This meeting was a hands-on workshop to introduce the dataset to the community. No previous GIS experience was necessary, and the first 20 people to register held available seats. Josh Pope, a volunteer from The Planning Center, assisted in this GIS workshop presentation. A tutorial was designed and presented to describe access to the datasets through the Internet. Participants at the computer lab filled out evaluation forms, which suggested a positive response.

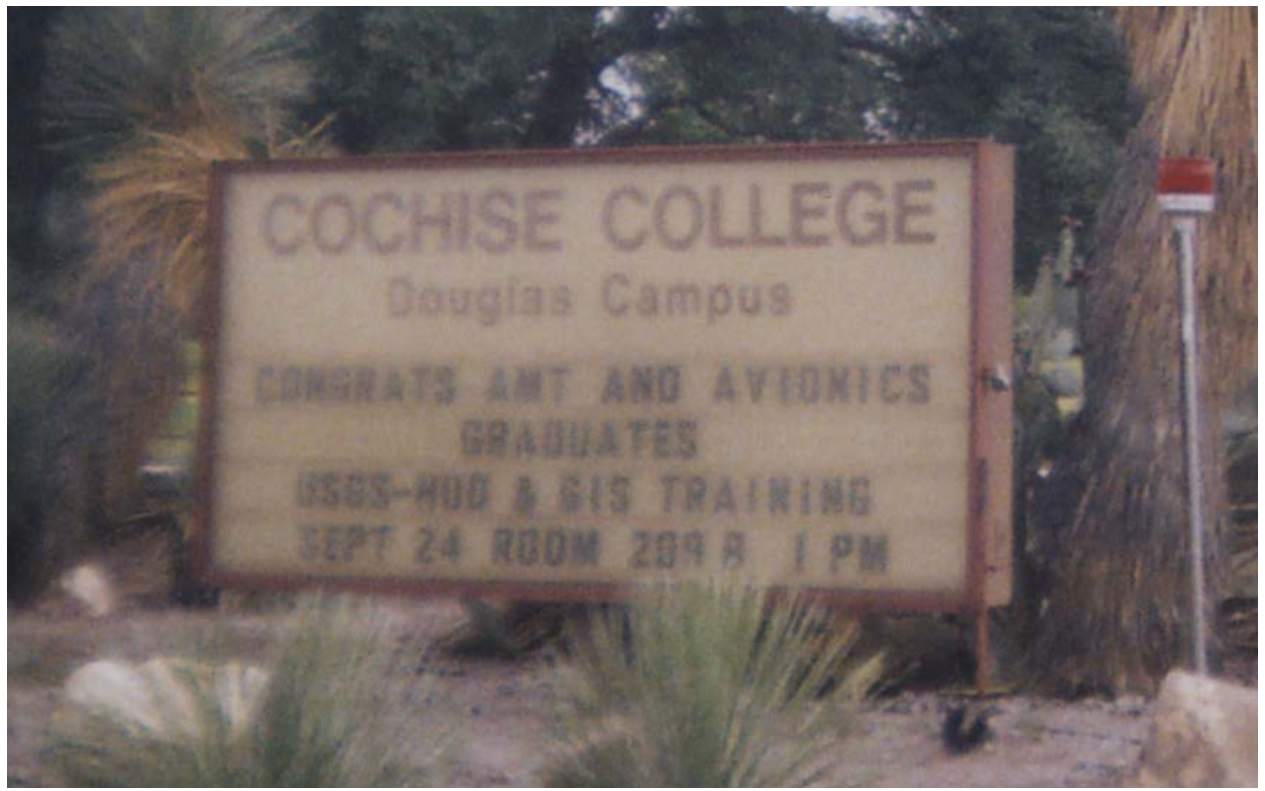

Figure 38: Cochise Community College, Douglas Campus, "USGS-HUD \& GIS Training" sign.

\section{Conclusions}

Development of new datasets describing urban neighborhoods and the implications of urban growth provides accessible and affordable information that can help promote sustainable development along the United States-Mexico border by providing local citizens with knowledge of their surroundings. The results from this project exemplify a paradigm shift regarding the dissemination of public records at the international level. Partnerships with other Federal, State, and local organizations, and with community members should improve both the quantity and accuracy of the acquired data. The Web-based mapping service consolidates and makes available demographic and urban-planning information to local nongovernmental organizations that are preparing grant and loan applications to improve the community. Community planners only need access to the Internet, which empowers everyone with tools previously available only to those who could afford expensive mapping software. 


\section{REFERENCES}

Acevedo, W., Richards, L.R., and Buchanan, J.T., 1999, Analysis of land use change in urban environments: U.S. Geological Survey Fact Sheet 188-99, 4 p.

Brady, Laura M., Gray, Floyd, Castaneda, Mario, Boltman, Mark, and Bolm, Karen Sue, 2002, Preliminary United States-Mexico border watershed analysis, twin cities area of Nogales, Arizona, and Nogales, Sonora: U.S. Geological Survey Open-File Report: Open-File Report 02-112.

Cañas, Jesus, and Coronado, Roberto, 2002, Maquiladora industry: past, present, and future, in El Paso Business Frontier, Federal Reserve Bank of Dallas, El Paso Branch, Issue 2.

Comisión De Cooperación Ecológica Fronteriza (COCEF/BECC), 1998, Agua Prieta, Sonora, Plan Maestro: Para el Mejoramiento de los Servicios de Agua Potable, Alcantarillado y Saneamiento de la Ciudad de Agua Prieta, Sonora, Y Levatamiento de Redes Hidraulicas. CONTA 98-02.

Crawford, J., Acevedo, W., Foresman, T., Buchanan, J., and Prince, W., 1996, Developing a temporal database for urban development for the Baltimore-Washington region. American Society for Photogrammetry and Remote Sensing Conference, Baltimore, Md., April 20-26, 1996.

Eastman, J.R., and Fulk, M., 1993, Long sequence time series evaluation using standardized principle components: Photogrammetric Engineering and Remote Sensing, v. 59, no. 6, p. 991-996.

Forney, W., Richards, L., Adams, K.D., Minor, T.B., Rowe, T.G., Smith, J.L., and Raumann, C.G., 2001, Land use change and effects on water quality and ecosystem health in the Lake Tahoe Basin, Nevada and California: U.S. Geological Survey Open-File Report 01-418, 29 p.

Haack, B., Bryant, N., Adams, S., 1987, An assessment of Landsat MSS and TM data for urban digital classification: Remote Sensing of Environment, v. 21, p. 201-213.

Howarth, P.J., 1986, Landsat digital enhancement for change detection in urban environment: Remote Sensing of Environment, v. 13, p. 149-160.

INEGI, 1995, Estadísticas Históricas de México Tomo I, 1994, México.

Jensen, J.R., and Toll, D.L., 1982, Detecting residential land-use development at the urban fringe: Photogrammetric Engineering and Remote Sensing, v. 48, p. 629-643.

Jensen, J.R., Rutchey, K., Koch, M.S., and Narumalani, S., 1995, Inland wetland change detection in everglades water conservation area $2 \mathrm{a}$ using a time series of normalized remotely sensed data: Photogrammetric Engineering and Remote Sensing, v. 61, no. 2, p. 199-209.

Kearney, Milo, 1995, Border Cuates: A history of the U.S.-Mexican Twin Cities: Austin, Eakin Press.

Kent, Robert, 1983, Agriculture and ranching, in Borderlands Sourcebook: A Guide to the Literature on Northern Mexico and the American Southwest: Norman, University of Oklahoma Press, p. 140. 
Kirkland, D., Gaydos, L., Clarke, K., DeCola, L., Acevedo, W., and Bell, C., 1994, An analysis of human-induced land transformation in the San Francisco Bay/Sacramento area: World Resource Review v. 6, no. 2, p. 206-217.

Lee, C.T., and Marsh, S.E., 1995, The use of archival Landsat MSS and ancillary data in a GIS environment to map historical change in an urban riparian habitat: Photogrammetric Engineering and Remote Sensing, v. 61, no. 8, p. 999-1,008.

Mack, C., Marsh, S.E., and Hutchinson, C.F., 1995, Application of aerial photography and GIS techniques in the development of an historical perspective of environmental hazards at the rural-urban fringe: Photogrammetric Engineering and Remote Sensing, v. 61, no. 8, p. 1,0151,020 .

Martynec, S., Peter, D.E., and Hardaker, C., 1994, Cultural Resources Survey and Monitoring of the Douglas-Naco Ariz. Sector of the United States-Mexico Border: Plano, Texas: GeoMarine, Inc.

McHarg, Ian L., 1969, Design with Nature: Garden City, New York, Doubleday/Natural History Press.

Myrick, David F., 1967, The railroads of Arizona: an approach to tombstone. Journal of Ariz. History, v. 8, no. 3, p. 155-170. [Tucson, Arizona, Historical Society].

Osborn, K., 1998. United States-Mexico transboundary aerial photography and mapping initiative: Photogrammetric Engineering and Remote Sensing, v. 64, no. 11, p. 1,085-1,088.

Ratcliffe, Michael R., 2003, Spatial and demographic data for colonias: Proceedings from the $42^{\text {nd }}$ Annual Meeting of the Western Regional Science Association, February 26-March 1, 2003, Rio Rico, Ariz.

Seltzer, Raymond, 1959, Head of University of Arizona Agricultural Economics Department, Cited in Arizona Cattlelog, January 1959, p. 26.

Shan, Z., 1999, Remote sensing and GIS as a tool in exploring the dynamics of urban spatial structure: the case of the Shanghai City: Proceedings of the $20^{\text {th }}$ Asian Conference on Remote Sensing, November 22-25, 1999, Hong Kong, China.

Trennert, Robert A., 1988, A different perspective: victorian travelers in Arizona, 1860-1900. Journal of Arizona History, v. 29, no. 4, p. 349-370. [Tucson, Arizona Historical Society].

U.S. Bureau of the Census, 1960-1990; 1997: Population, Social and Economic Characteristics.

Weaver, Thomas, 2001, Time, space and articulation in the economic development of the United States-Mexico border region from 1940 to 2000: Human Organization, v. 60, no. 2, p. 105120. 


\section{APPENDIX A: Local organizations regularly contacted}

Acosta y Asociados, Agua Prieta, Sonora

Arizona Department of Environmental Quality (ADEQ), Phoenix and Nogales, AZ

Arizona Department of Health Services (ADHS), Phoenix, AZ

Arizona-Mexico Commission, Phoenix, AZ

Border Environment Cooperation Commission: La Comisión de Cooperación Ecológica

Fronteriza (BECC/COCEF), El Paso/Juarez, Chichuahua

City of Bisbee, Bisbee, AZ

City of Douglas Department of Public Works, Douglas, AZ

City of Douglas Housing Authority, Douglas, AZ

City of Douglas, Douglas, AZ

Cochise College, Douglas, AZ

Cochise County Housing Authority, Bisbee, AZ

Cochise County, Bisbee, AZ

Comisión de Agua Potable y Alcantarillado del Estado de Sonora (COAPAES), Nogales and Agua Prieta, Sonora

Emergency Response Commission, Agua Prieta, Sonora

Gateway Commmunity College, Phoenix, AZ

Institute for the Environment and Sustainable Development of Sonora (IMADES), Hermosillo, Sonora

Instituto Nacional de Estadística Geografíae Informática (INEGI), Agua Calientes, Sonora

Libraries for the Future, Phoenix, AZ

Municipal de Agua Prieta, Agua Prieta, Sonora

New Turf/Youth Advocates, Douglas and Sierra Vista, AZ

Sonoran Desert Institute, Tucson, AZ

SouthEastern Arizona Behavioral Health Services (SEABHS), Douglas, AZ

SouthEastern Arizona Governments Organization (SEAGO), Douglas, AZ

The Planning Center, Tucson, AZ

The Promotora Institute, Nogales, AZ

The University of Arizona, Bureau of Applied Research in Anthropology (BARA), Tucson, AZ The University of Arizona, College of Architecture, Planning and Landscape Architecture

(CAPLA), Tucson, AZ

The University of Arizona, Department of Geography, Tucson, AZ

The University of Arizona, Latin American Studies, Tucson, AZ

The University of Arizona, School of Renewable Natural Resources (SRNR), Tucson, AZ

The University of Arizona, Udall Center for Studies in Public Policy, Tucson, AZ

The University of Texas, Austin, TX

Turning Point Non-Profit, Douglas, AZ

U.S. Border Patrol, Douglas, AZ

U.S. Census, Washington, DC

U.S. Department of Health, Cochise County, Bisbee, AZ

United States-Mexico Border Philanthropy Partnership, Douglas, AZ

USDA Rural Development, Sierra Vista, AZ

Youth Advocates!, Douglas, AZ 


\section{APPENDIX B: Photographs of Colonias}

Mike Ortega, (City Manager of Douglas), took USGS and HUD staff on a tour of colonias, where Angela Donelson (Southwest Border, Farmworker and Colonias Initiative, HUD) captured the following photographs (figs. 40-42). Silvia Villalobos de Zuñiga also took videotape in June 2003, describing some of the colonias in the municipal. The videotape was converted to 932 digital photographs by the USGS in Flagstaff, Arizona, under Edwin Pfeifer. Some photographs are included in this report and intended for publication at the interactive mapping Internet site (figs. 43-50).

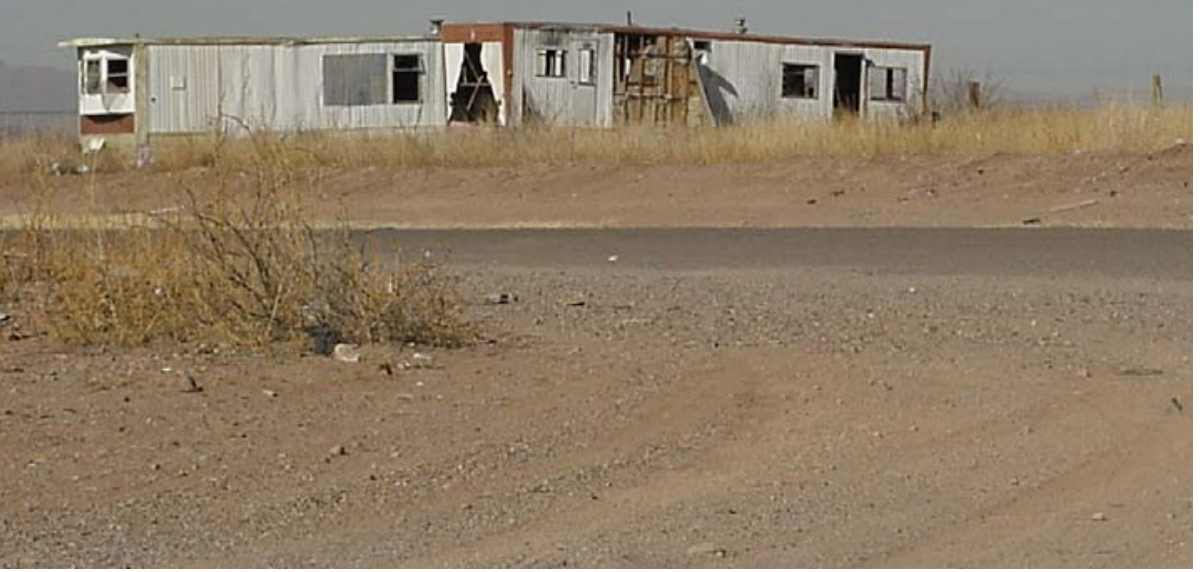

Figure 39: Colonia dwelling in Douglas (photo by Angela J. Donelson).

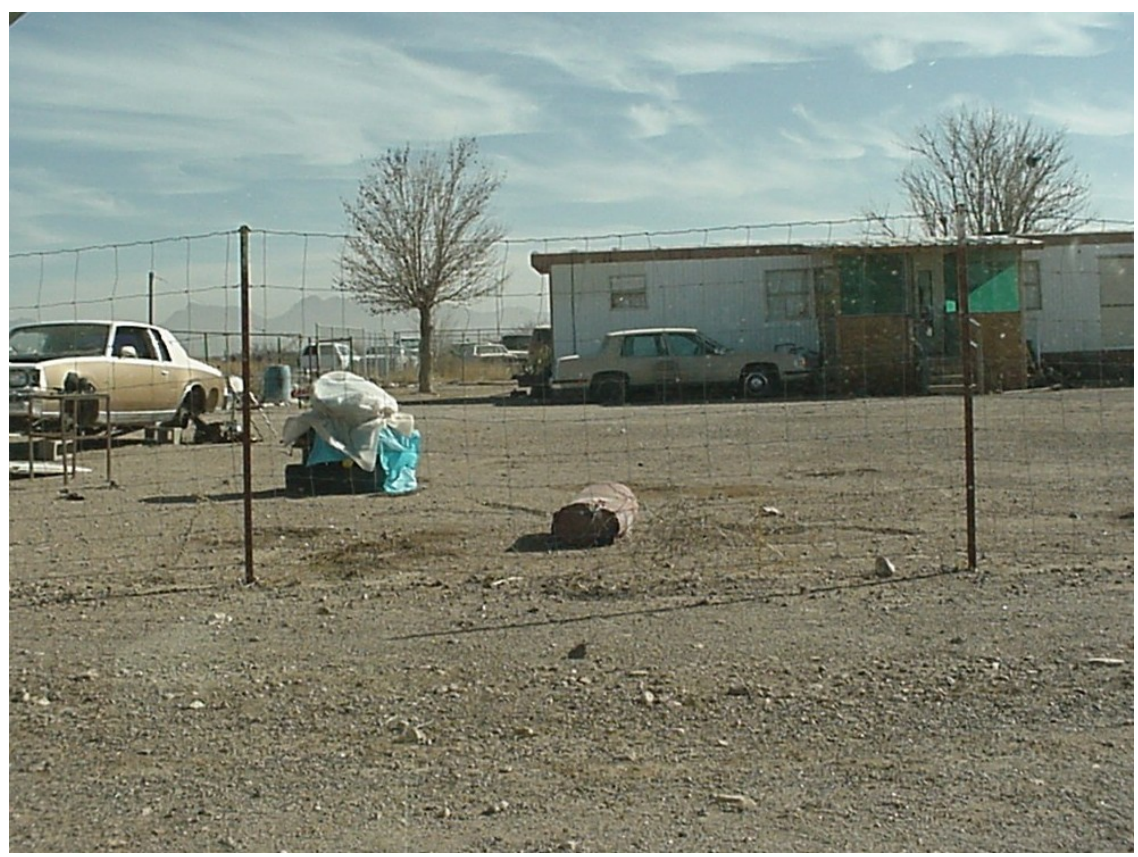

Figure 40: The Pirtleville colonia, outside of Douglas (photo by Angela J. Donelson). 


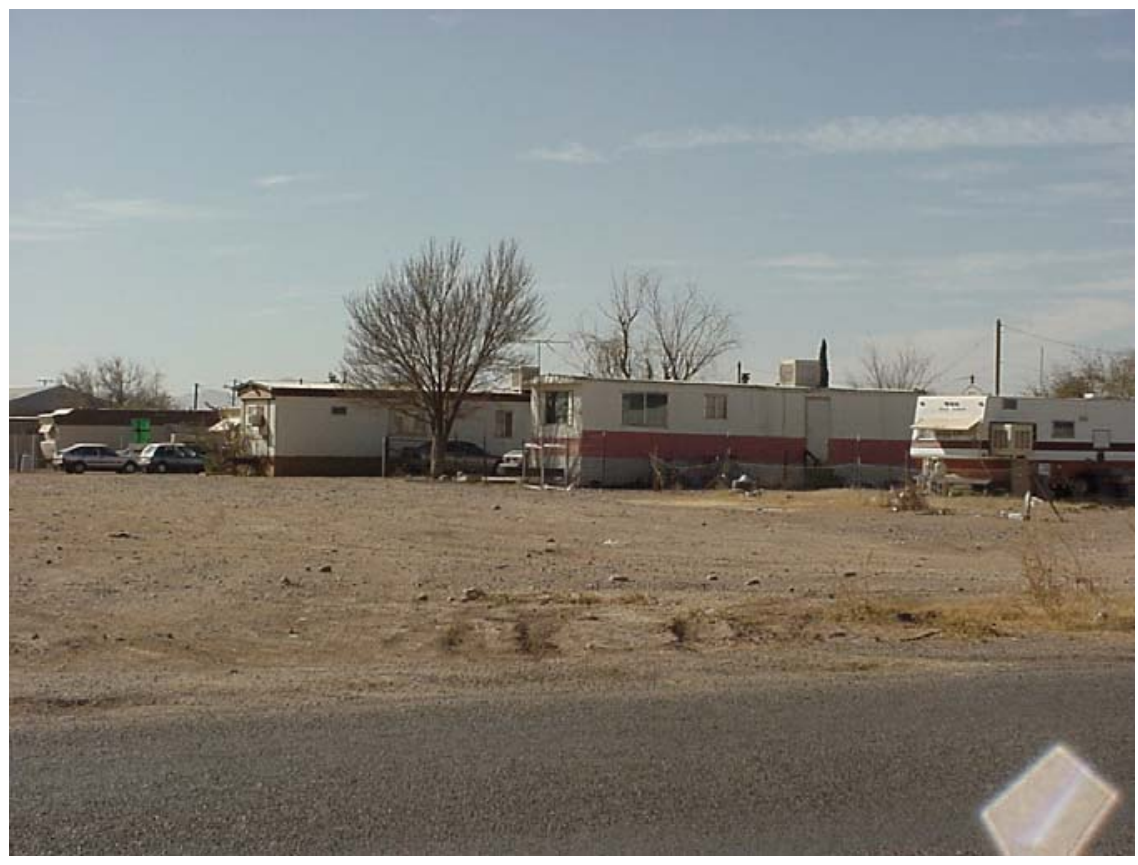

Figure 41: Trailers comprise some colonias in Douglas (photo by Angela J. Donelson).

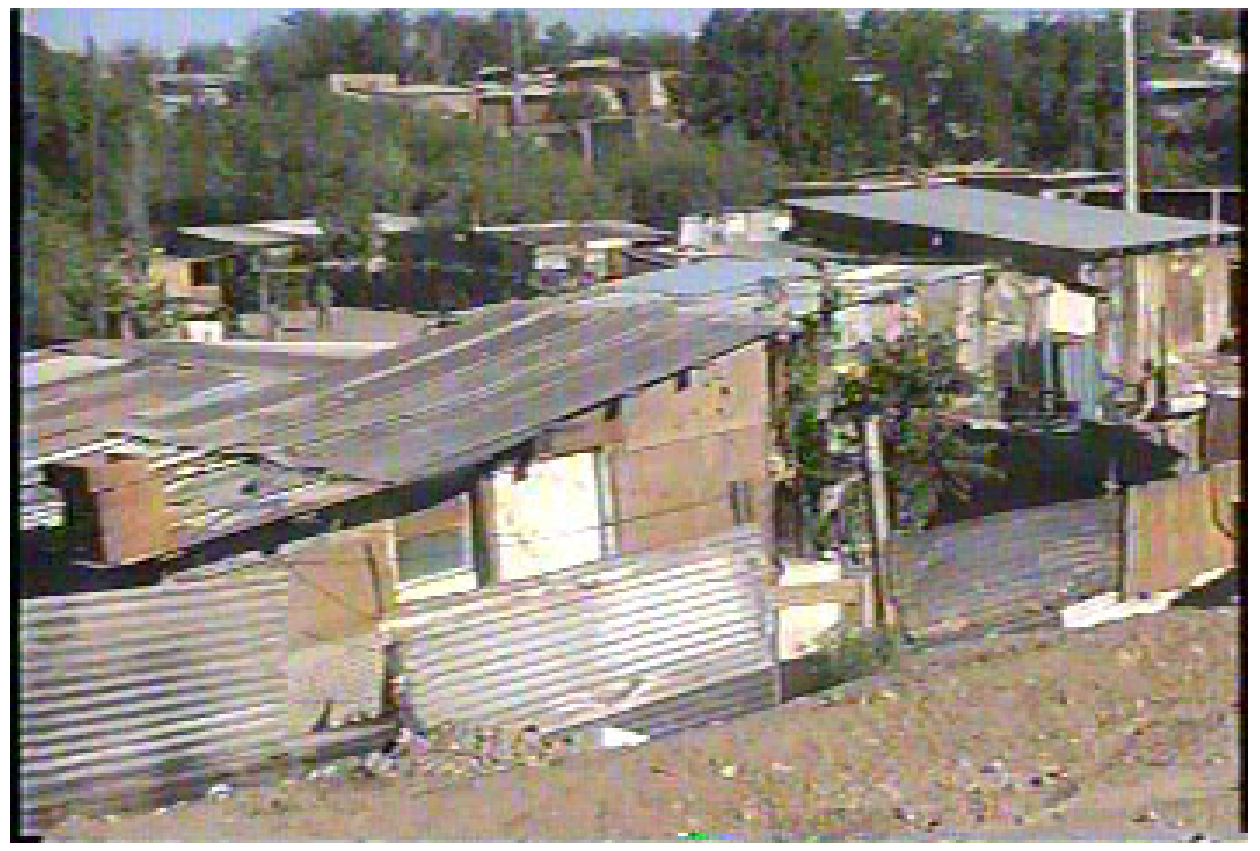

Figure 42: Houses are made of various materials in colonia Empacadora, Agua Prieta (photo by Silvia Villalobos de Zuñiga). 


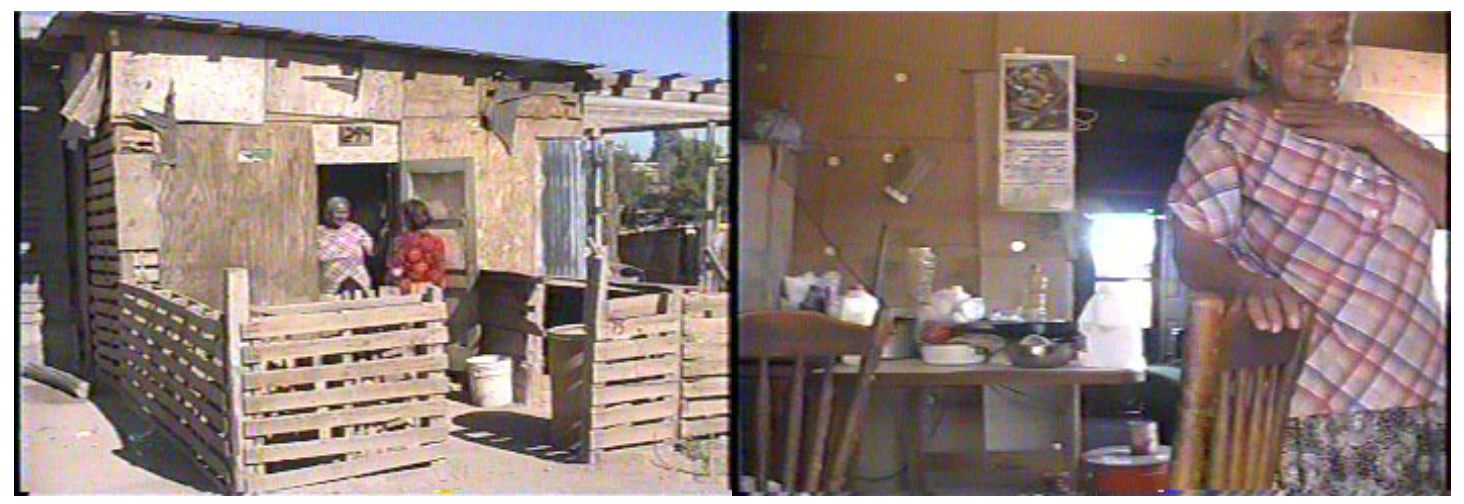

Figure 43: One woman living in colonia Empacadora, Agua Prieta (photos by Silvia Villalobos de Zuñiga).

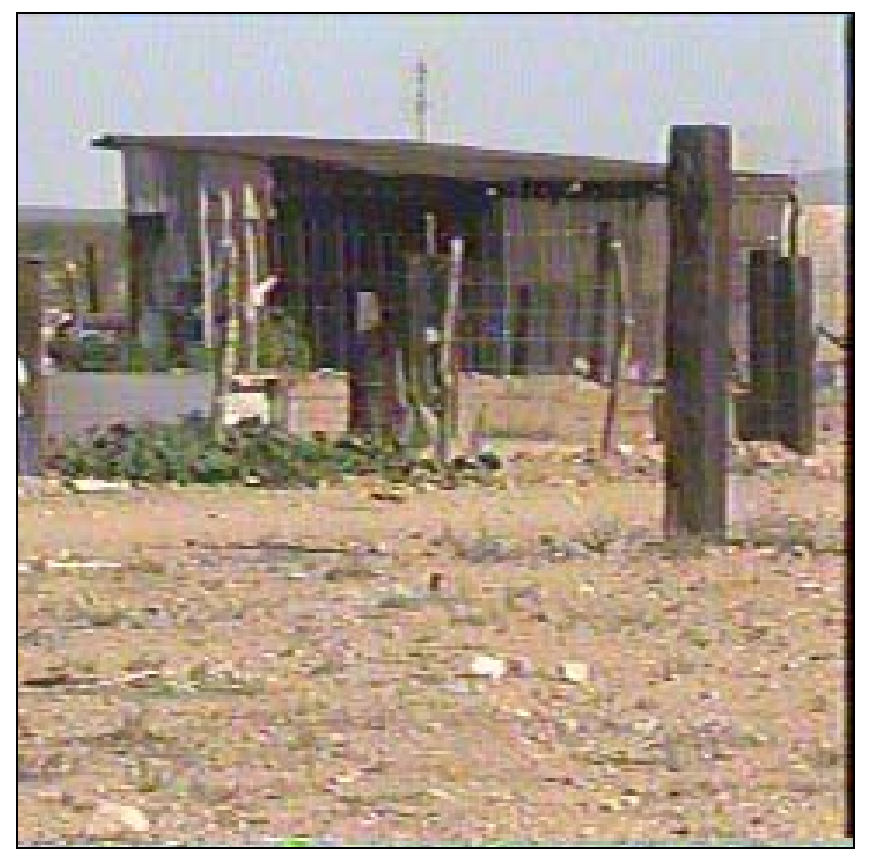

Figure 44: House in colonia Southern, Agua Prieta (photo by Silvia Villalobos de Zuñiga). 


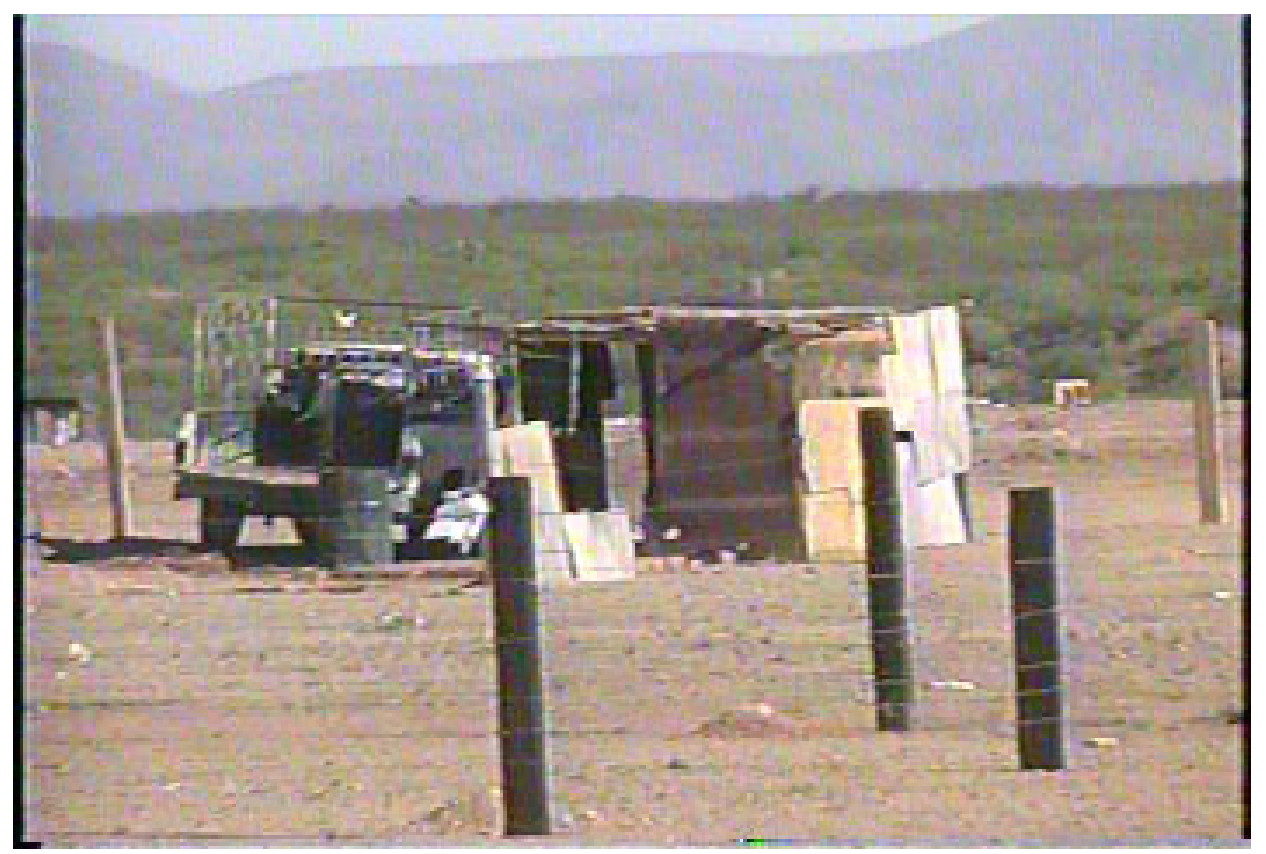

Figure 45: This family in colonia Bachicuy, Agua Prieta is not entitled to government subsidies due to ownership of automobile (a luxury) (photo by Silvia Villalobos de Zuñiga).

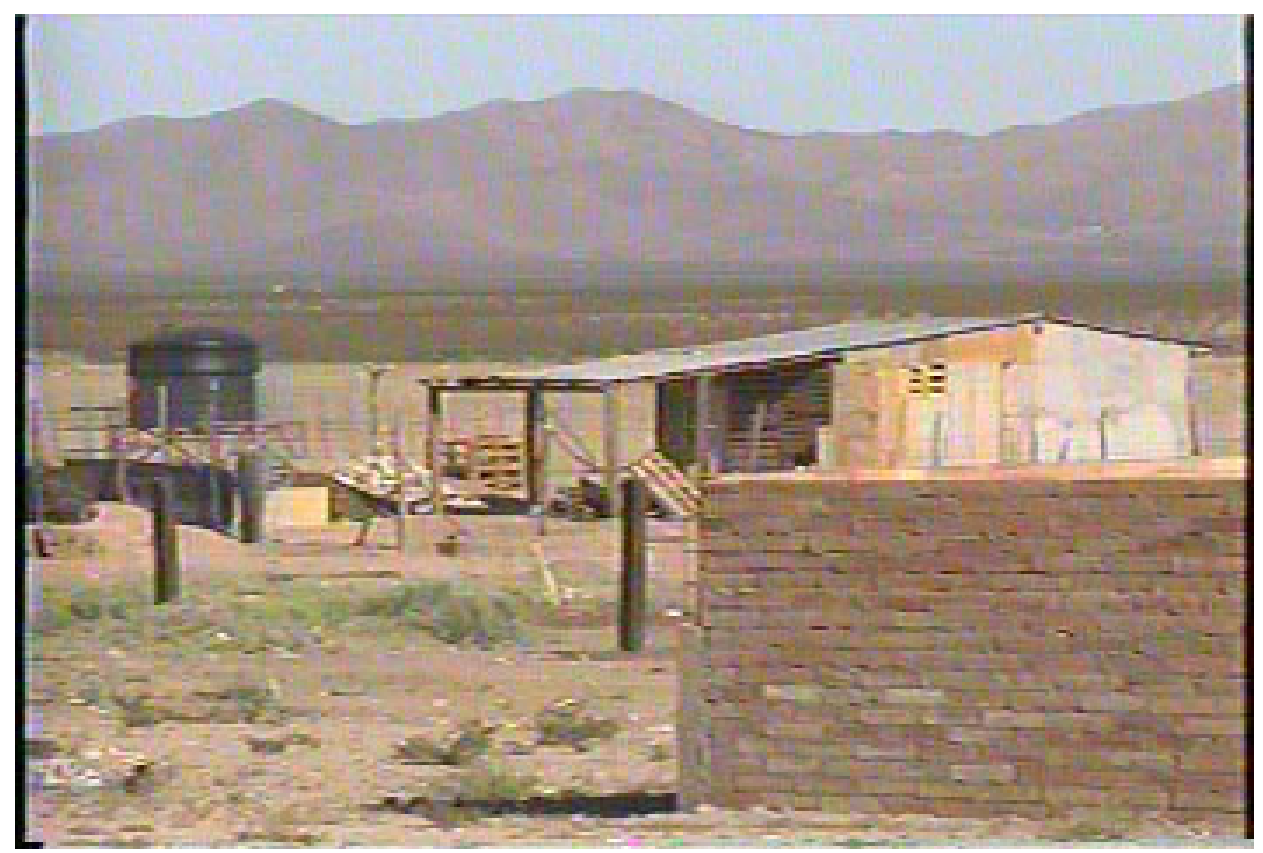

Figure 46: House with water tank in colonia Bachicuy, Agua Prieta (photo by Silvia Villalobos de Zuñiga). 


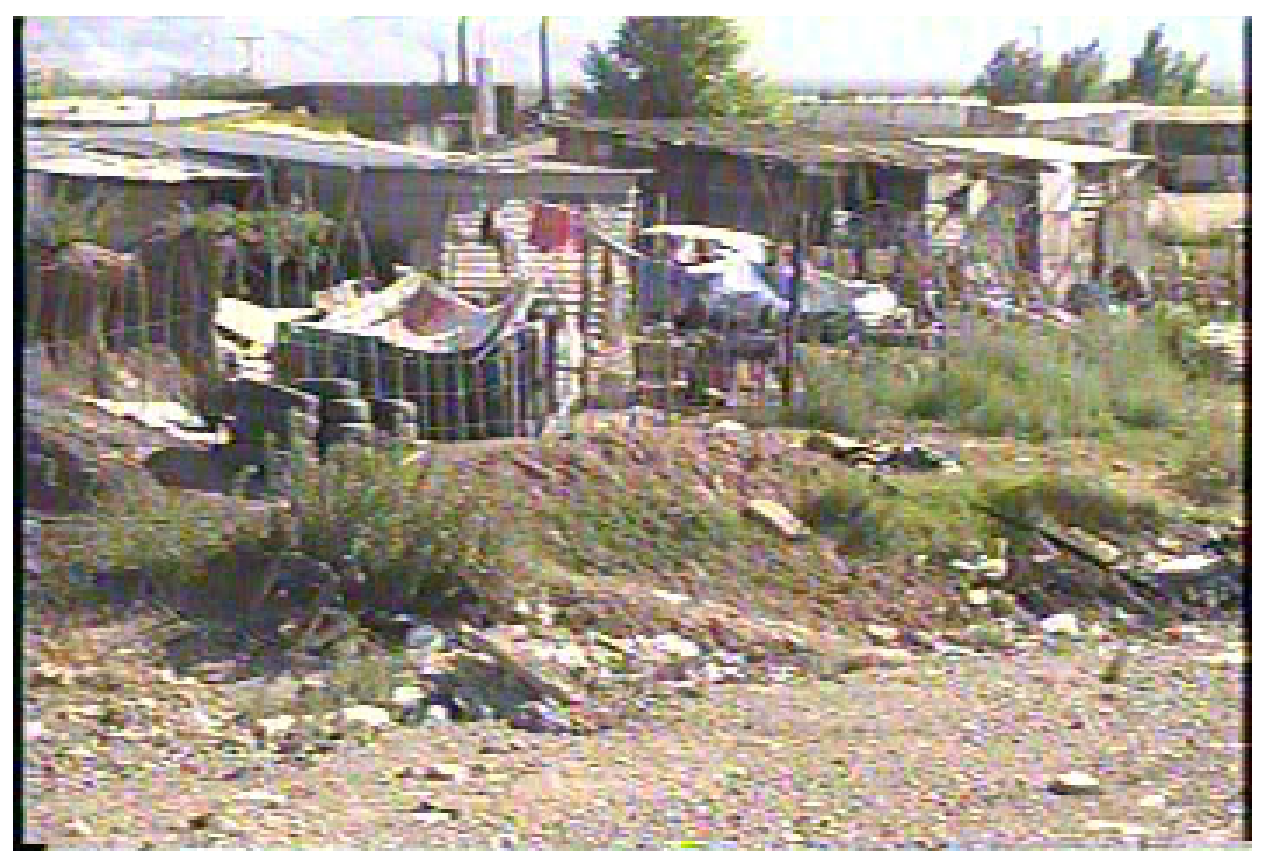

Figure 47: Colonia Ladrillera, Agua Prieta (photo by Silvia Villalobos de Zuñiga).

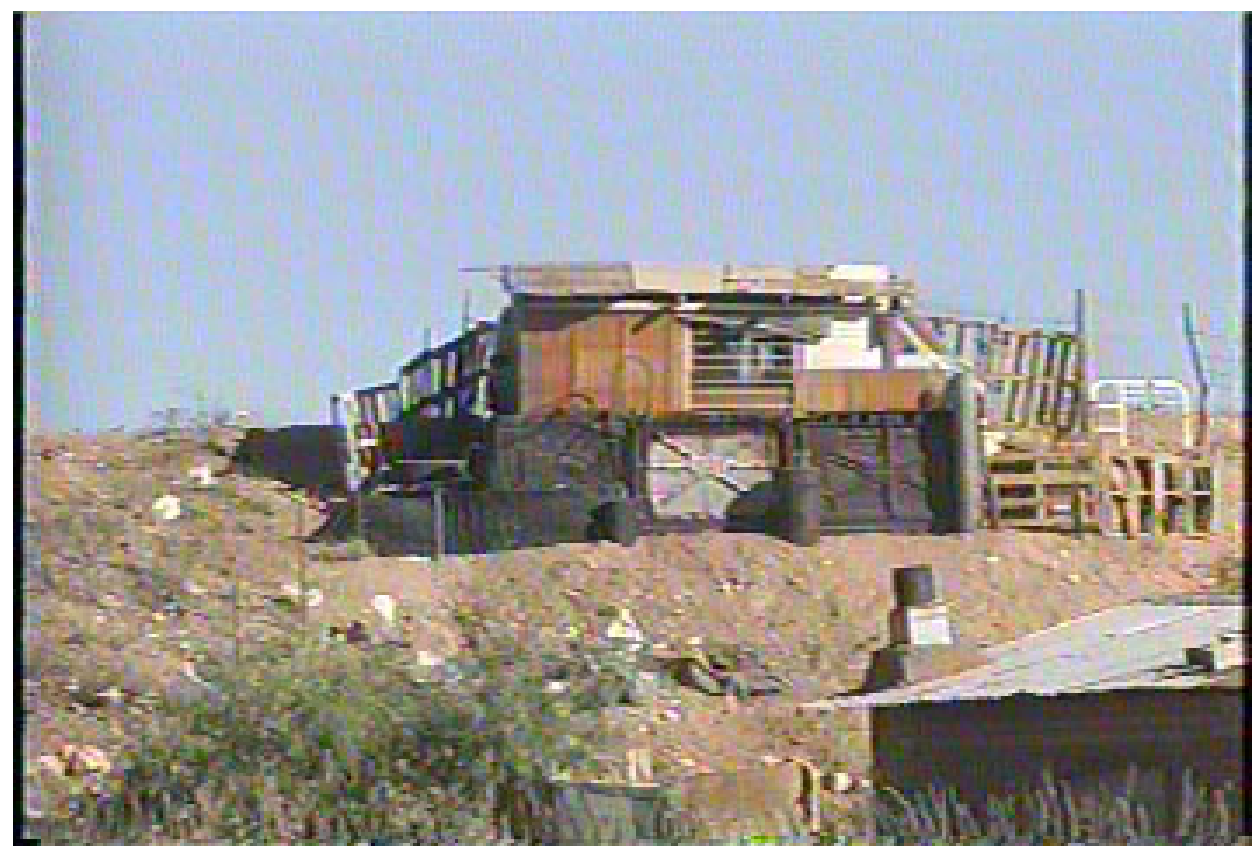

Figure 48: Materials for houses in colonia Pueblo Nuevo, Agua Prieta are makeshift (photo by Silvia Villalobos de Zuñiga). 


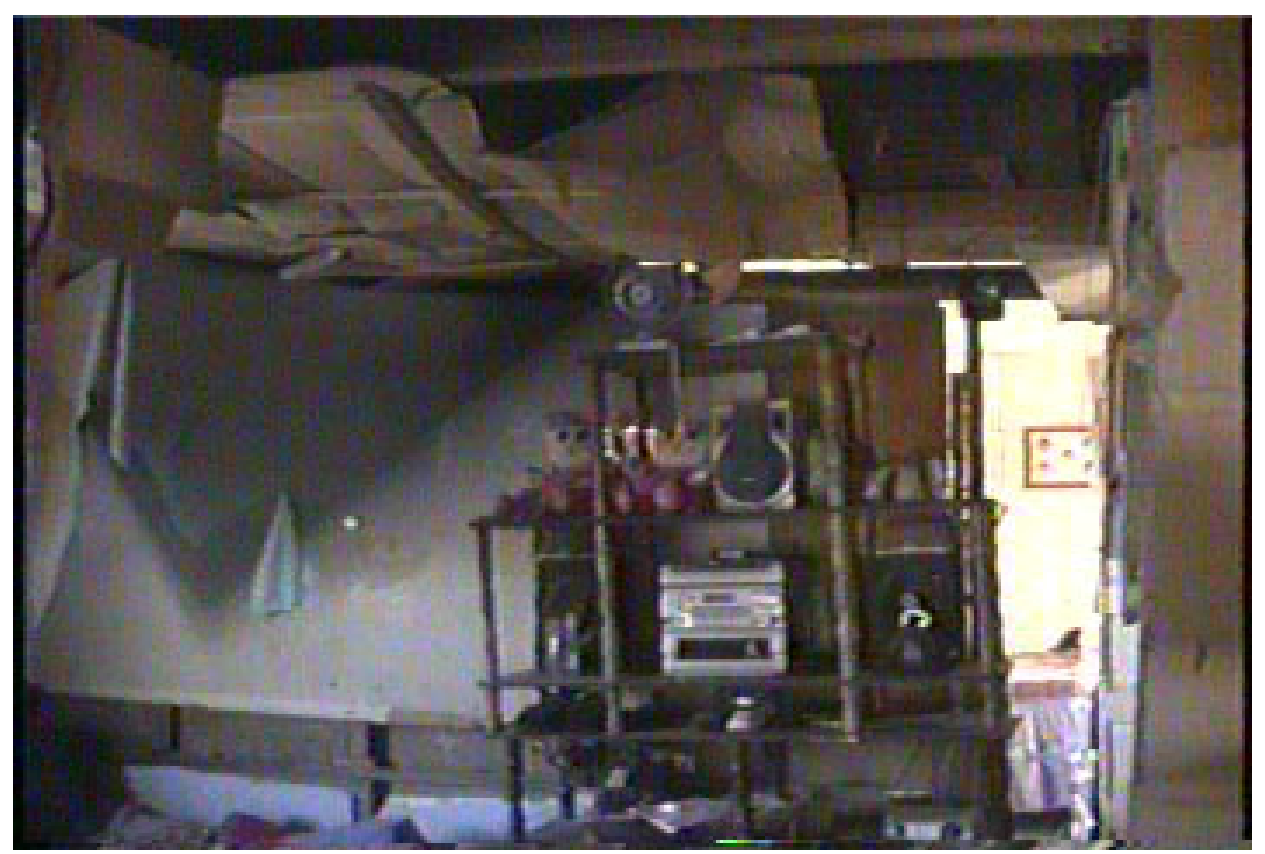

Figure 49: Cardboard roofing typical in colonia of Agua Prieta (photo by Silvia Villalobos de Zuñiga). 


\section{APPENDIX C: Metadata generated according to the Federal Geographic Data Committee (FGDC) standards for all new coverages.}

1973

Identification_Information:

Citation:

Citation_Information:

Originator: Laura M. Norman

Publication_Date: 12/03

Title: 1973 Urban Extent of Douglas, Arizona/Agua Prieta, Sonora

Edition: 1

Geospatial_Data_Presentation_Form: vector digital data

Series_Information:

Online Linkage: http://codd.art.srnr.arizona.edu/colonias

Larger_Work_Citation:

Citation_Information:

Originator: Norman, Laura M., Donelson, Angela J., Pfeifer, Edwin, Lam, Alven H., and

Osborn, Kenneth J.

Publication_Date: $12 / 03$

Title: Analyses of Urban Sprawl and Colonias Development in Douglas, Arizona \& Agua

Prieta, Sonora, on the United States-Mexico Border; A Process Application using GIS and

Remote Sensing

Geospatial_Data_Presentation_Form: vector digital data

Series_Information:

Series_Name: Open File Report

Issue_Identification: OFR 03-XXX

Publication_Information:

Publication_Place: Menlo Park, CA

Publisher: USGS

Online_Linkage: http://wgsc.wr.usgs.gov/wrgeog_pubs/

Description:

Abstract: Landsat imagery describing the Douglas, AZ and Agua Prieta, Sonora area (Path 35 Row 38) was acquired for place name Sierra Vista at 06/04/1973 from the Arizona Regional Image Archive, (http://aria.arizona.edu), an on-line interdisciplinary resource system for digital image and map data for the Sonoran desert region, including the U.S. Southwest and northern Mexico. The urban extent of the twin cities are was extracted from the satellite image.

Purpose: Image processing and subsequent temporal remote sensing analysis was done to quantify urban growth stemming from human settlement.

Time_Period_of_Content:

Time_Period_Information:

Single_Date/Time:

Calendar_Date: 06/04/1973

Currentness_Reference: 1973

Status:

Progress: Complete

Maintenance_and_Update_Frequency: None planned

Spatial_Domain:

Bounding_Coordinates:

West_Bounding_Coordinate: -109.568835

East_Bounding_Coordinate: -109.512347

North_Bounding_Coordinate: 31.378782

South_Bounding_Coordinate: 31.295863

Keywords:

Theme: 
Theme_Keyword_Thesaurus: none

Theme_Keyword: Land use

Theme_Keyword: Urban Sprawl

Place:

Place_Keyword: Arizona

Place_Keyword: Sonora

Use_Constraints: This digital database is not meant to be used or displayed at any scale larger than $\overline{1}: 24,000$ (for example, 1:12,000). Any hardcopies utilizing this dataset shall clearly indicate their source. If the user has modified the data in any way, he is obligated to describe the types of modifications he has performed on the hardcopy map. User specifically agrees not to misrepresent this dataset nor to imply that changes he made were approved by the U.S.

Geological Survey.

Point_of_Contact:

Contact_Information:

Contact_Person_Primary:

Contact_Person: Laura M. Norman

Contact_Organization: U.S. Geological Survey

Contact_Position: Cartographer, GIS Specialist

Contact_Address:

Address_Type: mailing address

Address: 520 N Park Ave, Ste \#355

City: Tucson

State_or_Province: AZ

Postal_Code: 85719

Country: U.S.A

Contact_Voice_Telephone: 5206705510

Contact_Facsimile_Telephone: 5206705571

Contact_Electronic_Mail_Address: Imbrady@usgs.gov

Hours_of_Service: $9-5$

Native_Data_Set_Environment: Microsoft Windows 2000 Version 5.0 (Build 2195) Service Pack

4; ESRI ArcCatalog 8.2.0.700

Cross_Reference:

Citation_Information:

Publication_Information:

Publication_Place: Tucson, Arizona

Publisher: U.S. Geological Survey

Larger_Work_Citation:

Citation_Information:

Publication_Information:

Publication_Place: USGS

Data_Quality_Information:

Attribute_Accuracy:

Attribute_Accuracy_Report: Although the satellite data were all acquired from the Landsat system, different sensors were accessed through the years, which may lead to some discrepancy in analysis. The Landsat 1 satellite acquired the MSS imagery for the 1973 year at a 79-meter resolution. Therefore, we were limited by pixel sixe. Other error that could have been introduced includes error due to rubbersheeting algorithm applied to the dataset.

Lineage:

Source_Information:

Source_Citation:

Citation_Information:

Publication_Date: Unknown

Title: Landsat 5 TM

Geospatial_Data_Presentation_Form: remote-sensing image

Other_Citation_Details: $79 \mathrm{~m}$. resolution

Online_Linkage: www.aria.arizona.edu 


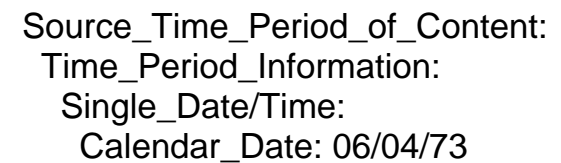

Source_Currentness_Reference: ground condition

Process_Step:

Process_Description: Geometric distortions were corrected by establishing a relationship between the satellite image and a Digital Orthophoto Quarter Quad (DOQQ) of the corresponding regions. Once these ground control points (GCP's) were established, the image is then converted, or rubbersheeted to the new coordinate system through a nearest neighbor resampling regime using a 3rd order polynomial, through a process called rectification. Identification of features by remote sensing involves computer software with the ability to identify pixels based upon their numerical properties and analyze them for statistical estimates. Using clustering methods to assign each pixel in an image to spectral classes, of which it has no foreknowledge, is called unsupervised classification. These procedures were applied to determine the location of the spectral classes into which the pixels are assigned. The analyst, who confirms these classes with information from ground maps, aerial photos, and ground visits, then identifies the output classes. Estimates of urban sprawl have been quantified by means of digitizing the urban extent area from the processed image.

Process_Date: 05/03

Spatial_Data_Organization_Information:

Direct_Spatial_Reference_Method: Vector

Point_and_Vector_Object_Information:

SDTS_Terms_Description:

SDTS_Point_and_Vector_Object_Type: G-polygon

Point_and_Vector_Object_Count: 6

Spatial_Reference_Information:

Horizontal_Coordinate_System_Definition:

Planar:

Grid_Coordinate_System:

Grid_Coordinate_System_Name: Universal Transverse Mercator

Universal_Transverse_Mercator:

UTM_Zone_Number: 12

Transverse_Mercator:

Scale_Factor_at_Central_Meridian: 0.999600

Longitude_of_Central_Meridian: -111.000000

Latitude_of_Projection_Origin: 0.000000

False_Easting: 500000.000000

False_Northing: 0.000000

Planar_Coordinate_Information:

Planar_Coordinate_Encoding_Method: coordinate pair

Coordinate_Representation:

Abscissa_Resolution: 0.000016

Ordinate_Resolution: 0.000016

Planar_Distance_Units: meters

Geodetic_Model:

Horizontal_Datum_Name: North American Datum of 1983

Ellipsoid_Name: Geodetic Reference System 80

Semi-major_Axis: 6378137.000000

Denominator_of_Flattening_Ratio: 298.257222

Entity_and_Attribute_Information:

Detailed_Description:

Entity_Type:

Entity_Type_Label: 1973

Entity_Type_Definition: Polygon used to portray urban extent in 1973

Attribute: 
Attribute_Label: FID

Attribute Definition: Internal feature number.

Attribute_Definition_Source: ESRI

Attribute Domain Values:

Unrepresentable_Domain: Sequential unique whole numbers that are automatically generated.

Attribute:

Attribute Label: Shape

Attribute_Definition: Feature geometry.

Attribute_Definition_Source: ESRI

Attribute_Domain_Values:

Unrepresentable_Domain: Coordinates defining the features.

Attribute:

Attribute Label: ID

Attribute:

Attribute_Label: GRIDCODE

Distribution_Information:

Distributor:

Contact Information:

Contact_Organization_Primary:

Contact_Organization: U.S. Geological Survey

Resource_Description: Downloadable Data

Distribution Liability:

The U.S. Geological Survey (USGS) provides these geographic data "as is." The USGS makes no guarantee or warranty concerning the accuracy of information contained in the geographic data. The USGS further makes no warranties, either expressed or implied, as to any other matter whatsoever, including, without limitation, the condition of the product or its fitness for any particular purpose. The burden for determining fitness for use lies entirely with the user. Although these data have been processed successfully on computers at the USGS, no warranty, expressed or implied, is made by the USGS regarding the use of these data on any other system nor does the fact of distribution constitute or imply any such warranty.

In no event shall the USGS have any liability whatsoever for payment of any consequential, incidental, indirect, special, or tort damages of any kind, including, but not limited to, any loss of profits arising out of use of or reliance on the geographic data or arising out of the delivery, installation, operation, or support by USGS.

Standard_Order_Process:

Digital_Form:

Digital_Transfer_Information:

Transfer Size: 0.018

Metadata_Reference_Information:

Metadata Date: 20031205

Metadata_Review_Date: 20031204

Metadata_Contact:

Contact_Information:

Contact_Person_Primary:

Contact_Person: Laura M. Norman

Contact_Organization: U.S. Geological Survey

Contact_Position: Cartographer, GIS Specialist

Contact_Address:

Address_Type: mailing address

Address: 520 N Park Ave, Ste \#355

City: Tucson

State_or_Province: AZ

Postal Code: 85719

Country: U.S.A 
Contact_Voice_Telephone: 5206705510

Contact_Facsimile_Telephone: 5206705571

Contact_Electronic_Mail_Address: Imbrady@usgs.gov

Hours_of_Service: $9-5$

Metadata_Standard_Name: FGDC Content Standards for Digital Geospatial Metadata

Metadata_Standard_Version: FGDC-STD-001-1998

Metadata_Time_Convention: local time

Metadata_Access_Constraints: none

Metadata Use Constraints: none

Metadata_Extensions:

Online_Linkage: http://www.esri.com/metadata/esriprof80.html

Profile_Name: ESRI Metadata Profile 
Identification_Information:

Citation:

Citation_Information:

Originator: Laura M. Norman

Publication_Date: 12/03

Title: 1985 Urban Extent of Douglas, Arizona/Agua Prieta, Sonora

Edition: 1

Geospatial_Data_Presentation_Form: vector digital data

Online Linkage: $\overline{h t t p}: / / c o d d . a r t . s r n r . a r i z o n a . e d u / c o l o n i a s$

Larger_Work_Citation:

Citation_Information:

Originator: Norman, Laura M., Donelson, Angela J., Pfeifer, Edwin, Lam, Alven H., and Osborn, Kenneth J.

Publication_Date: 12/03

Title: Analyses of Urban Sprawl and Colonias Development in Douglas, Arizona \& Agua

Prieta, Sonora on the United States-Mexico Border; A Process Application using GIS and

Remote Sensing

Geospatial_Data_Presentation_Form: vector digital data

Series_Information:

Series_Name: Open File Report

Issue_Identification: OFR-03-XXX

Publication_Information:

Publication_Place: Menlo Park, CA

Publisher: USGS

Online_Linkage: <http://wgsc.wr.usgs.gov/wrgeog_pubs/>

Description:

Abstract: Landsat imagery describing the Douglas, AZ and Agua Prieta, Sonora area (Path 35 Row 38) was acquired for place name Sierra Vista at 06/06/1985 from the Arizona Regional Image Archive, (http://aria.arizona.edu), an on-line interdisciplinary resource system for digital image and map data for the Sonoran desert region, including the U.S. Southwest and northern Mexico. The urban extent of the twin cities are was extracted from the satellite image.

Purpose: Image processing and subsequent temporal remote sensing analysis was done to quantify urban growth stemming from human settlement at this time period.

Time_Period_of_Content:

Timé_Period_Information:

Single_Date/Time:

Calendar_Date: 06/06/1985

Currentness_Reference: 1985

Status:

Progress: Complete

Maintenance_and_Update_Frequency: None planned

Spatial_Domain:

Bounding_Coordinates:

West_Bounding_Coordinate: -109.568835

East_Bounding_Coordinate: -109.512347

North_Bounding_Coordinate: 31.378782

South_Bounding_Coordinate: 31.295863

Keywords:

Theme:

Theme_Keyword_Thesaurus: none

Theme_Keyword: Land use

Theme_Keyword: Urban Sprawl 
Place:

Place Keyword Thesaurus: none

Place_Keyword: Arizona

Place_Keyword: Sonora

Place_Keyword: Douglas, AZ

Place_Keyword: Agua Prieta, Son.

Use_Constraints: This digital database is not meant to be used or displayed at any scale larger than $\overline{1}: 24,000$ (for example, 1:12,000). Any hardcopies utilizing this dataset shall clearly indicate their source. If the user has modified the data in any way, he is obligated to describe the types of modifications he has performed on the hardcopy map. User specifically agrees not to misrepresent this dataset nor to imply that changes he made were approved by the U.S.

Geological Survey.

Point_of_Contact:

Contact_Information:

Contact_Person_Primary:

Contact_Person: Laura M. Norman

Contact_Organization: U.S. Geological Survey

Contact_Position: Cartographer, GIS Specialist

Contact_Address:

Address_Type: mailing address

Address: 520 N Park Ave, Ste \#355

City: Tucson

State_or_Province: AZ

Postal_Code: 85745

Country: U.S.A

Contact_Voice_Telephone: 5206705510

Contact_Facsimile_Telephone: 5206705571

Contact_Electronic_Mail_Address: Imbrady@usgs.gov

Hours_of_Service: 9-5

Native_Data_Set_Environment: Microsoft Windows 2000 Version 5.0 (Build 2195) Service Pack

4; ESRI ArcCatalog 8.2.0.700

Cross_Reference:

Citation_Information:

Publication_Information:

Larger_Work_Citation:

Citation_Information:

Publication_Information:

Publication_Place: USGS

Data_Quality_Information:

Attribute_Accuracy:

Attribute_Accuracy_Report: Although the satellite data were all acquired from the Landsat system, different sensors were accessed through the years, which may lead to some discrepancy in analysis. Landsat 5 TM sensor acquired that MSS data in 1985 at a 30-m resolution. Therefore, we were limited by pixel size. Other error that could have been introduced includes error due to rubbersheeting algorithm applied to the dataset.

Lineage:

Source_Information:

Source_Citation:

Citation_Information:

Publication_Date: Unknown

Title: Landsat 5 TM

Geospatial_Data_Presentation_Form: remote-sensing image

Other_Citation_Details: $30 \mathrm{~m}$. resolution

Online_Linkage: www.aria.arizona.edu

Source_Time_Period_of_Content:

Time_Period_Information: 


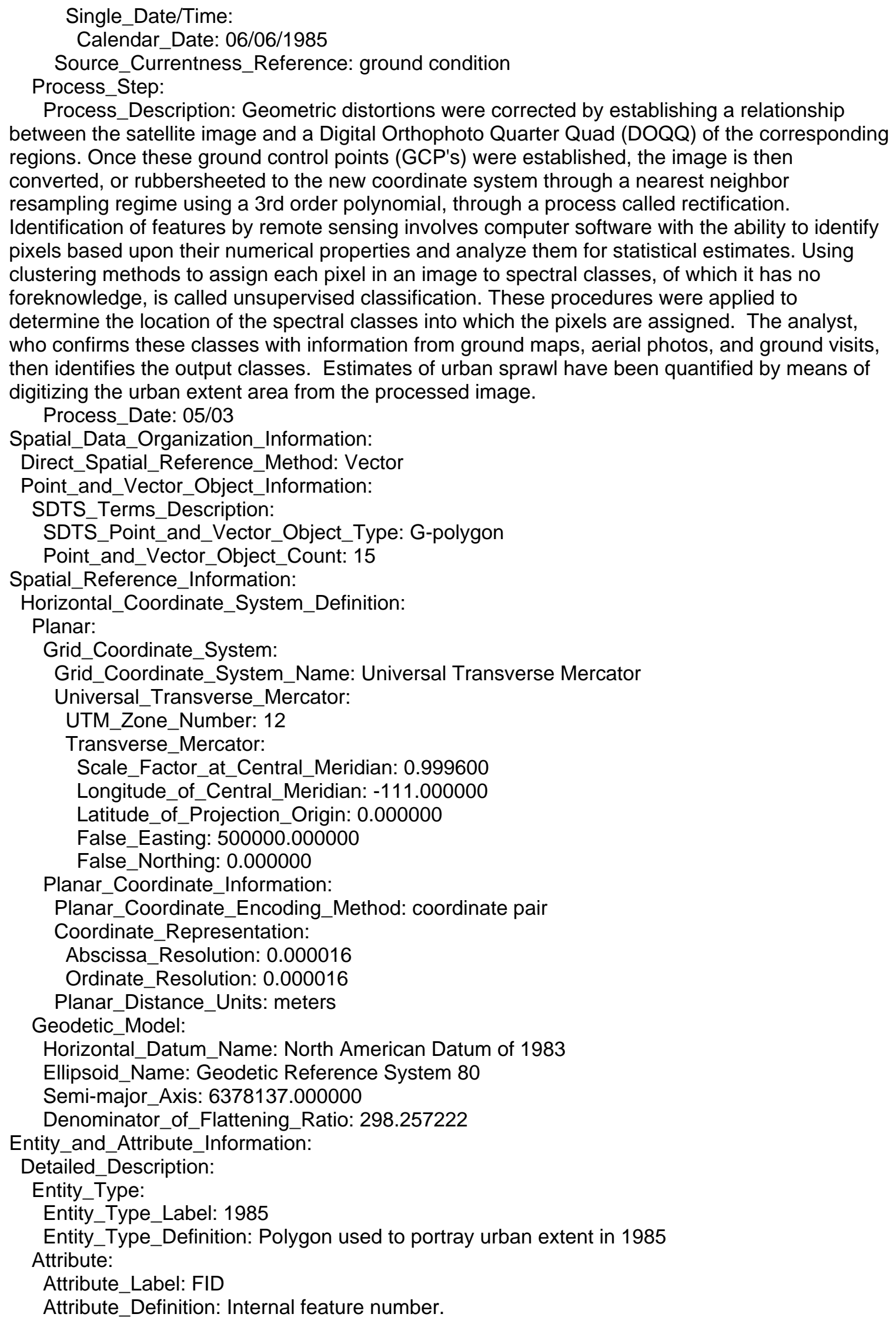

Process_Description: Geometric distortions were corrected by establishing a relationship between the satellite image and a Digital Orthophoto Quarter Quad (DOQQ) of the corresponding regions. Once these ground control points (GCP's) were established, the image is then converted, or rubbersheeted to the new coordinate system through a nearest neighbor resampling regime using a 3 rd order polynomial, through a process called rectification. Identification of features by remote sensing involves computer software with the ability to identify pixels based upon their numerical properties and analyze them for statistical estimates. Using clustering methods to assign each pixel in an image to spectral classes, of which it has no foreknowledge, is called unsupervised classification. These procedures were applied to determine the location of the spectral classes into which the pixels are assigned. The analyst, who confirms these classes with information from ground maps, aerial photos, and ground visits, then identifies the output classes. Estimates of urban sprawl have been quantified by means of digitizing the urban extent area from the processed image.

Process_Date: 05/03

Spatial_Data_organization_Information:

Direct_Spatial_Reference_Method: Vector

Point_and_Vector_Object_Information:

SDTS_Terms_Description:

SDTS_Point_and_Vector_Object_Type: G-polygon

Point_and_Vector_Object_Count: 15

Spatial_Reference_Information:

Horizontal_Coordinate_System_Definition:

Planar:

Grid_Coordinate_System:

Grid_Coordinate_System_Name: Universal Transverse Mercator

Universal_Transverse_Mercator:

UTM_Zone_Number: 12

Transverse_Mercator:

Scale_Factor_at_Central_Meridian: 0.999600

Longitude_of_Central_Meridian: -111.000000

Latitude_of_Projection_Origin: 0.000000

False_Easting: 500000.000000

False_Northing: 0.000000

Planar_Coordinate_Information:

Planar_Coordinate_Encoding_Method: coordinate pair

Coordinate_Representation:

Abscissa_Resolution: 0.000016

Ordinate_Resolution: 0.000016

Planar_Distance_Units: meters

Geodetic_Model:

Horizontal_Datum_Name: North American Datum of 1983

Ellipsoid_Name: Geodetic Reference System 80

Semi-major_Axis: 6378137.000000

Denominator_of_Flattening_Ratio: 298.257222

Entity_and_Attribute_Information:

Detailed_Description:

Entity_Type:

Entity_Type_Label: 1985

Entity_Type_Definition: Polygon used to portray urban extent in 1985

Attribute:

Attribute_Label: FID

Attribute_Definition: Internal feature number. 
Attribute_Definition_Source: ESRI

Attribute_Domain_Values:

Unrepresentable_Domain: Sequential unique whole numbers that are automatically generated.

Attribute:

Attribute_Label: Shape

Attribute_Definition: Feature geometry.

Attribute_Definition_Source: ESRI

Attribute_Domain_Values:

Unrepresentable_Domain: Coordinates defining the features.

Attribute:

Attribute_Label: ID

Attribute:

Attribute Label: GRIDCODE

Distribution_Information:

Distributor:

Contact_Information:

Contact_Organization_Primary:

Contact_Organization: U.S. Geological Survey

Resource_Description: Downloadable Data

Distribution_Liability:

The U.S. Geological Survey (USGS) provides these geographic data "as is." The USGS makes no guarantee or warranty concerning the accuracy of information contained in the geographic data. The USGS further makes no warranties, either expressed or implied, as to any other matter whatsoever, including, without limitation, the condition of the product or its fitness for any particular purpose. The burden for determining fitness for use lies entirely with the user. Although these data have been processed successfully on computers at the USGS, no warranty, expressed or implied, is made by the USGS regarding the use of these data on any other system, nor does the fact of distribution constitute or imply any such warranty.

In no event shall the USGS have any liability whatsoever for payment of any consequential, incidental, indirect, special, or tort damages of any kind, including, but not limited to, any loss of profits arising out of use of or reliance on the geographic data or arising out of the delivery, installation, operation, or support by USGS.

Standard_Order_Process:

Digital_Form:

Digital_Transfer_Information:

Transfer_Size: 0.016

Metadata_Reference_Information:

Metadata_Date: 20031205

Metadata_Contact:

Contact_Information:

Contact_Person_Primary:

Contact_Person: Laura M. Norman

Contact_Organization: U.S. Geological Survey

Contact_Position: Cartographer, GIS Specialist

Contact_Address:

Address_Type: mailing address

Address: 520 N Park Ave, Ste \#355

City: Tucson

State_or_Province: AZ

Postal_Code: 85719

Country: U.S.A

Contact_Voice_Telephone: 5206705510

Contact_Facsimile_Telephone: 5206705571

Contact_Electronic_Mail_Address: Imbrady@usgs.gov 
Hours_of_Service: 9-5

Metadata_Standard_Name: FGDC Content Standards for Digital Geospatial Metadata

Metadata_Standard_Version: FGDC-STD-001-1998

Metadata_Time_Convention: local time

Metadata_Access_Constraints: none

Metadata_Use_Constraints: none

Metadata_Extensions:

Online_Linkage: http://www.esri.com/metadata/esriprof80.html

Profile_Name: ESRI Metadata Profile

Metadata_Extensions:

Online_Linkage: http://www.esri.com/metadata/esriprof80.html

Profile_Name: ESRI Metadata Profile 
Identification_Information:

Citation:

Citation_Information:

Originator: Laura M. Norman

Publication_Date: 12/03

Publication_Time: Unknown

Title: 1995 Urban Extent of Douglas, Arizona/Agua Prieta, Sonora

Edition: 1

Geospatial_Data_Presentation_Form: vector digital data

Online Linkage: http://codd.art.srnr.arizona.edu/colonias

Larger_Work_Citation:

Citation_Information:

Originator: Norman, Laura M., Donelson, Angela J., Pfeifer, Edwin, Lam, Alven H., and Osborn, Kenneth J.

Publication_Date: Unknown

Title: Analyses of Urban Sprawl and Colonias Development in Douglas, Arizona \& Agua

Prieta, Sonora on the United States-Mexico Border; A Process Application using GIS and

Remote Sensing

Edition: Open File Report

Geospatial_Data_Presentation_Form: vector digital data

Series_Information:

Series_Name: Open File Report

Issue_Identification: OFR-03-XXX

Publication_Information:

Publication_Place: Menlo Park, CA

Publisher: USGS

Online_Linkage: <http://wgsc.wr.usgs.gov/wrgeog_pubs/>

Description:

Abstract: Landsat imagery describing the Douglas, AZ and Agua Prieta, Sonora area (Path 35 Row 38) was acquired for place name Sierra Vista at 06/18/1995 from the Arizona Regional Image Archive, (http://aria.arizona.edu), an on-line interdisciplinary resource system for digital image and map data for the Sonoran desert region, including the U.S. Southwest and northern Mexico. The urban extent of the twin cities are was extracted from the satellite image.

Purpose: Image processing and subsequent temporal remote sensing analysis was done to quantify urban growth stemming from human settlement.

Time_Period_of_Content:

Time_Period_Information:

Single_Date/Time:

Calendar_Date: 06/18/1995

Currentness_Reference: 1995

Status:

Progress: Complete

Maintenance_and_Update_Frequency: None planned

Spatial_Domain:

Bounding_Coordinates:

West_Bounding_Coordinate: -109.568835

East_Bounding_Coordinate: -109.512347

North_Bounding_Coordinate: 31.378782

South_Bounding_Coordinate: 31.295863

Keywords:

Theme:

Theme_Keyword: Land use

Theme_Keyword: Urban Sprawl 
Place:

Place Keyword: Arizona

Place_Keyword: Sonora

Place_Keyword: Douglas, AZ

Place_Keyword: Agua Prieta, Son.

Access_Constraints:

The U.S. Geological Survey (USGS) provides these geographic data "as is." The USGS makes no guarantee or warranty concerning the accuracy of information contained in the geographic data. The USGS further makes no warranties, either expressed or implied, as to any other matter whatsoever, including, without limitation, the condition of the product or its fitness for any particular purpose. The burden for determining fitness for use lies entirely with the user. Although these data have been processed successfully on computers at the USGS, no warranty, expressed or implied, is made by the USGS regarding the use of these data on any other system, nor does the fact of distribution constitute or imply any such warranty.

In no event shall the USGS have any liability whatsoever for payment of any consequential, incidental, indirect, special, or tort damages of any kind, including, but not limited to, any loss of profits arising out of use of or reliance on the geographic data or arising out of the delivery, installation, operation, or support by USGS.

Use_Constraints: This digital database is not meant to be used or displayed at any scale larger than $1: 24,000$ (for example, 1:12,000). Any hardcopies utilizing this dataset shall clearly indicate their source. If the user has modified the data in any way, he is obligated to describe the types of modifications he has performed on the hardcopy map. User specifically agrees not to misrepresent this dataset nor to imply that changes he made were approved by the U.S.

Geological Survey.

Point_of_Contact:

Contact_Information:

Contact_Person_Primary:

Contact_Person: Laura M. Norman

Contact_Organization: U.S. Geological Survey

Contact_Position: Cartographer, GIS Specialist

Contact_Voice_Telephone: 5206705510

Contact_Facsimile_Telephone: 5206705571

Contact_Electronic_Mail_Address: Imbrady@usgs.gov

Hours_of_Service: $9-5$

Native_Data_Set_Environment: Microsoft Windows 2000 Version 5.0 (Build 2195) Service Pack

4; ESRI ArcCatalog 8.2.0.700

Cross_Reference:

Citation_Information:

Publication_Information:

Larger_Work_Citation:

Citation_Information:

Publication_Information:

Publication_Place: USGS

Data_Quality_Information:

Attribute_Accuracy:

Attribute Accuracy Report: Although the satellite data were all acquired from the Landsat system, different sensors were accessed through the years, which may lead to some discrepancy in analysis. Landsat 5 TM sensor acquired that MSS data in 1995 at a 30-m resolution. Therefore, we were limited by pixel sixe. Other error that could have been introduced includes error due to rubbersheeting algorithm applied to the dataset.

Lineage:

Source_Information:

Source_Citation:

Citation_Information:

Publication_Date: Unknown 
Title: Landsat 5 TM

Geospatial_Data_Presentation_Form: remote-sensing image

Other_Citation_Details: $30 \mathrm{~m}$. resolution

Online_Linkage: www.aria.arizona.edu

Source_Time_Period_of_Content:

Time_Period_Information:

Single_Date/Time:

Caleñdar_Date: 06/06/1985

Source Currentness Reference: ground condition

Process_Step:

Process_Description: Geometric distortions were corrected by establishing a relationship between the satellite image and a Digital Orthophoto Quarter Quad (DOQQ) of the corresponding regions. Once these ground control points (GCP's) were established, the image is then converted, or rubbersheeted to the new coordinate system through a nearest neighbor resampling regime using a 3rd order polynomial, through a process called rectification. Identification of features by remote sensing involves computer software with the ability to identify pixels based upon their numerical properties and analyze them for statistical estimates. Using clustering methods to assign each pixel in an image to spectral classes, of which it has no foreknowledge, is called unsupervised classification. These procedures were applied to determine the location of the spectral classes into which the pixels are assigned. The analyst, who confirms these classes with information from ground maps, aerial photos, and ground visits, then identifies the output classes. Estimates of urban sprawl have been quantified by means of digitizing the urban extent area from the processed image.

Process_Date: 05/03

Spatial_Data_Organization_Information:

Direct_Spatial_Reference_Method: Vector

Point_and_Vector_Object_Information:

SDTS Terms Description:

SDTS_Point_and_Vector_Object_Type: G-polygon

Point_and_Vector_Object_Count: 14

Spatial_Reference_Information:

Horizontal_Coordinate_System_Definition:

Planar:

Grid_Coordinate_System:

Grid_Coordinate_System_Name: Universal Transverse Mercator

Universal_Transverse_Mercator:

UTM_Zone_Number: 12

Transverse_Mercator:

Scale_Factor_at_Central_Meridian: 0.999600

Longitude_of_Central_Meridian: -111.000000

Latitude_of_Projection_Origin: 0.000000

False_Easting: 500000.000000

False_Northing: 0.000000

Planar_Coordinate_Information:

Planar_Coordinate_Encoding_Method: coordinate pair

Coordinate_Representation:

Abscissa_Resolution: 0.000016

Ordinate_Resolution: 0.000016

Planar_Distance_Units: meters

Geodetic_Model:

Horizontal_Datum_Name: North American Datum of 1983

Ellipsoid_Name: Geodetic Reference System 80

Semi-major Axis: 6378137.000000

Denominator_of_Flattening_Ratio: 298.257222

Entity_and_Attribute_Information:

Detailed_Description: 
Entity_Type:

Entity_Type_Label: 1995

Entity_Type_Definition: Polygon used to portray urban extent in 1995

Attribute:

Attribute_Label: FID

Attribute_Definition: Internal feature number.

Attribute_Definition_Source: ESRI

Attribute_Domain_Values:

Unrepresentable_Domain: Sequential unique whole numbers that are automatically generated.

Attribute:

Attribute_Label: Shape

Attribute_Definition: Feature geometry.

Attribute_Definition_Source: ESRI

Attribute Domain Values:

Unrepresentable_Domain: Coordinates defining the features.

Attribute:

Attribute_Label: ID

Attribute:

Attribute Label: GRIDCODE

Distribution Information:

Distributor:

Contact_Information:

Contact_Organization_Primary:

Contact_Organization: U.S. Geological Survey

Resource_Description: Downloadable Data

Standard_Order_Process:

Digital Form:

Digital_Transfer_Information:

Transfer_Size: 0.016

Metadata_Reference_Information:

Metadata_Date: 20031204

Metadata_Contact:

Contact_Information:

Contact_Person_Primary:

Contact_Person: Laura M. Norman

Contact_Organization: U.S. Geological Survey

Contact_Position: Cartographer, GIS Specialist

Contact_Address:

Address_Type: mailing address

Address: 520 N Park Ave, Ste \#355

City: Tucson

State_or_Province: AZ

Postal_Code: 85719

Country: U.S.A

Contact_Voice_Telephone: 5206705510

Contact_Facsimile_Telephone: 5206705571

Contact_Electronic_Mail_Address:Imbrady@usgs.gov

Hours_of_Service: $9-5$

Metadata_Standard_Name: FGDC Content Standards for Digital Geospatial Metadata

Metadata_Standard_Version: FGDC-STD-001-1998

Metadata_Time_Convention: local time

Metadata_Access_Constraints: none

Metadata_Use_Constraints: none

Metadata_Extensions:

Online_Linkage: http://www.esri.com/metadata/esriprof80.html 
Profile_Name: ESRI Metadata Profile 
Identification_Information:

Citation:

Citation_Information:

Originator: Laura M. Norman

Publication_Date: 12/03

Title: 2000 Urban Extent of Douglas, AZ/Agua Prieta, Sonora

Geospatial_Data_Presentation_Form: vector digital data

Online Linkage: http://codd.art.srnr.arizona.edu/colonias

Larger_Work_Citation:

Citation Information:

Originator: Norman, Laura M., Donelson, Angela J., Pfeifer, Edwin, Lam, Alven H., and Osborn, Kenneth J.

Publication_Date: 12/03

Title: Analyses of Urban Sprawl and Colonias Development in Douglas, Arizona \& Agua

Prieta, Sonora on the United States-Mexico Border; A Process Application using GIS and

Remote Sensing

Geospatial_Data_Presentation_Form: vector digital data

Series Information:

Series_Name: Open File Report

Issue_Identification: OFR-03-XXX

Publication_Information:

Publication_Place: Menlo Park, CA

Publisher: USGS

Online_Linkage: <http://wgsc.wr.usgs.gov/wrgeog_pubs/>

Description:

Abstract: Landsat imagery describing the Douglas, AZ and Agua Prieta, Sonora area (Path 35

Row 38) was acquired for place name Sierra Vista at 04/05/2000 from the Arizona Regional Image Archive, (http://aria.arizona.edu), an on-line interdisciplinary resource system for digital image and map data for the Sonoran desert region, including the U.S. Southwest and northern Mexico. The urban extent of the twin cities are was extracted from the satellite image.

Purpose: Image processing and subsequent temporal remote sensing analysis was done to quantify urban growth stemming from human settlement.

Time_Period_of_Content:

Time_Period_Information:

Single_Date/Time:

Calendar_Date: 04/05/2000

Currentness_Reference: 2000

Status:

Progress: Complete

Maintenance_and_Update_Frequency: None planned

Spatial_Domain:

Bounding Coordinates:

West_Bounding_Coordinate: -109.568835

East_Bounding_Coordinate: -109.512347

North_Bounding_Coordinate: 31.378782

South_Bounding_Coordinate: 31.295863

Keywords:

Theme:

Theme_Keyword_Thesaurus: none

Theme_Keyword: Land use

Theme_Keyword: Urban Sprawl 
Place:

Place_Keyword: Arizona

Place_Keyword: Sonora

Place_Keyword: Douglas, AZ

Place_Keyword: Agua Prieta, Sonora

Use_Constraints: This digital database is not meant to be used or displayed at any scale larger than $\overline{1}: 24,000$ (for example, 1:12,000). Any hardcopies utilizing this dataset shall clearly indicate their source. If the user has modified the data in any way, he is obligated to describe the types of modifications he has performed on the hardcopy map. User specifically agrees not to misrepresent this dataset nor to imply that changes he made were approved by the U.S.

Geological Survey.

Point_of_Contact:

Contact_Information:

Contact_Person_Primary:

Contact_Person: Laura M. Norman

Contact_Organization: U.S. Geological Survey

Contact_Position: Cartographer, GIS Specialist

Contact_Address:

Address_Type: mailing address

Address: 520 N Park Ave, Ste \#355

City: Tucson

State_or_Province: AZ

Postal_Code: 85719

Country: U.S.A

Contact_Voice_Telephone: 5206705510

Contact_Facsimile_Telephone: 5206705571

Contact_Electronic_Mail_Address: Imbrady@usgs.gov

Hours_of_Service: $\overline{9}-5$

Native_Data_Set_Environment: Microsoft Windows 2000 Version 5.0 (Build 2195) Service Pack 4; ESRI ArcCatalog 8.2.0.700

Cross_Reference:

Citation_Information:

Publication_Information:

Larger_Work_Citation:

Citation_Information:

Publication_Information:

Publication_Place: USGS

Data_Quality_Information:

Attribute_Accuracy:

Attribute_Accuracy_Report: Although the satellite data were all acquired from the Landsat

system, different sensors were accessed through the years, which may lead to some discrepancy in analysis. The Landsat 7 Enhanced Thematic Mapper Plus (ETM+) MRLC data was acquired at $30 \mathrm{~m}$ resolution in year 2000. Therefore, we were limited by pixel sixe. Other error that could have been introduced includes error due to rubbersheeting algorithm applied to the dataset.

Lineage:

Source_Information:

Source_Citation:

Citation_Information:

Publication_Date: Unknown

Title: Landsat 7 ETM +

Geospatial_Data_Presentation_Form: remote-sensing image

Other_Citation_Details: $30 \mathrm{~m}$. resolution

Online_Linkage: www.aria.arizona.edu

Source_Time_Period_of_Content:

Time_Period_Information:

Single_Date/Time: 
Calendar_Date: 06/06/1985

Source_Currentness_Reference: ground condition

Process_Step:

Process_Description: Geometric distortions were corrected by establishing a relationship between the satellite image and a Digital Orthophoto Quarter Quad (DOQQ) of the corresponding regions. Once these ground control points (GCP's) were established, the image is then converted, or rubbersheeted to the new coordinate system through a nearest neighbor resampling regime using a 3rd order polynomial, through a process called rectification. Identification of features by remote sensing involves computer software with the ability to identify pixels based upon their numerical properties and analyze them for statistical estimates. Using clustering methods to assign each pixel in an image to spectral classes, of which it has no foreknowledge, is called unsupervised classification. These procedures were applied to determine the location of the spectral classes into which the pixels are assigned. The analyst, who confirms these classes with information from ground maps, aerial photos, and ground visits, then identifies the output classes. Estimates of urban sprawl have been quantified by means of digitizing the urban extent area from the processed image.

Process Date: 05/03

Spatial_Data_Organization_Information:

Direct_Spatial_Reference_Method: Vector

Point_and_Vector_Object_Information:

SDTS_Terms_Description:

SDTS_Point_and_Vector_Object_Type: G-polygon

Point_and_Vector_Object_Count: 33

Spatial_Reference_Information:

Horizontal_Coordinate_System_Definition:

Planar:

Grid_Coordinate_System:

Grid_Coordinate_System_Name: Universal Transverse Mercator

Universal_Transverse_Mercator:

UTM_Zone_Number: 12

Transverse_Mercator:

Scale_Factor_at_Central_Meridian: 0.999600

Longitude_of_Central_Meridian: -111.000000

Latitude_of_Projection_Origin: 0.000000

False_Easting: 500000.000000

False_Northing: 0.000000

Planar_Coordinate_Information:

Planar_Coordinate_Encoding_Method: coordinate pair

Coordinate_Representation:

Abscissa_Resolution: 0.000016

Ordinate_Resolution: 0.000016

Planar_Distance_Units: meters

Geodetic_Model:

Horizontal_Datum_Name: North American Datum of 1983

Ellipsoid_Name: Geodetic Reference System 80

Semi-major_Axis: 6378137.000000

Denominator_of_Flattening_Ratio: 298.257222

Entity_and_Attribute_Information:

Detailed_Description:

Entity_Type:

Entity_Type_Label: 2000

Entity_Type_Definition: Polygon used to portray urban extent in 2000

Attribute:

Attribute_Label: FID

Attribute_Definition: Internal feature number.

Attribute_Definition_Source: ESRI 
Attribute_Domain_Values:

Unrepresentable_Domain: Sequential unique whole numbers that are automatically generated.

Attribute:

Attribute_Label: Shape

Attribute_Definition: Feature geometry.

Attribute_Definition_Source: ESRI

Attribute_Domain_Values:

Unrepresentable_Domain: Coordinates defining the features.

Attribute:

Attribute_Label: ID

Distribution_Information:

Distributor:

Contact_Information:

Contact_Organization_Primary:

Contact_Organization: U.S. Geological Survey

Resource_Description: Downloadable Data

Distribution_Liability:

The U.S. Geological Survey (USGS) provides these geographic data "as is." The USGS makes no guarantee or warranty concerning the accuracy of information contained in the geographic data. The USGS further makes no warranties, either expressed or implied, as to any other matter whatsoever, including, without limitation, the condition of the product or its fitness for any particular purpose. The burden for determining fitness for use lies entirely with the user. Although these data have been processed successfully on computers at the USGS, no warranty, expressed or implied, is made by the USGS regarding the use of these data on any other system, nor does the fact of distribution constitute or imply any such warranty.

In no event shall the USGS have any liability whatsoever for payment of any consequential, incidental, indirect, special, or tort damages of any kind, including, but not limited to, any loss of profits arising out of use of or reliance on the geographic data or arising out of the delivery, installation, operation, or support by USGS.

Standard_Order_Process:

Digital_Form:

Digital_Transfer_Information:

Transfer_Size: 0.016

Metadata Reference Information:

Metadata_Date: 20031205

Metadata_Contact:

Contact_Information:

Contact_Person_Primary:

Contact_Person: Laura M. Norman

Contact_Organization: U.S. Geological Survey

Contact_Position: Cartographer, GIS Specialist

Contact_Address:

Address_Type: mailing address

Address: 520 N Park Ave, Ste \#355

City: Tucson

State_or_Province: AZ

Postal_Code: 85719

Country: U.S.A

Contact_Voice_Telephone: 5206705510

Contact_Facsimile_Telephone: 5206705571

Contact_Electronic_Mail_Address: Imbrady@usgs.gov

Hours_of_Service: $9-5$

Metadata_Standard_Name: FGDC Content Standards for Digital Geospatial Metadata

Metadata_Standard_Version: FGDC-STD-001-1998 
Metadata_Time_Convention: local time

Metadata Access Constraints: none

Metadata_Use_Constraints: none

Metadata Extensions:

Online_Linkage: http://www.esri.com/metadata/esriprof80.html

Profile_Name: ESRI Metadata Profile 


\section{Colonias in Agua Prieta, Sonora}

Identification_Information:

Citation:

Citation_Information:

Originator: Laura M. Norman

Publication_Date: 07/03/03

Title: Colonias in Agua Prieta, Sonora

Geospatial_Data_Presentation_Form: vector digital data

Online Linkage: http://codd.art.srnr.arizona.edu/colonias

Larger_Work_Citation:

Citation_Information:

Originator: Norman, Laura M., Donelson, Angela J., Pfeifer, Edwin, Lam, Alven H., and

Osborn, Kenneth J.

Publication Date: 12/03

Title: Analyses of Urban Sprawl and Colonias Development in Douglas, Arizona \& Agua

Prieta, Sonora on the United States-Mexico Border; A Process Application using GIS and

Remote Sensing

Geospatial_Data_Presentation_Form: vector digital data

Series_Information:

Series_Name: Open File Report

Issue_Identification: OFR-03-XXX

Publication_Information:

Publication_Place: Menlo Park, CA

Publisher: USGS

Online_Linkage: <http://wgsc.wr.usgs.gov/wrgeog_pubs/>

Description:

Abstract: A suitability/ capability analysis (SCA) was implemented based on the housing and infrastructure suitability and/or capability of given areas to support colonias in Agua Prieta, Sonora.

Purpose: Colonias designation was done in Agua Prieta, Sonora to identify colonias-like neighborhoods in the area to make those neighborhoods recognizable to apply for funding

Time_Period_of_Content:

Time_Period_Information:

Single_Date/Time:

Currentness_Reference: 2003

Status:

Progress: Complete

Maintenance_and_Update_Frequency: None planned

Spatial_Domain:

Bounding_Coordinates:

West_Bounding_Coordinate: -109.568835

East_Bounding_Coordinate: -109.512347

North_Bounding_Coordinate: 31.378782

South_Bounding_Coordinate: 31.295863

Keywords:

Theme:

Theme_Keyword_Thesaurus: none

Theme_Keyword: Colonias

Theme_Keyword: Agua Prieta

Place:

Place_Keyword_Thesaurus: none

Place_Keyword: Agua Prieta

Place_Keyword: Sonora 
Place_Keyword: Mexico

Use_Constraints: This digital database is not meant to be used or displayed at any scale larger than $\overline{1}: 24,000$ (for example, 1:12,000). Any hardcopies utilizing this dataset shall clearly indicate their source. If the user has modified the data in any way, he is obligated to describe the types of modifications he has performed on the hardcopy map. User specifically agrees not to misrepresent this dataset nor to imply that changes he made were approved by the U.S. Geological Survey

Point_of_Contact:

Contact_Information:

Contact_Person_Primary:

Contact_Person: Laura M. Norman

Contact_Organization: U.S. Geological Survey

Contact_Position: Cartographer, GIS Specialist

Contact_Address:

Address_Type: mailing address

Address: 520 N Park Ave, Ste \#355

City: Tucson

State_or_Province: AZ

Postal_Code: 85719

Country: U.S.A

Contact_Voice_Telephone: 5206705510

Contact_Facsimile_Telephone: 5206705571

Contact_Electronic_Mail_Address:Imbrady@usgs.gov

Hours_of_Service: 9-5

Data_Set_Credit: In the municipal of Agua Prieta, Silvia Villalobos de Zuñiga (director of the Agua Prieta's National System for the Integral Development of the Family (DIF) and sister to the Mayor of Agua Prieta, Irma Villalobos de Terán), Del Cabarga (dual citizen and coordinator for Take to the Hills non-profit org), \& Reverend Jesus Gallegos (minister at Lily of the Valley Presbyterian Church in Agua Prieta, Mexico affiliate of the Frontera de Cristo border ministry) identified the poorest neighborhoods (barrios pobres) to call "colonias" for this project.

Native_Data_Set_Environment: Microsoft Windows 2000 Version 5.0 (Build 2195) Service Pack

4; ESRI ArcCatalog 8.2.0.700

Cross_Reference:

Citation Information:

Publication_Information:

Larger_Work_Citation:

Citation_Information:

Publication_Information:

Publication_Place: USGS

Data_Quality_Information:

Attribute_Accuracy:

Attribute_Accuracy_Report: While the boundaries are thought to be most accurate according to the people who were involved in their deliniation, there were no legal boundaries used to define the colonias adataset.

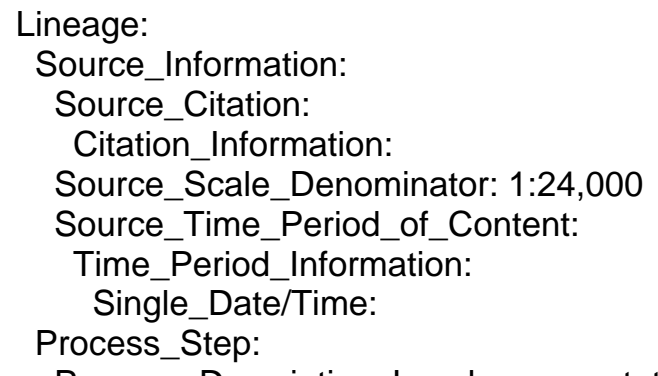

Process_Description: Local representatives were asked to draw boundaries on hard copy print out maps describing the roads, sewer, and water infrastructure overlain on aerial photos of their community. These approximations were based upon previous knowledge and familiarity 
with the most impoverished and underprivileged areas known to them at that time. These

polygons boundaries were then digitized and attributed.

Process_Date: 06/03

Spatial_Data_Organization_Information:

Direct_Spatial_Reference_Method: Vector

Point_and_Vector_Object_Information:

SDTS_Terms_Description:

SDTS_Point_and_Vector_Object_Type: G-polygon

Point_and_Vector_Object_Count: 8

Spatial_Reference_Information:

Horizontal_Coordinate_System_Definition:

Planar:

Grid_Coordinate_System:

Grid_Coordinate__System_Name: Universal Transverse Mercator

Universal_Transverse_Mercator:

UTM_Zone_Number: 12

Transverse Mercator:

Scale_Factor_at_Central_Meridian: 0.999600

Longitude_of_Central_Meridian: -111.000000

Latitude_of_Projection_Origin: 0.000000

False_Easting: 500000.000000

False_Northing: 0.000000

Planar_Coordinate_Information:

Planar_Coordinate_Encoding_Method: coordinate pair

Coordinate_Representation:

Abscissa_Resolution: 0.000016

Ordinate_Resolution: 0.000016

Planar_Distance_Units: meters

Geodetic_Model:

Horizontal_Datum_Name: North American Datum of 1983

Ellipsoid_Name: Geodetic Reference System 80

Semi-major_Axis: 6378137.000000

Denominator_of_Flattening_Ratio: 298.257222

Entity_and_Attribute_Information:

Detailed_Description:

Entity_Type:

Entity_Type_Label: Colonias

Entity_Type_Definition: Colonias were defined by the Cranston-Gonzales Act of 1990 as rural communities and neighborhoods located within 150 miles of the United States-Mexican border. Some colonias may be entire border communities, while others are comprised of neighborhoods within incorporated communities. They lack adequate infrastructure (sewer or water lines) and/or housing.Colonias were defined by the Cranston-Gonzales Act of 1990 as rural communities and neighborhoods located within 150 miles of the United States-Mexican border. Some colonias may be entire border communities, while others are comprised of neighborhoods within incorporated communities. They lack adequate infrastructure (sewer or water lines) and/or housing.

Entity_Type_Definition_Source: (http://www.hud.gov/groups/frmwrkcoln/whatcol.cfm). Attribute:

Attribute_Label: FID

Attribute_Definition: Internal feature number.

Attribute_Definition_Source: ESRI

Attribute_Domain_Values:

Unrepresentable_Domain: Sequential unique whole numbers that are automatically generated.

Attribute:

Attribute_Label: Shape 
Attribute_Definition: Feature geometry.

Attribute Definition Source: ESRI

Attribute_Domain_Values:

Unrepresentable_Domain: Coordinates defining the features.

Attribute:

Attribute_Label: ID

Attribute:

Attribute_Label: Name

Attribute_Definition: Name of colonia

Attribute_Definition_Source: Local interpretation

Distribution_Information:

Distributor:

Contact_Information:

Contact_Organization_Primary:

Contact_Organization: U.S. Geological Survey

Resource_Description: Downloadable Data

Distribution_Liability:

The U.S. Geological Survey (USGS) provides these geographic data "as is." The USGS makes no guarantee or warranty concerning the accuracy of information contained in the geographic data. The USGS further makes no warranties, either expressed or implied, as to any other matter whatsoever, including, without limitation, the condition of the product or its fitness for any particular purpose. The burden for determining fitness for use lies entirely with the user. Although these data have been processed successfully on computers at the USGS, no warranty, expressed or implied, is made by the USGS regarding the use of these data on any other system, nor does the fact of distribution constitute or imply any such warranty.

In no event shall the USGS have any liability whatsoever for payment of any consequential, incidental, indirect, special, or tort damages of any kind, including, but not limited to, any loss of profits arising out of use of or reliance on the geographic data or arising out of the delivery, installation, operation, or support by USGS.

Standard_Order_Process:

Digital_Form:

Digital_Transfer_Information:

Transfer Size: 0.016

Metadata_Reference_Information:

Metadata_Date: 20031205

Metadata_Contact:

Contact_Information:

Contact_Person_Primary:

Contact_Persoñ: Laura M. Norman

Contact_Organization: U.S. Geological Survey

Contact_Position: Cartographer, GIS Specialist

Contact_Address:

Address_Type: mailing address

Address: 520 N Park Ave, Ste \#355

City: Tucson

State_or_Province: AZ

Postal_Code: 85719

Country: U.S.A

Contact_Voice_Telephone: 5206705510

Contact_Facsimile_Telephone: 5206705571

Contact_Electronic_Mail_Address: Imbrady@usgs.gov

Hours_of_Service: $9-5$

Metadata_Standard_Name: FGDC Content Standards for Digital Geospatial Metadata

Metadata_Standard_Version: FGDC-STD-001-1998

Metadata_Time_Convention: local time 
Metadata_Access_Constraints: none

Metadata Use Constraints: none

Metadata_Extensions:

Online Linkage: http://www.esri.com/metadata/esriprof80.html

Profile_Name: ESRI Metadata Profile 
Identification_Information:

Citation:

Citation Information:

Originator: Laura M. Norman

Publication_Date: 12/03

Title: Waterlines in Agua Prieta, Sonora

Geospatial_Data_Presentation_Form: vector digital data

Online Linkage: http://codd.art.srnr.arizona.edu/colonias

Larger_Work_Citation:

Citation Information:

Originator: Norman, Laura M., Donelson, Angela J., Pfeifer, Edwin, Lam, Alven H., and Osborn, Kenneth J.

Publication_Date: 12/03

Title: Analyses of Urban Sprawl and Colonias Development in Douglas, Arizona \& Agua

Prieta, Sonora on the United States-Mexico Border; A Process Application using GIS and

Remote Sensing

Geospatial_Data_Presentation_Form: vector digital data

Series Information:

Series_Name: Open File Report

Issue_Identification: OFR-03-XXX

Publication_Information:

Publication Place: Menlo Park, CA

Publisher: USGS

Online_Linkage: http://wgsc.wr.usgs.gov/wrgeog_pubs/

Description:

Abstract: Data gathered for report (Comisión De Cooperación Ecológica Fronteriza

(COCEF/BECC)) was systematically translated and synthesized. AutoCAD drawings describing the the waterlines in Agua Prieta, Sonora were rectified and digitized within a GIS. These

geographic features describing the Municipal of Agua Prieta were automated into the geospatial database.

Purpose: TThe map of waterlines was used to help define colonias.

Time_Period_of_Content:

Time_Period_Information:

Single_Date/Time:

Calendar Date: 12/03

Currentness_Reference: publication date

Status:

Progress: Complete

Maintenance_and_Update_Frequency: None planned

Spatial_Domain:

Bounding_Coordinates:

West_Bounding_Coordinate: -109.569582

East_Bounding_Coordinate: -109.510386

North_Bounding_Coordinate: 31.334005

South_Bounding_Coordinate: 31.303353

Keywords:

Theme:

Theme Keyword Thesaurus: none

Theme_Keyword: Agua Prieta

Theme_Keyword: Infrastructure

Theme_Keyword: COCEF/BECC 


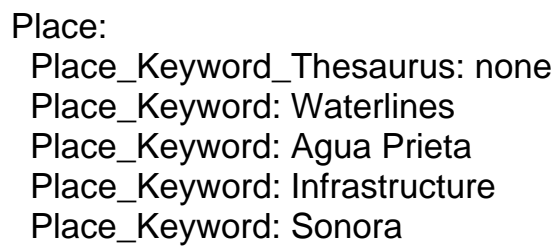

Use_Constraints: This digital database is not meant to be used or displayed at any scale larger than $\overline{1}: 24,000$ (for example, 1:12,000). Any hardcopies utilizing this dataset shall clearly indicate their source. If the user has modified the data in any way, he is obligated to describe the types of modifications he has performed on the hardcopy map. User specifically agrees not to

misrepresent this dataset nor to imply that changes he made were approved by the U.S.

Geological Survey.

Point_of_Contact:

Contact_Information:

Contact_Person_Primary:

Contact_Person: Laura M. Norman

Contact_Organization: U.S. Geological Survey

Contact_Position: Cartographer, GIS Specialist

Contact_Address:

Address_Type: mailing address

Address: 520 N Park Ave, Ste \#355

City: Tucson

State or Province: AZ

Postal_Code: 85719

Country: U.S.A

Contact_Voice_Telephone: 5206705510

Contact_Facsimile_Telephone: 5206705571

Contact_Electronic_Mail_Address: Imbrady@usgs.gov

Hours_of_Service: $9-5$

Native_Data_Set_Environment: Microsoft Windows 2000 Version 5.0 (Build 2195) Service Pack

4; ESRI ArcCatalog 8.2.0.700

Cross Reference:

Citation_Information:

Data_Quality_Information:

Attribute_Accuracy:

Attribute_Accuracy_Report: Accuracy is based on AutoCAD drawings from 1998.

Completeness_Report: This information was created according to data compiled in 1998.

Lineage:

Source_Information:

Source_Citation:

Citation_Information:

Originator: Comisión De Cooperación Ecológica Fronteriza (COCEF/BECC)

Publication_Date: 1998

Title: Agua Prieta, Sonora, Plan Maestro; Para el Mejoramiento de los Servicios de Agua

Potable, Alcantarillado y Saneamiento de la Ciudad de Agua Prieta, Son. Y Levatamiento de Redes Hidraulicas.

Geospatial_Data_Presentation_Form: document

Other_Citation_Details: CONTA 98-023

Source_Time_Period_of_Content:

Time_Period_Information:

Single_Date/Time:

Calendar_Date: unknown

Source Currentness Reference: ground condition

Process_Step:

Process_Description: AutoCAD drawings were rectified in ArcView 3.3 using world files that were created according to known bounding coordinates. The data were exported into ArcGIS for 
processing. In ArcPlot coverages were generated utilizing drawing layers from AutoCAD created previously by COCEF/BECC in the master plan of the city. Coverages were exported to ArcEdit, cleaned and built. And in ArcINFO exported to shapefiles.

Process_Date: 05/03

Spatial_Data_Organization_Information:

Direct_Spatial_Reference_Method: Vector

Point_and_Vector_Object_Information:

SDTS Terms Description:

SDTS_Point_and_Vector_Object_Type: String

Point_and_Vector_Object_Count: 1023

Spatial_Reference_Information:

Horizontal_Coordinate_System_Definition:

Planar:

Grid_Coordinate_System:

Grid_Coordinate_System_Name: Universal Transverse Mercator

Universal_Transverse_Mercator:

UTM Zone Number: 12

Transverse_Mercator:

Scale_Factor_at_Central_Meridian: 0.999600

Longitude_of_Central_Meridian: -111.000000

Latitude_of_Projection_Origin: 0.000000

False_Easting: 500000.000000

False_Northing: 0.000000

Planar_Coordinate_Information:

Planar_Coordinate_Encoding_Method: coordinate pair

Coordinate_Representation:

Abscissa_Resolution: 0.000008

Ordinate_Resolution: 0.000008

Planar_Distance_Units: meters

Geodetic_Model:

Horizontal_Datum_Name: North American Datum of 1983

Ellipsoid_Name: Geodetic Reference System 80

Semi-major_Axis: 6378137.000000

Denominator_of_Flattening_Ratio: 298.257222

Vertical_Coordinate_System_Definition:

Altitude_System_Definition:

Altitude_Resolution: 0.000001

Altitude_Encoding_Method: Explicit elevation coordinate included with horizontal coordinates

Entity_and_Attribute_Information:

Detailed_Description:

Entity_Type:

Entity_Type_Label: ap_waterlines

Attribute:

Attribute_Label: FID

Attribute_Definition: Internal feature number.

Attribute_Definition_Source: ESRI

Attribute_Domain_Values:

Unrepresentable_Domain: Sequential unique whole numbers that are automatically generated.

Attribute:

Attribute_Label: Shape

Attribute_Definition: Feature geometry.

Attribute_Definition_Source: ESRI

Attribute_Domain_Values:

Unrepresentable_Domain: Coordinates defining the features.

Attribute: 
Attribute Label: ENTITY

Attribute_Definition: This may have to do with diameter variation of the pipes.

Attribute:

Attribute Label: LAYER

Attribute_Definition: AutoCAD color assigned to pipe.

Attribute:

Attribute_Label: COLOR

Attribute_Definition: Well access number.

Attribute:

Attribute_Label: AREA_POZO

Distribution_Information:

Distributor:

Contact_Information:

Contact_Organization_Primary:

Contact_Organization: U.S. Geological Survey

Resource_Description: Downloadable Data

Distribution Liability:

The U.S. Geological Survey (USGS) provides these geographic data "as is." The USGS makes no guarantee or warranty concerning the accuracy of information contained in the geographic data. The USGS further makes no warranties, either expressed or implied, as to any other matter whatsoever, including, without limitation, the condition of the product or its fitness for any particular purpose. The burden for determining fitness for use lies entirely with the user. Although these data have been processed successfully on computers at the USGS, no warranty,

expressed or implied, is made by the USGS regarding the use of these data on any other system, nor does the fact of distribution constitute or imply any such warranty.

In no event shall the USGS have any liability whatsoever for payment of any consequential, incidental, indirect, special, or tort damages of any kind, including, but not limited to, any loss of profits arising out of use of or reliance on the geographic data or arising out of the delivery, installation, operation, or support by USGS.

Standard_Order_Process:

Digital_Form:

Digital_Transfer_Information:

Transfer_Size: 0.016

Metadata Reference Information:

Metadata_Date: 20031205

Metadata Contact:

Contact_Information:

Contact_Person_Primary:

Contact_Person: Laura M. Norman

Contact_Organization: U.S. Geological Survey

Contact_Position: Cartographer, GIS Specialist

Contact_Address:

Address_Type: mailing address

Address: 520 N Park Ave, Ste \#355

City: Tucson

State_or_Province: AZ

Postal_Code: 85719

Country: U.S.A

Contact_Voice_Telephone: 5206705510

Contact_Facsimile_Telephone: 5206705571

Contact_Electronic_Mail_Address:Imbrady@usgs.gov

Hours_of_Service: $9-5$

Metadata_Standard_Name: FGDC Content Standards for Digital Geospatial Metadata

Metadata_Standard_Version: FGDC-STD-001-1998

Metadata_Time_Convention: local time

Metadata_Access_Constraints: none 
Metadata_Use_Constraints: none

Metadata Extensions:

Online_Linkage: http://www.esri.com/metadata/esriprof80.html

Profile_Name: ESRI Metadata Profile 
Identification_Information:

Citation:

Citation_Information:

Originator: Laura M. Norman

Publication_Date: 07/03/03

Title: Floodzones in Agua Prieta, Sonora

Geospatial_Data_Presentation_Form: vector digital data

Online Linkage: http://codd.art.srnr.arizona.edu/colonias

Larger_Work_Citation:

Citation Information:

Originator: Norman, Laura M., Donelson, Angela J., Pfeifer, Edwin, Lam, Alven H., and Osborn, Kenneth J.

Publication_Date: 12/03

Title: Analyses of Urban Sprawl and Colonias Development in Douglas, Arizona \& Agua

Prieta, Sonora on the United States-Mexico Border; A Process Application using GIS and

Remote Sensing

Geospatial_Data_Presentation_Form: vector digital data

Series Information:

Series_Name: Open File Report

Issue_Identification: OFR-03-XXX

Publication_Information:

Publication Place: Menlo Park, CA

Publisher: USGS

Online_Linkage: http://wgsc.wr.usgs.gov/wrgeog_pubs/

Description:

Abstract: Data gathered for report (Comisión De Cooperación Ecológica Fronteriza

(COCEF/BECC)) was systematically translated and synthesized. AutoCAD drawings describing the floodzones in Agua Prieta, Sonora were rectified and digitized within a GIS. Geographic

features describing the Municipal of Agua Prieta were automated into the geospatial database.

Purpose: This information was automated to assist in planning in the city of Agua Prieta, Sonora.

Time_Period_of_Content:

Time_Period_Information:

Single_Date/Time:

Calendar Date: 12/03

Currentness_Reference: publication date

Status:

Progress: Complete

Maintenance_and_Update_Frequency: None planned

Spatial_Domain:

Bounding_Coordinates:

West_Bounding_Coordinate: -109.568835

East_Bounding_Coordinate: -109.512347

North_Bounding_Coordinate: 31.323972

South_Bounding_Coordinate: 31.295863

Keywords:

Theme:

Theme_Keyword_Thesaurus: none

Theme_Keyword: COCEF/BECC

Theme_Keyword: Floodzone

Place: 
Place_Keyword_Thesaurus: none

Place_Keyword: Sonora

Place_Keyword: Agua Prieta

Place_Keyword: Mexico

Use_Constraints: This digital database is not meant to be used or displayed at any scale larger than 1:24,000 (for example, 1:12,000). Any hardcopies utilizing this dataset shall clearly indicate their source. If the user has modified the data in any way, he is obligated to describe the types of modifications he has performed on the hardcopy map. User specifically agrees not to misrepresent this dataset nor to imply that changes he made were approved by the U.S.

Geological Survey.

Point_of_Contact:

Contact_Information:

Contact_Person_Primary:

Contact_Person: Laura M. Norman

Contact_Organization: U.S. Geological Survey

Contact_Position: Cartographer, GIS Specialist

Contact_Address:

Address_Type: mailing address

Address: 520 N Park Ave, Ste\#355

City: Tucson

State_or_Province: AZ

Postal_Code: 85719

Country: U.S.A

Contact_Voice_Telephone: 5206705510

Contact_Facsimile_Telephone: 5206705571

Contact_Electronic_Mail_Address: Imbrady@usgs.gov

Hours_of_Service: $9-5$

Native_Data_Set_Environment: Microsoft Windows 2000 Version 5.0 (Build 2195) Service Pack

4; ESRI ArcCatalog 8.2.0.700

Cross_Reference:

Citation_Information:

Data_Quality_Information:

Attribute_Accuracy:

Attribute_Accuracy_Report: Dataset according to AutoCAD darwings done in 1998.

Lineage:

Source_Information:

Source_Citation:

Citation_Information:

Originator: Comisión De Cooperación Ecológica Fronteriza (COCEF/BECC)

Publication_Date: 1998

Title: Agua Prieta, Sonora, Plan Maestro; Para el Mejoramiento de los Servicios de Agua

Potable, Alcantarillado y Saneamiento de la Ciudad de Agua Prieta, Son. Y Levatamiento de

Redes Hidraulicas.

Geospatial_Data_Presentation_Form: document

Other_Citation_Details: CONTA $98-023$

Source_Time_Period_of_Content:

Time_Period_Information:

Single_Date/Time:

Calendar_Date: unknown

Source_Currentness_Reference: ground condition

Process_Step:

Process_Description: AutoCAD drawings of floodzones in Agua Prieta were rectified in

ArcView 3.3 using world files that were created according to known bounding coordinates. The data were exported into ArcGIS for processing. In ArcPlot coverages were generated utilizing drawing layers from AutoCAD created previously by COCEF/BECC in the master plan of the city. Coverages were exported to ArcEdit, cleaned and built. And in ArcINFO exported to shapefiles. 
Process Date: 05/03

Spatial Data Organization Information:

Direct_Spatial_Reference_Method: Vector

Point_and_Vector_Object_Information:

SDTS_Terms_Description:

SDTS_Point_and_Vector_Object_Type: String

Point_and_Vector_Object_Count: 45

Spatial_Reference_Information:

Horizontal_Coordinate_System_Definition:

Planar:

Grid_Coordinate_System:

Grid_Coordinate_System_Name: Universal Transverse Mercator

Universal_Transverse_Mercator:

UTM_Zone_Number: 12

Transverse_Mercator:

Scale_Factor_at_Central_Meridian: 0.999600

Longitude_of_Central_Meridian: -111.000000

Latitude_of_Projection_Origin: 0.000000

False_Easting: 500000.000000

False_Northing: 0.000000

Planar_Coordinate_Information:

Planar_Coordinate_Encoding_Method: coordinate pair

Coordinate_Representation:

Abscissa_Resolution: 0.000008

Ordinate_Resolution: 0.000008

Planar_Distance_Units: meters

Geodetic_Model:

Horizontal_Datum_Name: North American Datum of 1983

Ellipsoid_Name: Geodetic Reference System 80

Semi-major_Axis: 6378137.000000

Denominator_of_Flattening_Ratio: 298.257222

Vertical_Coordinate_System_Definition:

Altitude_System_Definition:

Altitude Resolution: 0.000001

Altitude_Encoding_Method: Explicit elevation coordinate included with horizontal coordinates

Entity_and_Attribute_Information:

Detailed_Description:

Entity_Type:

Entity_Type_Label: ap_floodzone

Attribute:

Attribute Label: FID

Attribute_Definition: Internal feature number.

Attribute_Definition_Source: ESRI

Attribute_Domain_Values:

Unrepresentable_Domain: Sequential unique whole numbers that are automatically generated.

Attribute:

Attribute_Label: Shape

Attribute_Definition: Feature geometry.

Attribute_Definition_Source: ESRI

Attribute_Domain_Values:

Unrepresentable_Domain: Coordinates defining the features.

Attribute:

Attribute_Label: ENTITY

Attribute:

Attribute_Label: LAYER 
Attribute_Definition: Describes flood (INUNDATION) zones

Attribute:

Attribute_Label: COLOR

Attribute_Definition: That AutoCAD color assigned to floodzones.

Distribution_Information:

Distributor:

Contact_Information:

Contact_Organization_Primary:

Contact_Organization: U.S. Geological Survey

Resource_Description: Downloadable Data

Distribution_Liability: The U.S. Geological Survey (USGS) provides these geographic data "as is." The USGS makes no guarantee or warranty concerning the accuracy of information contained in the geographic data. The USGS further makes no warranties, either expressed or implied, as to any other matter whatsoever, including, without limitation, the condition of the product or its fitness for any particular purpose. The burden for determining fitness for use lies entirely with the user. Although these data have been processed successfully on computers at the USGS, no warranty, expressed or implied, is made by the USGS regarding the use of these data on any other system, nor does the fact of distribution constitute or imply any such warranty. In no event shall the USGS have any liability whatsoever for payment of any consequential, incidental, indirect, special, or tort damages of any kind, including, but not limited to, any loss of profits arising out of use of or reliance on the geographic data or arising out of the delivery, installation, operation, or support by USGS.

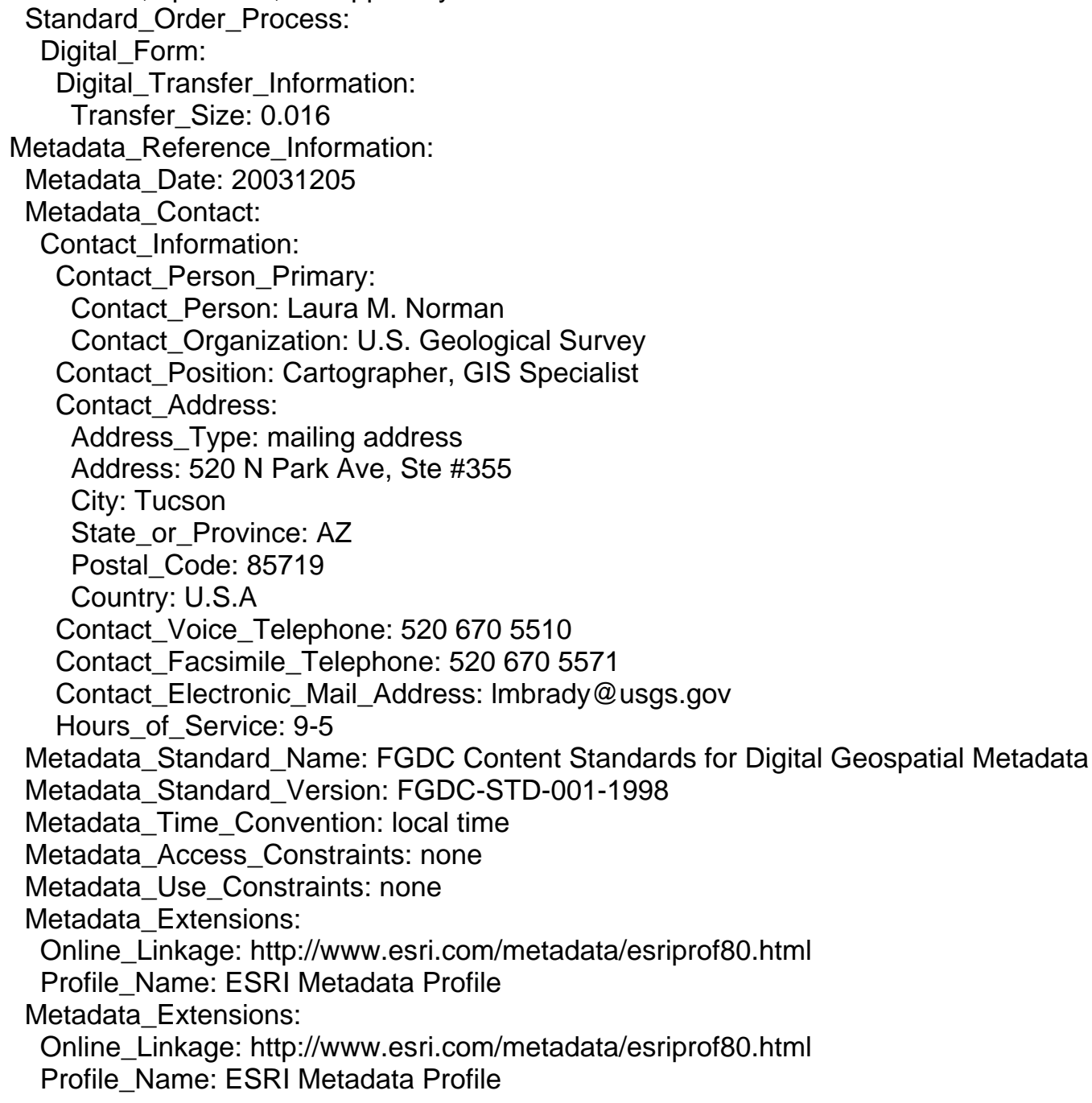


Identification_Information:

Citation:

Citation Information:

Originator: Laura M. Norman

Publication_Date: 12/03

Title: Sewerlines in Agua Prieta, Sonora

Geospatial_Data_Presentation_Form: vector digital data

Online Linkage: http://codd.art.srnr.arizona.edu/colonias

Larger_Work_Citation:

Citation Information:

Originator: Norman, Laura M., Donelson, Angela J., Pfeifer, Edwin, Lam, Alven H., and Osborn, Kenneth J.

Publication_Date: 12/03

Title: Analyses of Urban Sprawl and Colonias Development in Douglas, Arizona \& Agua

Prieta, Sonora on the United States-Mexico Border; A Process Application using GIS and

Remote Sensing

Geospatial_Data_Presentation_Form: vector digital data

Series Information:

Series_Name: Open File Report

Issue_Identification: OFR-03-XXX

Publication_Information:

Publication_Place: Menlo Park, CA

Publisher: USGS

Online_Linkage: <http://wgsc.wr.usgs.gov/wrgeog_pubs/>

Description:

Abstract: Data gathered for report (Comisión De Cooperación Ecológica Fronteriza

(COCEF/BECC)) was systematically translated and synthesized. AutoCAD drawings describing the sewerlines in Agua Prieta, Sonora were rectified and digitized within a GIS. Geographic

features describing the Municipal of Agua Prieta were automated into the geospatial database.

Purpose: The map of sewerlines was used to help define colonias.

Time_Period_of_Content:

Time_Period_Information:

Single_Date/Time:

Calendar_Date: 12/03

Currentness_Reference: publication date

Status:

Progress: Complete

Maintenance_and_Update_Frequency: None planned

Spatial_Domain:

Bounding_Coordinates:

West_Bounding_Coordinate: -109.571534

East_Bounding_Coordinate: -109.497212

North_Bounding_Coordinate: 31.334142

South_Bounding_Coordinate: 31.296728

Keywords:

Theme:

Theme_Keyword_Thesaurus: none

Theme_Keyword: Infrastructure

Theme_Keyword: COCEF/BECC

Theme_Keyword: sewerlines

Place: 
Place_Keyword_Thesaurus: none

Place_Keyword: Agua Preita

Place_Keyword: Sonora

Place_Keyword: Mexico

Use_Constraints: This digital database is not meant to be used or displayed at any scale larger than 1:24,000 (for example, 1:12,000). Any hardcopies utilizing this dataset shall clearly indicate their source. If the user has modified the data in any way, he is obligated to describe the types of modifications he has performed on the hardcopy map. User specifically agrees not to misrepresent this dataset nor to imply that changes he made were approved by the U.S.

Geological Survey.

Point_of_Contact:

Contact_Information:

Contact_Person_Primary:

Contact_Person: Laura M. Norman

Contact_Organization: U.S. Geological Survey

Contact_Position: Cartographer, GIS Specialist

Contact_Address:

Address_Type: mailing address

Address: 520 N Park Ave, Ste \#355

City: Tucson

State_or_Province: AZ

Postal_Code: 85719

Country: U.S.A

Contact_Voice_Telephone: 5206705510

Contact_Facsimile_Telephone: 5206705571

Contact_Electronic_Mail_Address: Imbrady@usgs.gov

Hours_of_Service: $9-5$

Native_Data_Set_Environment: Microsoft Windows 2000 Version 5.0 (Build 2195) Service Pack

4; ESRI ArcCatalog 8.2.0.700

Cross_Reference:

Citation_Information:

Data_Quality_Information:

Attribute_Accuracy:

Attribute_Accuracy_Report: Accuracy dependant on AutoCAD drawings from 1998.

Lineage:

Source_Information:

Source_Citation:

Citation_Information:

Originator: Comisión De Cooperación Ecológica Fronteriza (COCEF/BECC)

Publication_Date: 1998

Title: Agua Prieta, Sonora, Plan Maestro; Para el Mejoramiento de los Servicios de Agua

Potable, Alcantarillado y Saneamiento de la Ciudad de Agua Prieta, Son. Y Levatamiento de

Redes Hidraulicas.

Geospatial_Data_Presentation_Form: document

Other_Citation_Details: CONTA $98-023$

Source_Time_Period_of_Content:

Time_Period_Information:

Single_Date/Time:

Calendar_Date: 1998

Source_Currentness_Reference: ground condition

Process_Step:

Process_Description: AutoCAD drawings of sewerlines in Agua Prieta, Sonora were rectified in ArcView 3.3 using world files that were created according to known bounding coordinates. The data were exported into ArcGIS for processing. In ArcPlot coverages were generated utilizing drawing layers from AutoCAD created previously by COCEF/BECC in the master plan of the city. Coverages were exported to ArcEdit, cleaned and built. And in ArcINFO exported to shapefiles. 
Process Date: 05/03

Spatial Data Organization Information:

Direct_Spatial_Reference_Method: Vector

Point_and_Vector_Object_Information:

SDTS_Terms_Description:

SDTS_Point_and_Vector_Object_Type: String

Point_and_Vector_Object_Count: 57

Spatial_Reference_Information:

Horizontal_Coordinate_System_Definition:

Planar:

Grid_Coordinate_System:

Grid_Coordinate_System_Name: Universal Transverse Mercator

Universal_Transverse_Mercator:

UTM_Zone_Number: 12

Transverse_Mercator:

Scale_Factor_at_Central_Meridian: 0.999600

Longitude_of_Central_Meridian: -111.000000

Latitude_of_Projection_Origin: 0.000000

False_Easting: 500000.000000

False_Northing: 0.000000

Planar_Coordinate_Information:

Planar_Coordinate_Encoding_Method: coordinate pair

Coordinate_Representation:

Abscissa_Resolution: 0.000016

Ordinate_Resolution: 0.000016

Planar_Distance_Units: meters

Geodetic_Model:

Horizontal_Datum_Name: North American Datum of 1983

Ellipsoid_Name: Geodetic Reference System 80

Semi-major_Axis: 6378137.000000

Denominator_of_Flattening_Ratio: 298.257222

Vertical_Coordinate_System_Definition:

Altitude_System_Definition:

Altitude Resolution: 0.000001

Altitude_Encoding_Method: Explicit elevation coordinate included with horizontal coordinates

Entity_and_Attribute_Information:

Detailed_Description:

Entity_Type:

Entity_Type_Label: ap_sewerlines

Attribute:

Attribute_Label: FID

Attribute_Definition: Internal feature number.

Attribute_Definition_Source: ESRI

Attribute_Domain_Values:

Unrepresentable_Domain: Sequential unique whole numbers that are automatically generated.

Attribute:

Attribute_Label: Shape

Attribute_Definition: Feature geometry.

Attribute_Definition_Source: ESRI

Attribute_Domain_Values:

Unrepresentable_Domain: Coordinates defining the features.

Attribute:

Attribute_Label: ENTITY

Attribute:

Attribute_Label: LAYER 
Attribute_Definition: This may have to do with the diameter of the pipes.

Attribute:

Attribute_Label: COLOR

Attribute_Definition: This is the color assigned to the attribute for AutoCAD drawings.

Distribution_Information:

Distributor:

Contact_Information:

Contact_Organization_Primary:

Contact_Organization: U.S. Geological Survey

Resource_Description: Downloadable Data

Distribution_Liability: The U.S. Geological Survey (USGS) provides these geographic data "as is." The USGS makes no guarantee or warranty concerning the accuracy of information contained in the geographic data. The USGS further makes no warranties, either expressed or implied, as to any other matter whatsoever, including, without limitation, the condition of the product or its fitness for any particular purpose. The burden for determining fitness for use lies entirely with the user. Although these data have been processed successfully on computers at the USGS, no warranty, expressed or implied, is made by the USGS regarding the use of these data on any other system, nor does the fact of distribution constitute or imply any such warranty. In no event shall the USGS have any liability whatsoever for payment of any consequential, incidental, indirect, special, or tort damages of any kind, including, but not limited to, any loss of profits arising out of use of or reliance on the geographic data or arising out of the delivery, installation, operation, or support by USGS.

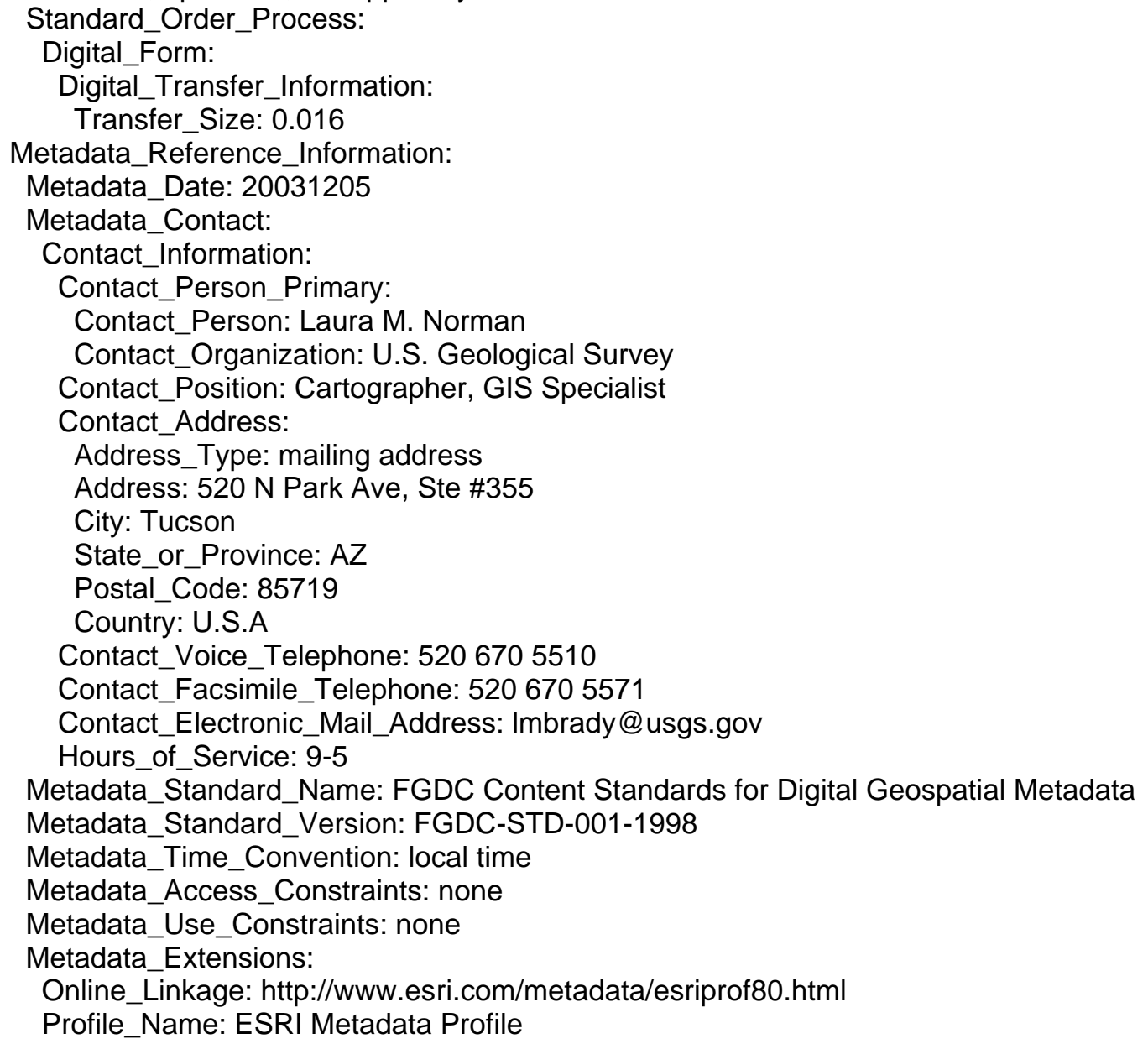




\author{
Wells in Agua Prieta, Sonora \\ Identification_Information: \\ Citation: \\ Citation_Information: \\ Originator: Laura M. Norman \\ Publication_Date: 12/03 \\ Title: Wells in Agua Prieta, Sonora \\ Geospatial_Data_Presentation_Form: vector digital data \\ Online Linkage: http://codd.art.srnr.arizona.edu/colonias \\ Larger_Work_Citation: \\ Citation_Information: \\ Originator: Norman, Laura M., Donelson, Angela J., Pfeifer, Edwin, Lam, Alven H., and
}

Osborn, Kenneth J.

Publication Date: 12/03

Title: Analyses of Urban Sprawl and Colonias Development in Douglas, Arizona \& Agua

Prieta, Sonora on the United States-Mexico Border; A Process Application using GIS and

Remote Sensing

Geospatial_Data_Presentation_Form: vector digital data

Series_Information:

Series_Name: Open File Report

Issue_Identification: OFR-03-XXX

Publication_Information:

Publication_Place: Menlo Park, CA

Publisher: USGS

Online_Linkage: <http://wgsc.wr.usgs.gov/wrgeog_pubs/>

Description:

Abstract: Data gathered for report (Comisión De Cooperación Ecológica Fronteriza

(COCEF/BECC)) was systematically translated and synthesized. AutoCAD drawings describing the wells in Agua Prieta, Sonora were rectified and digitized within a GIS. Geographic features describing the Municipal of Agua Prieta were automated into the geospatial database.

Purpose: The process was necessary to create real-time maps of the city's infrastructure for colonias designation.

Time_Period_of_Content:

Time_Period_Information:

Single_Date/Time:

Calendar_Date: unknown

Currentness_Reference: publication date

Status:

Progress: Complete

Maintenance_and_Update_Frequency: None planned

Spatial_Domain:

Bounding_Coordinates:

West_Bounding_Coordinate: -109.549092

East_Bounding_Coordinate: -109.521078

North_Bounding_Coordinate: 31.333764

South_Bounding_Coordinate: 31.306057

Keywords:

Theme:

Theme_Keyword_Thesaurus: none

Theme_Keyword: Infrastructure

Theme_Keyword: COCEF/BECC

Theme_Keyword: Wells

Place: 
Place_Keyword_Thesaurus: none

Place_Keyword: Agua Prieta

Place_Keyword: Sonora

Place_Keyword: Mexico

Use_Constraints: This digital database is not meant to be used or displayed at any scale larger than 1:24,000 (for example, 1:12,000). Any hardcopies utilizing this dataset shall clearly indicate their source. If the user has modified the data in any way, he is obligated to describe the types of modifications he has performed on the hardcopy map. User specifically agrees not to misrepresent this dataset nor to imply that changes he made were approved by the U.S.

Geological Survey.

Point_of_Contact:

Contact_Information:

Contact_Person_Primary:

Contact_Person: Laura M. Norman

Contact_Organization: U.S. Geological Survey

Contact_Position: Cartographer, GIS Specialist

Contact_Address:

Address_Type: mailing address

Address: 520 N Park Ave, Ste \#355

City: Tucson

State_or_Province: AZ

Postal_Code: 85719

Country: U.S.A

Contact_Voice_Telephone: 5206705510

Contact_Facsimile_Telephone: 5206705571

Contact_Electronic_Mail_Address: Imbrady@usgs.gov

Hours_of_Service: $9-5$

Native_Data_Set_Environment: Microsoft Windows 2000 Version 5.0 (Build 2195) Service Pack

4; ESRI ArcCatalog 8.2.0.700

Cross_Reference:

Citation_Information:

Data_Quality_Information:

Attribute_Accuracy:

Attribute Accuracy Report: Localities were assigned in AutoCAD in 1998.

Completeness_Report: These wells are those that were represented in the cited document. It is not known if other wells exist.

Lineage:

Source_Information:

Source_Citation:

Citation_Information:

Originator: Comisión De Cooperación Ecológica Fronteriza (COCEF/BECC)

Publication_Date: 1998

Title: Agua Prieta, Sonora, Plan Maestro; Para el Mejoramiento de los Servicios de Agua

Potable, Alcantarillado y Saneamiento de la Ciudad de Agua Prieta, Son. Y Levatamiento de Redes Hidraulicas.

Geospatial_Data_Presentation_Form: document

Other_Citation_Details: CONTA $98-023$

Source_Time_Period_of_Content:

Time_Period_Information:

Single_Date/Time:

Calendar_Date: unknown

Source_Currentness_Reference: ground condition

Process Step:

Process_Description: AutoCAD drawings of well locations in Agua Prieta, Sonora were rectified in ArcView 3.3 using world files that were created according to known bounding coordinates. The data was then exported into ArcGIS for processing. In ArcPlot coverages were 
generated utilizing drawing layers from AutoCAD created previously by COCEF/BECC in the master plan of the city. Coverages were exported to ArcEdit, cleaned and built. And in ArcINFO exported to shapefiles.

Process_Date: 05/03

Spatial_Data_Organization_Information:

Direct_Spatial_Reference_Method: Vector

Point_and_Vector_Object_Information:

SDTS Terms Description:

SDTS_Point_and_Vector_Object_Type: Entity point

Point_and_Vector_Object_Count: 11

Spatial_Reference_Information:

Horizontal_Coordinate_System_Definition:

Planar:

Grid_Coordinate_System:

Grid_Coordinate_System_Name: Universal Transverse Mercator

Universal_Transverse_Mercator:

UTM_Zone_Number: 12

Transverse_Mercator:

Scale_Factor_at_Central_Meridian: 0.999600

Longitude_of_Central_Meridian: -111.000000

Latitude_of_Projection_Origin: 0.000000

False_Easting: 500000.000000

False_Northing: 0.000000

Planar_Coordinate_Information:

Planar_Coordinate_Encoding_Method: coordinate pair

Coordinate_Representation:

Abscissa_Resolution: 0.000008

Ordinate_Resolution: 0.000008

Planar_Distance_Units: meters

Geodetic_Model:

Horizontal_Datum_Name: North American Datum of 1983

Ellipsoid_Name: Geodetic Reference System 80

Semi-major_Axis: 6378137.000000

Denominator_of_Flattening_Ratio: 298.257222

Vertical_Coordinate_System_Definition:

Altitude_System_Definition:

Altitude_Resolution: 0.000001

Altitude_Encoding_Method: Explicit elevation coordinate included with horizontal coordinates

Entity_and_Attribute_Information:

Detailed_Description:

Entity_Type:

Entity_Type_Label: ap_wells

Attribute:

Attribute_Label: FID

Attribute_Definition: Internal feature number.

Attribute_Definition_Source: ESRI

Attribute_Domain_Values:

Unrepresentable_Domain: Sequential unique whole numbers that are automatically generated.

Attribute:

Attribute_Label: Shape

Attribute_Definition: Feature geometry.

Attribute_Definition_Source: ESRI

Attribute_Domain_Values:

Unrepresentable_Domain: Coordinates defining the features.

Attribute: 
Attribute_Label: ID

Distribution Information:

Distributor:

Contact_Information:

Contact_Organization_Primary:

Contact_Organization: U.S. Geological Survey

Resource_Description: Downloadable Data

Distribution_Liability: The U.S. Geological Survey (USGS) provides these geographic data "as is." The USGS makes no guarantee or warranty concerning the accuracy of information contained in the geographic data. The USGS further makes no warranties, either expressed or implied, as to any other matter whatsoever, including, without limitation, the condition of the product or its fitness for any particular purpose. The burden for determining fitness for use lies entirely with the user. Although these data have been processed successfully on computers at the USGS, no warranty, expressed or implied, is made by the USGS regarding the use of these data on any other system, nor does the fact of distribution constitute or imply any such warranty. In no event shall the USGS have any liability whatsoever for payment of any consequential, incidental, indirect, special, or tort damages of any kind, including, but not limited to, any loss of profits arising out of use of or reliance on the geographic data or arising out of the delivery, installation, operation, or support by USGS.

Standard_Order_Process:

Digital_Form:

Digital_Transfer_Information:

Transfer Size: 0.016

Metadata_Reference_Information:

Metadata_Date: 20031205

Metadata_Contact:

Contact_Information:

Contact_Person_Primary:

Contact_Person: Laura M. Norman

Contact_Organization: U.S. Geological Survey

Contact_Position: Cartographer, GIS Specialist

Contact_Address:

Address_Type: mailing address

Address: 520 N Park Ave, Ste \#355

City: Tucson

State or Province: AZ

Postal_Code: 85719

Country: U.S.A

Contact_Voice_Telephone: 5206705510

Contact_Facsimile_Telephone: 5206705571

Contact_Electronic_Mail_Address: Imbrady@usgs.gov

Hours_of_Service: $9-5$

Metadata_Standard_Name: FGDC Content Standards for Digital Geospatial Metadata

Metadata_Standard_Version: FGDC-STD-001-1998

Metadata_Time_Convention: local time

Metadata_Access_Constraints: none

Metadata_Use_Constraints: none

Metadata Extensions:

Online_Linkage: http://www.esri.com/metadata/esriprof80.html

Profile_Name: ESRI Metadata Profile 


\section{Colonias in Douglas, Ariz.}

Identification_Information:

Citation:

Citation_Information:

Originator: Laura M. Norman

Publication_Date: 12/03

Title: Colonias in Douglas, AZ

Geospatial_Data_Presentation_Form: vector digital data

Online Linkage: http://codd.art.srnr.arizona.edu/colonias

Larger_Work_Citation:

Citation_Information:

Originator: Norman, Laura M., Donelson, Angela J., Pfeifer, Edwin, Lam, Alven H., and

Osborn, Kenneth J.

Publication Date: 12/03

Title: Analyses of Urban Sprawl and Colonias Development in Douglas, Arizona \& Agua

Prieta, Sonora on the U.S.-Mexico Border; A Process Application using GIS and Remote Sensing

Geospatial_Data_Presentation_Form: vector digital data

Series_Information:

Series_Name: Open File Report

Issue_Identification: OFR-03-XXX

Publication_Information:

Publication_Place: Menlo Park, CA

Publisher: USGS

Online_Linkage: <http://wgsc.wr.usgs.gov/wrgeog_pubs/>

Description:

Abstract: A suitability/ capability analysis (SCA) was implemented based on the housing and infrastructure suitability and/or capability of given areas to support colonias in Douglas, AZ. The City of Douglas, Public Works Department used these newly automated sewer lines and water lines in collaboration with street maps to pinpoint known colonia boundaries. It was recorded in the city office that the 'suggested' boundaries be included in this project according to complaints and pleas for assistance from those neighborhoods to install new infrastructure.

Purpose: Colonias designation was done in Douglas, AZ to identify colonias-like neighborhoods in the area to make those neighborhoods recognizable to apply for funding.

Time_Period_of_Content:

Time_Periō_Information:

Single_Date/Time:

Currentness_Reference: 2003

Status:

Progress: Complete

Maintenance_and_Update_Frequency: None planned

Spatial_Domain:

Bounding_Coordinates:

West_Bounding_Coordinate: -109.568835

East_Bounding_Coordinate: -109.512347

North_Bounding_Coordinate: 31.378782

South_Bounding_Coordinate: 31.295863

Keywords:

Theme:

Theme_Keyword_Thesaurus: none

Theme_Keyword: Colonias

Place:

Place_Keyword_Thesaurus: none

Place_Keyword: Douglas 
Place_Keyword: Arizona

Use_Constraints: This digital database is not meant to be used or displayed at any scale larger than $\overline{1}: 24,000$ (for example, 1:12,000). Any hardcopies utilizing this dataset shall clearly indicate their source. If the user has modified the data in any way, he is obligated to describe the types of modifications he has performed on the hardcopy map. User specifically agrees not to misrepresent this dataset nor to imply that changes he made were approved by the U.S.

Geological Survey.

Point_of_Contact:

Contact_Information:

Contact_Person_Primary:

Contact_Person: Laura M. Norman

Contact_Organization: U.S. Geological Survey

Contact_Position: Cartographer, GIS Specialist

Contact_Address:

Address_Type: mailing address

Address: 520 N Park Ave, Ste \#355

City: Tucson

State_or_Province: AZ

Postal_Code: 85719

Country: U.S.A

Contact_Voice_Telephone: 5206705510

Contact_Facsimile_Telephone: 5206705571

Contact_Electronic_Mail_Address:Imbrady@usgs.gov

Hours_of_Service: 9-5

Data_Set_Credit: Chuck Ebner (City of Douglas - Department of Public Works, Assistant

Director), Rosael Torres (City of Douglas-Housing Authority), Carlos de la Torre (City of Douglas Department of Public Works, Director), Carol Huddleston (head of Turning Point, a non-profit local organization) identified the poorest neighborhoods to call "colonias" for this project.

Native_Data_Set_Environment: Microsoft Windows 2000 Version 5.0 (Build 2195) Service Pack 4; ESRI ArcCatalog 8.2.0.700

Cross_Reference:

Citation_Information:

Publication_Information:

Larger_Work_Citation:

Citation_Information:

Publication_Information:

Publication_Place: USGS

Data_Quality_Information:

Attribute_Accuracy:

Attribute_Accuracy_Report: While the boundaries are thought to be most accurate according to the people who were involved in their deliniation, there were no legal boundaries used to define the colonias dataset.

Completeness_Report: Only those neighborhoods that were deemed colonias by the

participants were incorporated in this dataset.

Lineage:

Source_Information:

Source_Citation:

Citation_Information:

Source_Time_Period_of_Content:

Time_Period_Information:

Single_Date/Time:

Process_Step:

Process_Description: Local representatives were asked to draw boundaries on hard copy print out maps describing the roads, sewer, and water infrastructure overlain on aerial photos of their community. These approximations were based upon previous knowledge and familiarity 
with the most impoverished and underprivileged areas known to them at that time. These

polygons boundaries were then digitized and attributed.

Process_Date: 06/03

Spatial_Data_Organization_Information:

Direct_Spatial_Reference_Method: Vector

Point_and_Vector_Object_Information:

SDTS_Terms_Description:

SDTS_Point_and_Vector_Object_Type: G-polygon

Point_and_Vector_Object_Count: 9

Spatial_Reference_Information:

Horizontal_Coordinate_System_Definition:

Planar:

Grid_Coordinate_System:

Grid_Coordinate__System_Name: Universal Transverse Mercator

Universal_Transverse_Mercator:

UTM_Zone_Number: 12

Transverse Mercator:

Scale_Factor_at_Central_Meridian: 0.999600

Longitude_of_Central_Meridian: -111.000000

Latitude_of_Projection_Origin: 0.000000

False_Easting: 500000.000000

False_Northing: 0.000000

Planar_Coordinate_Information:

Planar_Coordinate_Encoding_Method: coordinate pair

Coordinate_Representation:

Abscissa_Resolution: 0.000016

Ordinate_Resolution: 0.000016

Planar_Distance_Units: meters

Geodetic_Model:

Horizontal_Datum_Name: North American Datum of 1983

Ellipsoid_Name: Geodetic Reference System 80

Semi-major_Axis: 6378137.000000

Denominator_of_Flattening_Ratio: 298.257222

Entity_and_Attribute_Information:

Detailed_Description:

Entity_Type:

Entity_Type_Label: Colonias

Entity_Type_Definition: Colonias were defined by the Cranston-Gonzales Act of 1990 as rural communities and neighborhoods located within 150 miles of the United States-Mexican border. Some colonias may be entire border communities, while others are comprised of neighborhoods within incorporated communities. They lack adequate infrastructure (sewer or water lines) and/or housing.

Entity_Type_Definition_Source: http://www.hud.gov/groups/frmwrkcoln/whatcol.cfm

Attribute:

Attribute_Label: FID

Attribute_Definition: Internal feature number.

Attribute_Definition_Source: ESRI

Attribute_Domain_Values:

Unrepresentable_Domain: Sequential unique whole numbers that are automatically generated.

Attribute:

Attribute_Label: Shape

Attribute_Definition: Feature geometry.

Attribute_Definition_Source: ESRI

Attribute_Domain_Values:

Unrepresentable_Domain: Coordinates defining the features. 
Attribute:

Attribute_Label: ID

Attribute:

Attribute_Label: NAME

Attribute_Definition: Name of colonia

Attribute:

Attribute_Label: AREA

Attribute_Definition: Area of polygon (Square meters)

Attribute:

Attribute_Label: POP2000

Attribute_Definition: Population according to sum of U.S. Census 2000 Blocks within boundaries.

Distribution_Information:

Distributor:

Contact_Information:

Contact_Organization_Primary:

Contact_Organization: U.S. Geological Survey

Resource_Description: Downloadable Data

Distribution_Liability:

The U.S. Geological Survey (USGS) provides these geographic data "as is." The USGS makes no guarantee or warranty concerning the accuracy of information contained in the geographic data. The USGS further makes no warranties, either expressed or implied, as to any other matter whatsoever, including, without limitation, the condition of the product or its fitness for any particular purpose. The burden for determining fitness for use lies entirely with the user. Although these data have been processed successfully on computers at the USGS, no warranty, expressed or implied, is made by the USGS regarding the use of these data on any other system, nor does the fact of distribution constitute or imply any such warranty.

In no event shall the USGS have any liability whatsoever for payment of any consequential, incidental, indirect, special, or tort damages of any kind, including, but not limited to, any loss of profits arising out of use of or reliance on the geographic data or arising out of the delivery, installation, operation, or support by USGS.

Standard_Order_Process:

Digital Form:

Digital_Transfer_Information:

Transfer Size: 0.016

Metadata_Reference_Information:

Metadata_Date: 20031205

Metadata_Contact:

Contact_Information:

Contact_Person_Primary:

Contact_Person: Laura M. Norman

Contact_Organization: U.S. Geological Survey

Contact_Position: Cartographer, GIS Specialist

Contact_Address:

Address_Type: mailing address

Address: 520 N Park Ave, Ste \#355

City: Tucson

State_or_Province: AZ

Postal_Code: 85719

Country: U.S.A

Contact_Voice_Telephone: 5206705510

Contact_Facsimile_Telephone: 5206705571

Contact_Electronic_Mail_Address: Imbrady@usgs.gov

Hours_of_Service: $9-5$

Metadata_Standard_Name: FGDC Content Standards for Digital Geospatial Metadata 
Metadata_Standard_Version: FGDC-STD-001-1998

Metadata_Time_Convention: local time

Metadata_Access_Constraints: none

Metadata_Use_Constraints: none

Metadata_Extensions:

Online_Linkage: http://www.esri.com/metadata/esriprof80.html

Profile_Name: ESRI Metadata Profile 
Sewerlines- Douglas, Ariz.

Identification_Information:

Citation:

Citation_Information:

Originator: Laura M. Norman

Publication_Date: 12/03

Title: Sewerlines in Douglas, AZ

Geospatial_Data_Presentation_Form: vector digital data

Online Linkage: http://codd.art.srnr.arizona.edu/colonias

Larger_Work_Citation:

Citation Information:

Originator: Norman, Laura M., Donelson, Angela J., Pfeifer, Edwin, Lam, Alven H., and

Osborn, Kenneth J.

Publication_Date: 12/03

Title: Analyses of Urban Sprawl and Colonias Development in Douglas, Arizona \& Agua

Prieta, Sonora on the U.S.-Mexico Border; A Process Application using GIS and Remote Sensing

Geospatial_Data_Presentation_Form: vector digital data

Series_Information:

Series_Name: Open File Report

Issue_Identification: OFR-03-XXX

Publication_Information:

Publication_Place: Menlo Park, CA

Publisher: USGS

Online_Linkage: http://wgsc.wr.usgs.gov/wrgeog_pubs/

Description:

Abstract: This shapefile of sewerlines in Douglas, AZ was taken from infrastructure data from the City of Douglas Public Works Department's AutoCAD drawings in relation to street maps

Purpose: The was done to aid in the delineation of neighborhood style colonias that exist within the city itself.

Time_Period_of_Content:

Time_Period_Information:

Single Date/Time:

Currentness_Reference: 2003

Status:

Progress: Complete

Maintenance_and_Update_Frequency: None planned

Spatial_Domain:

Bounding Coordinates:

West_Bounding_Coordinate: -109.568835

East_Bounding_Coordinate: -109.512347

North_Bounding_Coordinate: 31.378782

South_Bounding_Coordinate: 31.295863

Keywords:

Theme:

Theme_Keyword_Thesaurus: none

Theme_Keyword: Sewerlines

Theme_Keyword: Infrastructure

Place:

Place_Keyword_Thesaurus: none

Place_Keyword: Douglas

Place_Keyword: Arizona

Stratum: 
Temporal:

Use_Constraints: This digital database is not meant to be used or displayed at any scale larger than $\overline{1}: 24,000$ (for example, 1:12,000). Any hardcopies utilizing this dataset shall clearly indicate their source. If the user has modified the data in any way, he is obligated to describe the types of modifications he has performed on the hardcopy map. User specifically agrees not to misrepresent this dataset nor to imply that changes he made were approved by the U.S.

Geological Survey.

Point_of_Contact:

Contact_Information:

Contact_Person_Primary:

Contact_Person: Laura M. Norman

Contact_Organization: U.S. Geological Survey

Contact_Position: Cartographer, GIS Specialist

Contact_Address:

Address_Type: mailing address

Address: 520 N Park Ave, Ste \#355

City: Tucson

State_or_Province: AZ

Postal_Code: 85719

Country: U.S.A

Contact_Voice_Telephone: 5206705510

Contact_Facsimile_Telephone: 5206705571

Contact_Electronic_Mail_Address:Imbrady@usgs.gov

Hours_of_Service: 9-5

Native_Data_Set_Environment: Microsoft Windows 2000 Version 5.0 (Build 2195) Service Pack

4; ESRI ArcCatalog 8.2.0.700

Cross Reference:

Citation Information:

Publication_Information:

Larger_Work_Citation:

Citation_Information:

Publication_Information:

Publication_Place: USGS

Data_Quality_Information:

Attribute_Accuracy:

Attribute_Accuracy_Report: The sewerlines were digitized by means of dead reckoning and are only as good as those AutoCAD drawings they were digitized from, and may contain errors in this process.

Completeness_Report: This dataset represents sewerlines as described by the Dept of Public Works for the City of Douglas in 2003.

Lineage:

Source_Information:

Source_Citation:

Citation_Information:

Source_Time_Period_of_Content:

Time_Period_Information:

Single_Date/Time:

Calendar_Date: 06/06/1985

Source_Currentness_Reference: ground condition

Process_Step:

Process_Description: These data were automated through the means of dead reckoning in

Arc View $3 . \overline{3}$, by heads up digitizing the CAD drawings onto DOQQ's, with known street lines overlain

Process_Date: 05/03

Spatial_Data_Organization_Information:

Direct_Spatial_Reference_Method: Vector 


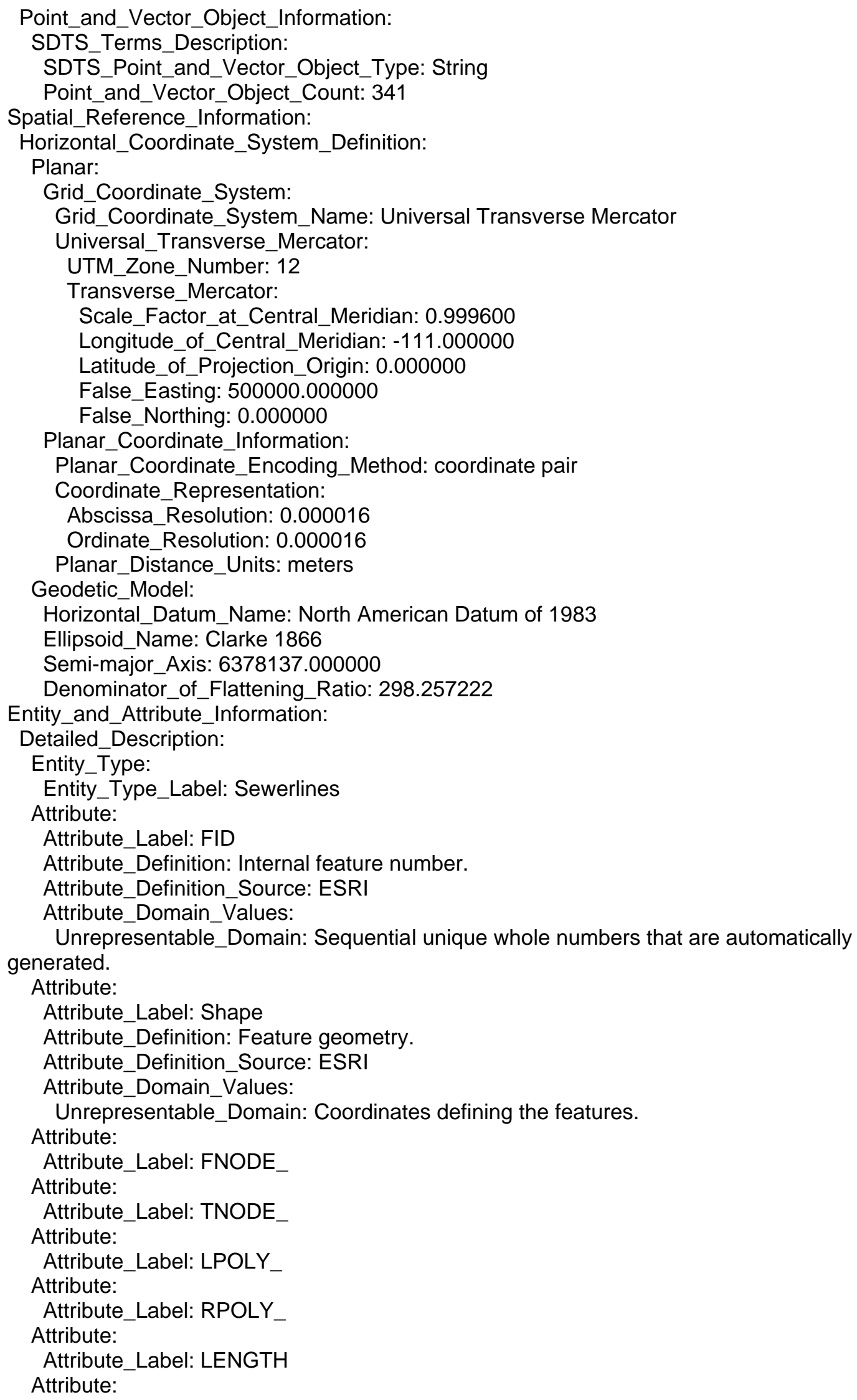


Attribute_Label: SEWER1

Attribute:

Attribute_Label: SEWER1_ID

Attribute:

Attribute_Label: NUMBER

Attribute_Definition: Number assigned to AutoCAD color

Attribute:

Attribute_Label: DIAMETER

Attribute_Definition: Pipeline diameter (inches)

Distribution_Information:

Distributor:

Contact_Information:

Contact_Organization_Primary:

Contact_Organization: U.S. Geological Survey

Resource_Description: Downloadable Data

Distribution_Liability:

The U.S. Geological Survey (USGS) provides these geographic data "as is." The USGS makes no guarantee or warranty concerning the accuracy of information contained in the geographic data. The USGS further makes no warranties, either expressed or implied, as to any other matter whatsoever, including, without limitation, the condition of the product or its fitness for any particular purpose. The burden for determining fitness for use lies entirely with the user. Although these data have been processed successfully on computers at the USGS, no warranty, expressed or implied, is made by the USGS regarding the use of these data on any other system, nor does the fact of distribution constitute or imply any such warranty.

In no event shall the USGS have any liability whatsoever for payment of any consequential, incidental, indirect, special, or tort damages of any kind, including, but not limited to, any loss of profits arising out of use of or reliance on the geographic data or arising out of the delivery, installation, operation, or support by USGS.

Standard_Order_Process:

Digital_Form:

Digital_Transfer_Information:

Transfer_Size: 0.016

Metadata_Reference_Information:

Metadata_Date: 20031205

Metadata Contact:

Contact_Information:

Contact_Person_Primary:

Contact_Person: Laura M. Norman

Contact_Organization: U.S. Geological Survey

Contact_Position: Cartographer, GIS Specialist

Contact_Address:

Address_Type: mailing address

Address: 520 N Park Ave, Ste \#355

City: Tucson

State_or_Province: AZ

Postal_Code: 85719

Country: U.S.A

Contact_Voice_Telephone: 5206705510

Contact_Facsimile_Telephone: 5206705571

Contact_Electronic_Mail_Address: Imbrady@usgs.gov

Hours_of_Service: $\overline{9}-5$

Metadata_Standard_Name: FGDC Content Standards for Digital Geospatial Metadata

Metadata_Standard_Version: FGDC-STD-001-1998

Metadata_Time_Convention: local time

Metadata_Access_Constraints: none 
Metadata_Use_Constraints: none

Metadata Extensions:

Online_Linkage: http://www.esri.com/metadata/esriprof80.html

Profile_Name: ESRI Metadata Profile

Metadata_Extensions:

Online_Linkage: http://www.esri.com/metadata/esriprof80.html

Profile_Name: ESRI Metadata Profile

Metadata_Extensions:

Online_Linkage: http://www.esri.com/metadata/esriprof80.html

Profile_Name: ESRI Metadata Profile 


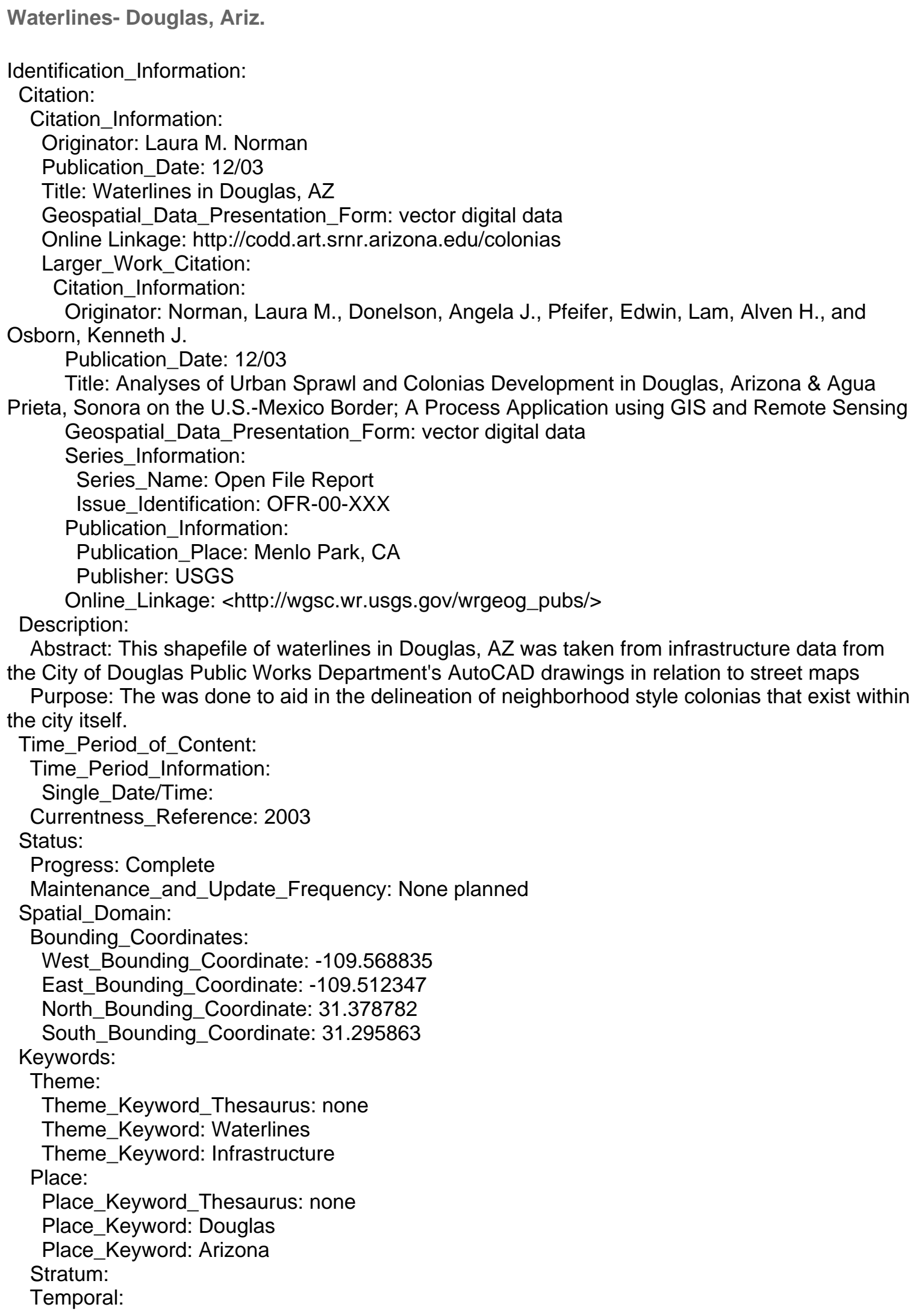

Abstract: This shapefile of waterlines in Douglas, AZ was taken from infrastructure data from the City of Douglas Public Works Department's AutoCAD drawings in relation to street maps

Purpose: The was done to aid in the delineation of neighborhood style colonias that exist within the city itself.

Time_Period_of_Content:

Time_Period_Information:

Single_Date/Time:

Currentness_Reference: 2003

Status:

Progress: Complete

Maintenance_and_Update_Frequency: None planned

Spatial_Domain:

Bounding_Coordinates:

West_Bounding_Coordinate: -109.568835

East_Bounding_Coordinate: -109.512347

North_Bounding_Coordinate: 31.378782

South_Bounding_Coordinate: 31.295863

Keywords:

Theme:

Theme_Keyword_Thesaurus: none

Theme_Keyword: Waterlines

Theme_Keyword: Infrastructure

Place:

Place_Keyword_Thesaurus: none

Place_Keyword: Douglas

Place_Keyword: Arizona

Stratum:

Temporal: 
Use_Constraints: This digital database is not meant to be used or displayed at any scale larger than $1: 24,000$ (for example, 1:12,000). Any hardcopies utilizing this dataset shall clearly indicate their source. If the user has modified the data in any way, he is obligated to describe the types of modifications he has performed on the hardcopy map. User specifically agrees not to

misrepresent this dataset nor to imply that changes he made were approved by the U.S.

Geological Survey.

Point_of_Contact:

Contact_Information:

Contact_Person_Primary:

Contact_Person: Laura M. Norman

Contact_Organization: U.S. Geological Survey

Contact_Position: Cartographer, GIS Specialist

Contact_Address:

Address_Type: mailing address

Address: 520 N Park Ave, Ste \#355

City: Tucson

State_or_Province: AZ

Postal_Code: 85719

Country: U.S.A

Contact_Voice_Telephone: 5206705510

Contact_Facsimile_Telephone: 5206705571

Contact_Electronic_Mail_Address: Imbrady@usgs.gov

Hours_of_Service: 9-5

Native_Data_Set_Environment: Microsoft Windows 2000 Version 5.0 (Build 2195) Service Pack

4; ESRI ArcCatalog 8.2.0.700

Cross_Reference:

Citation_Information:

Publication_Information:

Larger_Work_Citation:

Citation_Information:

Publication_Information:

Publication_Place: USGS

Data_Quality_Information:

Attribute_Accuracy:

Attribute_Accuracy_Report: The waterlines were digitized by means of dead reckoning and are only as good as those AutoCAD drawings they were digitized from, and may contain errors in this process.

Completeness_Report: This dataset represents waterlines as described by the Dept of Public Works for the City of Douglas in 2003.

Lineage:

Source_Information:

Source_Citation:

Citation_Information:

Source_Time_Period_of_Content:

Time_Period_Information:

Single_Date/Time:

Process_Step:

Process_Description: These data were automated through the means of dead reckoning in Arc View 3.3, by heads up digitizing the CAD drawings onto DOQQ's, with known street lines overlain

Process_Date: 05/03

Spatial_Data_organization_Information:

Direct_Spatial_Reference_Method: Vector

Point_and_Vector_Object_Information:

SDTS_Terms_Description:

SDTS__Point_and_Vector_Object_Type: String 
Point_and_Vector_Object_Count: 709

Spatial_Reference_Information:

Horizontal_Coordinate_System_Definition:

Planar:

Grid_Coordinate_System:

Grid_Coordinate_System_Name: Universal Transverse Mercator

Universal_Transverse_Mercator:

UTM_Zone_Number: 12

Transverse_Mercator:

Scale_Factor_at_Central_Meridian: 0.999600

Longitude_of_Central_Meridian: -111.000000

Latitude_of_Projection_Origin: 0.000000

False_Easting: 500000.000000

False_Northing: 0.000000

Planar_Coordinate_Information:

Planar_Coordinate_Encoding_Method: coordinate pair

Coordinate_Representation:

Abscissa_Resolution: 0.000016

Ordinate_Resolution: 0.000016

Planar_Distance_Units: meters

Geodetic_Model:

Horizontal_Datum_Name: North American Datum of 1983

Ellipsoid_Name: Clarke 1866

Semi-major_Axis: 6378137.000000

Denominator_of_Flattening_Ratio: 298.257222

Entity_and_Attribute_Information:

Detailed_Description:

Entity_Type:

Entity_Type_Label: waterlines

Attribute:

Attribute_Label: FID

Attribute_Definition: Internal feature number.

Attribute_Definition_Source: ESRI

Attribute Domain Values:

Unrepresentable_Domain: Sequential unique whole numbers that are automatically generated.

Attribute:

Attribute_Label: Shape

Attribute_Definition: Feature geometry.

Attribute_Definition_Source: ESRI

Attribute_Domain_Values:

Unrepresentable_Domain: Coordinates defining the features.

Attribute:

Attribute_Label: FNODE_

Attribute:

Attribute_Label: TNODE_

Attribute:

Attribute_Label: LPOLY_

Attribute:

Attribute_Label: RPOLY_

Attribute:

Attribute_Label: LENGTH

Attribute:

Attribute_Label: WATER1_

Attribute:

Attribute_Label: WATER1_ID 
Attribute:

Attribute Label: NUMBER

Attribute_Definition: Number assigned to AutoCAD color

Attribute:

Attribute_Label: DIAMETER

Attribute_Definition: Pipeline diameter (inches)

Distribution_Information:

Distributor:

Contact_Information:

Contact_Organization_Primary:

Contact_Organization: U.S. Geological Survey

Resource_Description: Downloadable Data

Distribution_Liability:

The U.S. Geological Survey (USGS) provides these geographic data "as is." The USGS makes no guarantee or warranty concerning the accuracy of information contained in the geographic data. The USGS further makes no warranties, either expressed or implied, as to any other matter whatsoever, including, without limitation, the condition of the product or its fitness for any particular purpose. The burden for determining fitness for use lies entirely with the user. Although these data have been processed successfully on computers at the USGS, no warranty, expressed or implied, is made by the USGS regarding the use of these data on any other system, nor does the fact of distribution constitute or imply any such warranty.

In no event shall the USGS have any liability whatsoever for payment of any consequential, incidental, indirect, special, or tort damages of any kind, including, but not limited to, any loss of profits arising out of use of or reliance on the geographic data or arising out of the delivery, installation, operation, or support by USGS.

Standard_Order_Process:

Digital_Form:

Digital_Transfer_Information:

Transfer_Size: 0.016

Metadata_Reference_Information:

Metadata_Date: 20031205

Metadata_Contact:

Contact_Information:

Contact_Person_Primary:

Contact_Person: Laura M. Norman

Contact_Organization: U.S. Geological Survey

Contact_Position: Cartographer, GIS Specialist

Contact_Address:

Address_Type: mailing address

Address: 520 N Park Ave, Ste \#355

City: Tucson

State_or_Province: AZ

Postal_Code: 85719

Country: U.S.A

Contact_Voice_Telephone: 5206705510

Contact_Facsimile_Telephone: 5206705571

Contact_Electronic_Mail_Address: Imbrady@usgs.gov

Hours_of_Service: 9-5

Metadata_Standard_Name: FGDC Content Standards for Digital Geospatial Metadata

Metadata_Standard_Version: FGDC-STD-001-1998

Metadata_Time_Convention: local time

Metadata_Access_Constraints: none

Metadata_Use_Constraints: none

Metadata_Extensions:

Online_Linkage: http://www.esri.com/metadata/esriprof80.html

Profile_Name: ESRI Metadata Profile 
Metadata_Extensions:

Online_Linkage: http://www.esri.com/metadata/esriprof80.html

Profile_Name: ESRI Metadata Profile 


\author{
Attractions in Douglas, Ariz. \\ Identification_Information: \\ Citation: \\ Citation_Information: \\ Originator: Laura M. Norman \\ Publication_Date: 2003 \\ Title: Attractions in Douglas, AZ Identified by Youth Advocates! \\ Geospatial_Data_Presentation_Form: vector digital data \\ Online Linkage: http://codd.art.srnr.arizona.edu/colonias \\ Larger_Work_Citation: \\ Citation_Information: \\ Originator: Norman, Laura M., Donelson, Angela J., Pfeifer, Edwin, Lam, Alven H., and
}

Osborn, Kenneth J.

Publication Date: 12/03

Title: Analyses of Urban Sprawl and Colonias Development in Douglas, Arizona \& Agua

Prieta, Sonora on the U.S.-Mexico Border; A Process Application using GIS and Remote Sensing

Geospatial_Data_Presentation_Form: vector digital data

Series_Information:

Series_Name: Open File Report

Issue_Identification: OFR-03-XXX

Publication_Information:

Publication_Place: Menlo Park, CA

Publisher: USGS

Online_Linkage: <http://wgsc.wr.usgs.gov/wrgeog_pubs/>

Description:

Abstract: The Southeast Arizona Health Behavioral Services (SEAHBS) sponsors a group

called the New Turf/ Youth Advocates, which is comprised of about 20 high school aged kids and mentored by Ana Maria Flannigan. An informal presentation at their conference room in Douglas was presented to the group. Using aerial photos plotted onto posters, the kids identified features that they could recognize on the map (pools, baseball diamonds, track \& field). This was followed by an introduction of how to turn layers describing their city on/off in Arc View and a

demonstration of a hand held GPS device-- to help the youths conceptualize the transition of XY coordinates to a hard copy map. The youth group offered to help in the project.

Purpose: To identify Attractions in the City of Douglas, AZ

Time_Period_of_Content:

Timé_Period_Information:

Single_Date/Time:

Calendar_Date: 12/03

Currentness_Reference: Completed September 9, 2003

Status:

Progress: Complete

Maintenance_and_Update_Frequency: As needed

Spatial_Domain:

Bounding_Coordinates:

West_Bounding_Coordinate: -109.568835

East_Bounding_Coordinate: -109.512347

North_Bounding_Coordinate: 31.378782

South_Bounding_Coordinate: 31.295863

Keywords:

Theme:

Theme_Keyword_Thesaurus: none

Theme_Keyword: Attractions

Place: 
Place_Keyword_Thesaurus: none

Place_Keyword: Douglas, AZ

Place_Keyword: Arizona

Use_Constraints: This digital database is not meant to be used or displayed at any scale larger than $1: 24,000$ (for example, 1:12,000). Any hardcopies utilizing this dataset shall clearly indicate their source. If the user has modified the data in any way, he is obligated to describe the types of modifications he has performed on the hardcopy map. User specifically agrees not to

misrepresent this dataset nor to imply that changes he made were approved by the U.S.

Geological Survey.

Point_of_Contact:

Contact_Information:

Contact_Person_Primary:

Contact_Person: Laura M. Norman

Contact_Organization: U.S.G.S.

Contact_Position: Cartographer

Contact_Address:

Address_Type: mailing address

Address: 520 N Park Ave, Ste \#355

City: Tucson

State_or_Province: AZ

Postal_Code: 85719

Country: U.S.A

Contact_Voice_Telephone: 520-670-5510

Contact_Electronic_Mail_Address: Imbrady@usgs.gov

Native_Data_Set_Environment: Microsoft Windows 2000 Version 5.0 (Build 2195) Service Pack 4; ESRI ArcCatalog 8.2.0.700

Data_Quality_Information:

Attribute_Accuracy:

Attribute_Accuracy_Report: The kids identified most of the locations using street maps, addresses and recognizable intersections. The accuracy of the locations is variable and dependent on the youth group's knowledge of that site. Most locations are correspondent with the street addresses provided.

Completeness_Report: These are not all of the attractions that are available in Douglas, AZ- just a representative sample.

Lineage:

Process_Step:

Process_Description:

This "photo-points" project for the cities was implemented in 4 phases.

1. The youths began identifying important resources in their community; these included a new skate park, community pools and soccer fields.

2. The youths out in the City to photograph these sights and others (town hall, movie theatre, etc.)

3. The locations of the resources were coordinated with these photographs using Global Positioning System (GPS) readings. Carlos de la Torre instructed the youth group using a Trimble 4700-4800 GPS system from the neighboring City of Bisbee, AZ.

4. Lastly, this was incorporated into the GIS database and is be viewable on the proposed web site, allowing the Internet user to click on a point on a map and open up the photograph taken by the youth.

Spatial_Data_Organization_Information:

Direct_Spatial_Reference_Method: Vector

Point_and_Vector_Object_Information:

SDTS_Terms_Description:

SDTS_Point_and_Vector_Object_Type: Entity point

Point_and_Vector_Object_Count: 20

Spatial_Reference_Information:

Horizontal_Coordinate_System_Definition: 
Planar:

Grid_Coordinate_System:

Grid_Coordinate_System_Name: Universal Transverse Mercator

Universal_Transverse_Mercator:

UTM_Zone_Number: 12

Transverse_Mercator:

Scale_Factor_at_Central_Meridian: 0.999600

Longitude_of_Central_Meridian: -111.000000

Latitude_of_Projection_Origin: 0.000000

False_Easting: 500000.000000

False_Northing: 0.000000

Planar_Coordinate_Information:

Planar_Coordinate_Encoding_Method: coordinate pair

Coordinate_Representation:

Abscissa_Resolution: 0.000008

Ordinate_Resolution: 0.000008

Planar_Distance_Units: meters

Geodetic_Model:

Horizontal_Datum_Name: North American Datum of 1983

Ellipsoid_Name: Geodetic Reference System 80

Semi-major_Axis: 6378137.000000

Denominator_of_Flattening_Ratio: 298.257222

Entity_and_Attribute_Information:

Detailed_Description:

Entity_Type:

Entity_Type_Label: d_attractions

Attribute:

Attribute Label: FID

Attribute_Definition: Internal feature number.

Attribute_Definition_Source: ESRI

Attribute_Domain_Values:

Unrepresentable_Domain: Sequential unique whole numbers that are automatically generated.

Attribute:

Attribute_Label: Shape

Attribute_Definition: Feature geometry.

Attribute_Definition_Source: ESRI

Attribute_Domain_Values:

Unrepresentable_Domain: Coordinates defining the features.

Attribute:

Attribute_Label: ID

Attribute:

Attribute_Label: NAME

Attribute_Definition: Name of feature

Attribute:

Attribute_Label: ADDRESS

Attribute_Definition: Addresss

Attribute:

Attribute_Label: PHONE

Attribute_Definition: Phone Number

Attribute:

Attribute_Label: ATTRACTION

Attribute_Definition: Web address of picture portraying feature, as taken by Youth Advocates! Distribution_Information:

Resource_Description: Downloadable Data

Distribution_Liability: 
The U.S. Geological Survey (USGS) provides these geographic data "as is." The USGS makes no guarantee or warranty concerning the accuracy of information contained in the geographic data. The USGS further makes no warranties, either expressed or implied, as to any other matter whatsoever, including, without limitation, the condition of the product or its fitness for any particular purpose. The burden for determining fitness for use lies entirely with the user. Although these data have been processed successfully on computers at the USGS, no warranty, expressed or implied, is made by the USGS regarding the use of these data on any other system, nor does the fact of distribution constitute or imply any such warranty.

In no event shall the USGS have any liability whatsoever for payment of any consequential, incidental, indirect, special, or tort damages of any kind, including, but not limited to, any loss of profits arising out of use of or reliance on the geographic data or arising out of the delivery, installation, operation, or support by USGS.

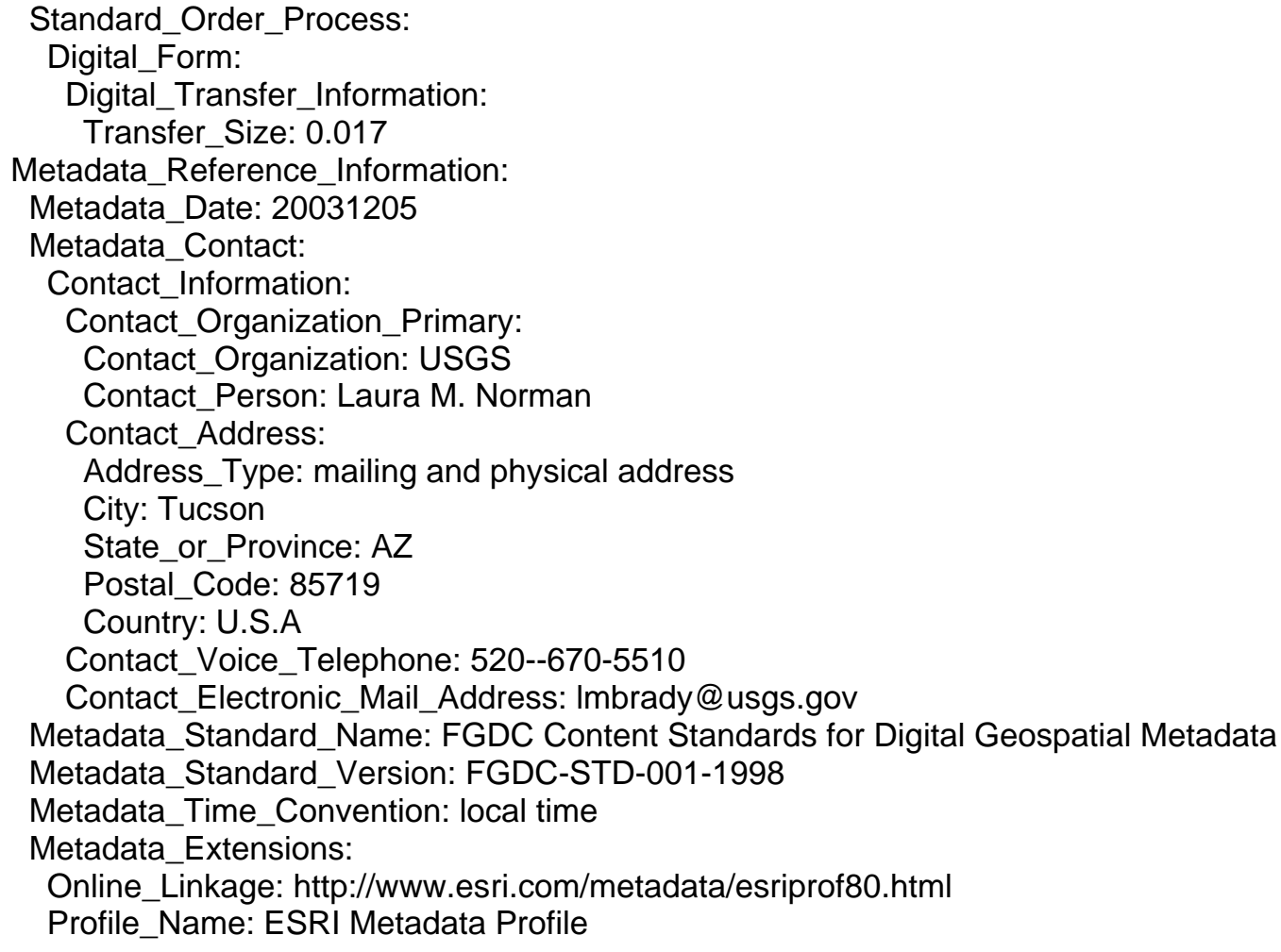

